\title{
Integrating Passive Thermal Comfort Features with Seismic Retrofitting Techniques for Non-engineered Housing in India
}

\author{
Yasmin Bhattacharya
}

A thesis submitted in fulfillment of the requirements for the degree of Master of Architecture (2011).

School of Architecture and Design

Victoria University of Wellington 


\section{Abstract}

The lack of seismic provisions for non-engineered buildings in developing countries is corroborated by the high fatality rates during earthquakes and is a source of major concern. As a means for promoting seismic retrofitting among the low-income population in India, this study investigates the integration of passive thermal comfort features with retrofitting techniques in order to provide day-to-day benefits in addition to the structural safety required for earthquakes.

Three separate regions in India with the same level of seismic risk and differing climatic conditions are addressed in this study in order to consider the varying thermal comfort requirements within the same required level of seismic resistance. These are: Gujarat, Jammu \& Kashmir, and Sikkim, which are typical of hot-dry, composite and cold climates respectively, and are located in areas with high seismicity (Seismic zone IV by Indian seismic code standards).

The development of suitable integrative techniques is not solely a structural challenge. A thorough understanding of the population and their needs, the climate and geographical landscape, and most importantly, of the previous research regarding thermal comfort and seismic retrofitting for developing countries is essential. This has been achieved through a literature review, which provides the theoretical framework and identifies which seismic and thermal comfort strategies are appropriate for which type of constructions and climates respectively. Following this, a research-by-design methodology is employed to formulate possible integrative solutions.

The study finds that the possibilities of integrating passive thermal comfort features with seismic retrofitting for non-engineered houses are limited. However, the few proposed integrative solutions do have the potential to improve thermal comfort inside the houses in an energy efficient manner if developed further. They are expected to be beneficial for many regions of the developing world which have similar seismic and climatic characteristics. 


\section{Acknowledgements}

I am deeply indebted to my supervisor, Professor Andrew Charleson who has guided me throughout this study. Being new to this field of research, and requiring knowledge on two vastly established subjects of seismic design and thermal comfort, I was often at a loss of direction. Without his support, encouragement and constructive feedback, I would not have been able to deliver this study to completion. I also wish to thank Professor George Baird for his help and advice through this study.

I wish to extend my gratitude to the Faculty of Architecture and the Faculty of Languages and Cultures for allowing me to pursue two concurrent degrees and being considerate during times of difficulty. I am also appreciative of the Victoria University Graduate Award for the financial support towards my studies.

I am grateful for all my friends who have supported me both at the Department and outside of it. The insightful discussions during study group sessions provided food for thought and time for interaction. I am grateful to my friends outside of school for keeping me connected to the real world and lending their ears when I needed to be heard.

Last, but not least, I wish to express my thanks to my family members, especially my mother and my grandmother, who have been an invaluable source of support and encouragement, and have remained tolerant with me during my days of frustration.

The duration of my study was also marked with several devastating earthquake disasters both in New Zealand and abroad in Chile, Haiti and Japan. Seeing the scale of devastation caused by the unreinforced buildings has kept me focused on my study and reiterated the importance and necessity for my research. This work is dedicated to all those in need of safer and more comfortable houses living in seismically active regions of developing countries. 


\section{Contents}

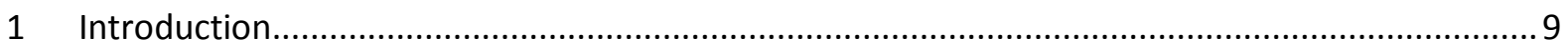

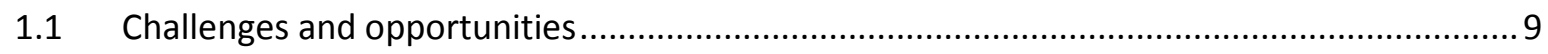

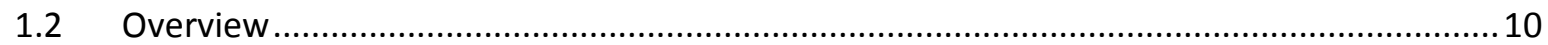

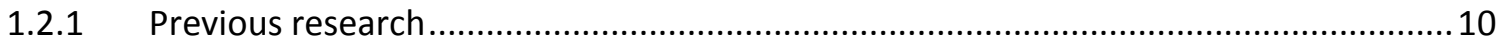

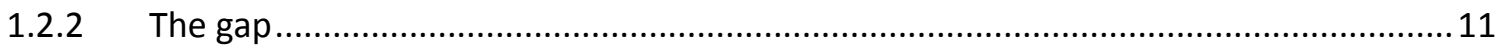

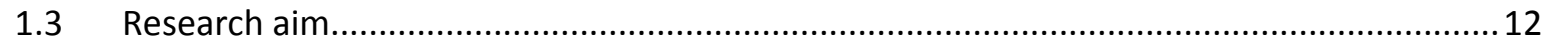

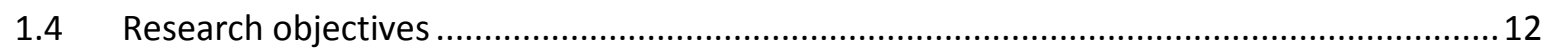

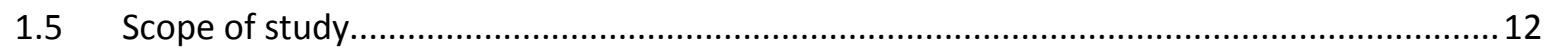

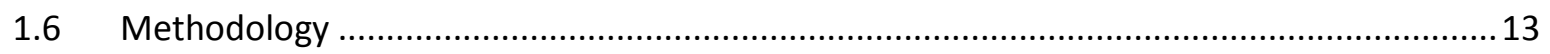

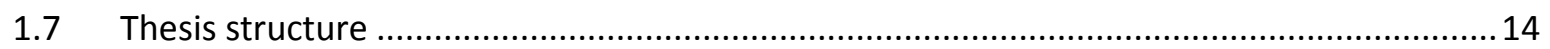

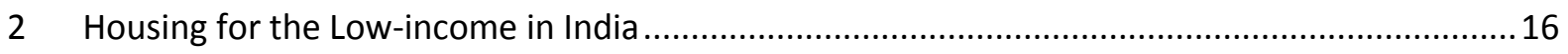

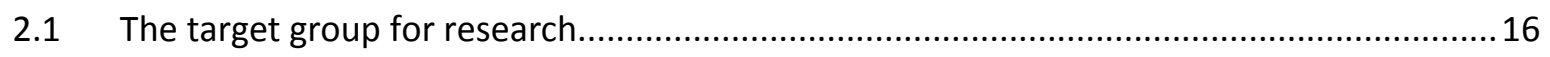

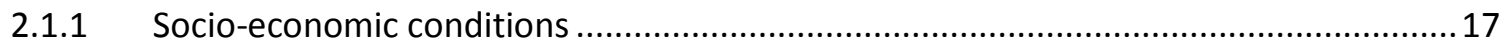

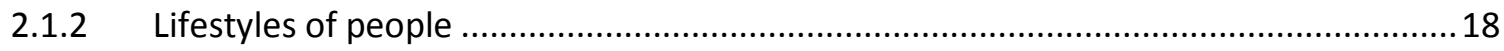

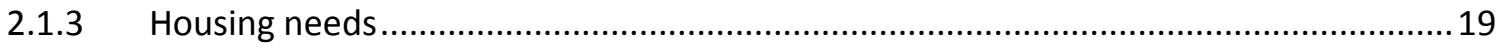

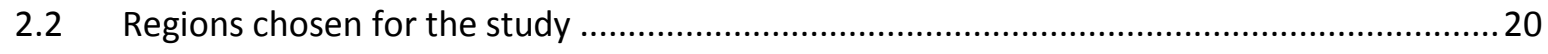

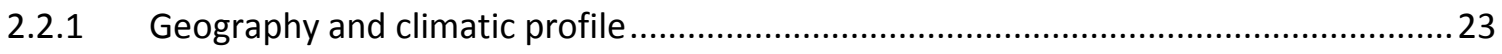

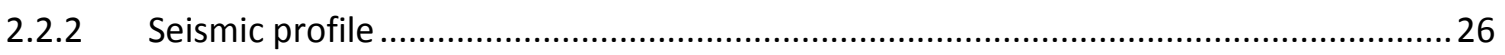

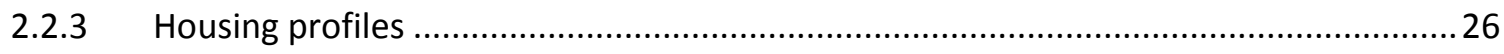

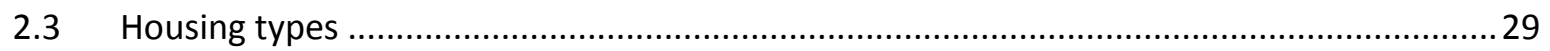

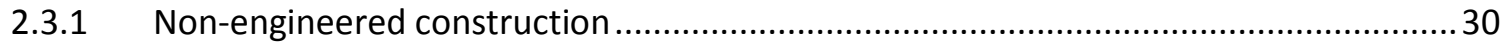

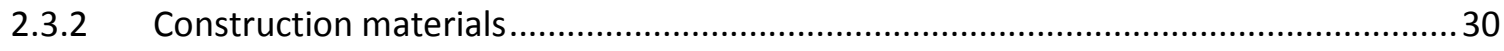

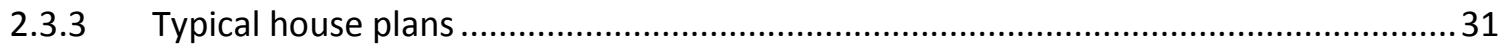

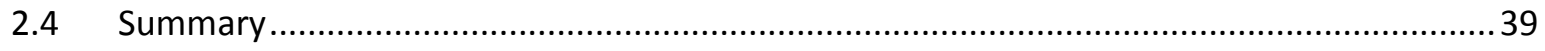

3 Importance of Thermal Comfort in the Built Environment …................................................... 40

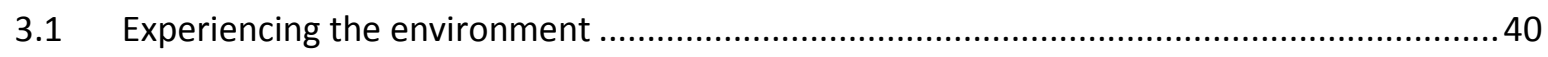


3.2 Definition of thermal comfort

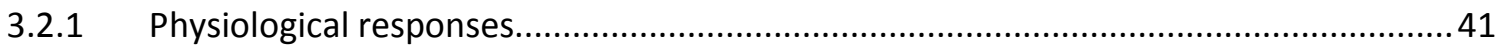

3.2.2 Psychological and behavioural responses................................................................. 42

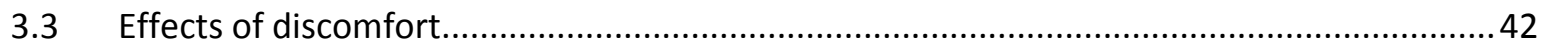

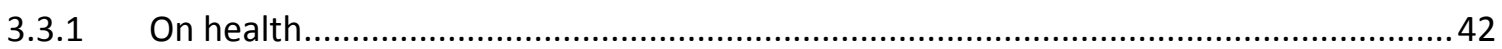

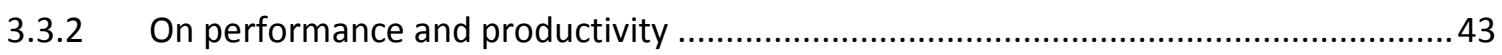

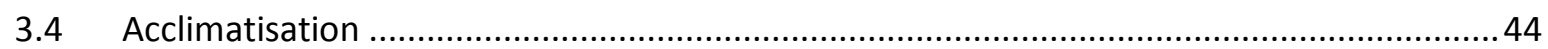

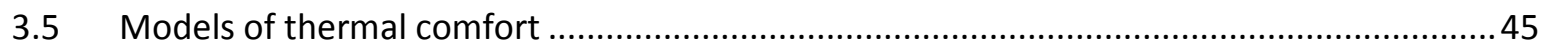

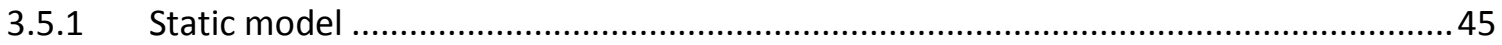

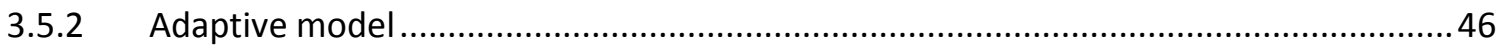

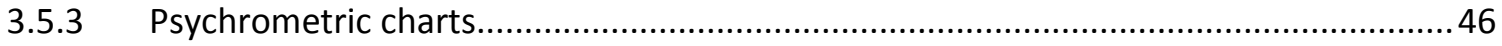

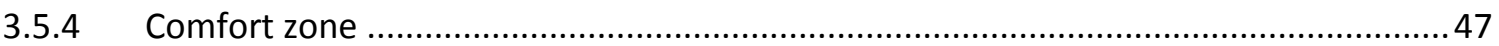

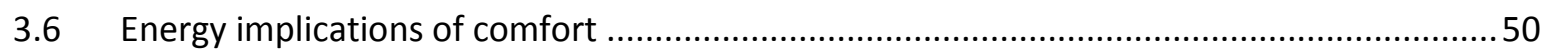

3.7 Current level of comfort conditions provided in low-income housing .................................51

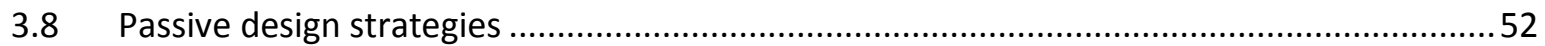

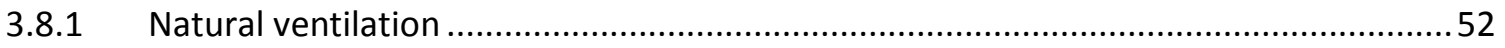

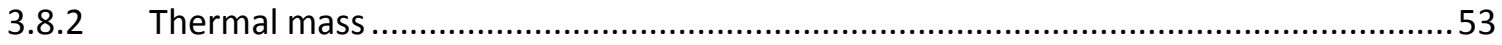

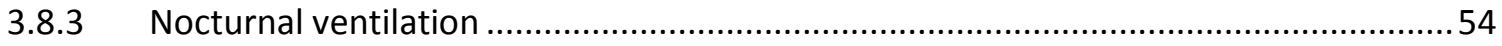

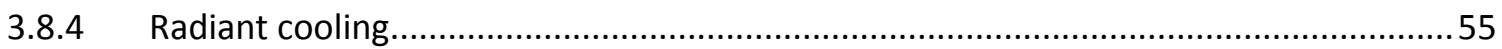

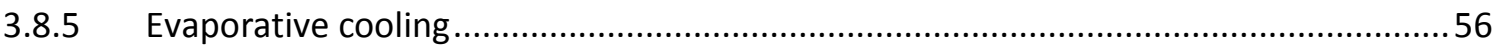

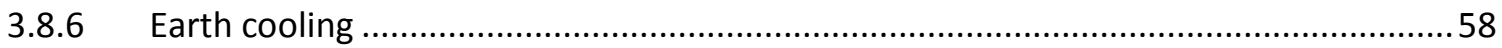

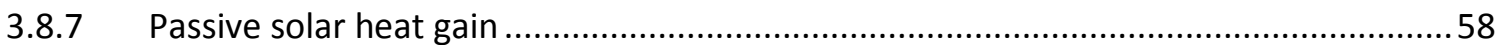

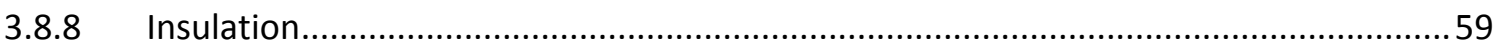

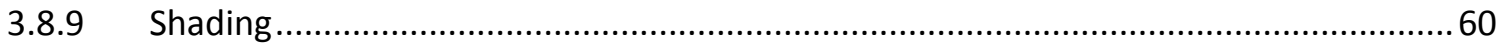

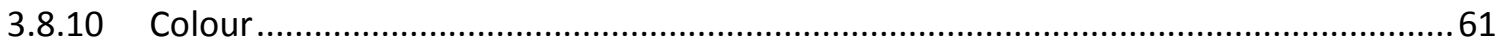

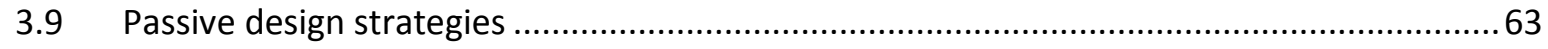

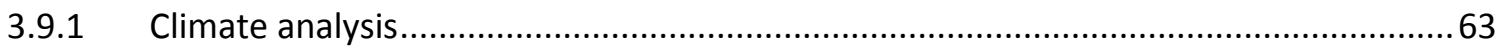


3.10 Summary

4 Seismic Retrofitting for Non-Engineered Housing ...............................................................69

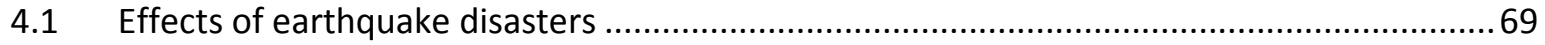

4.2 Attitudes towards safety in developing countries......................................................... 70

4.3 Current level of seismic provisions provided in low-income housing ................................ 72

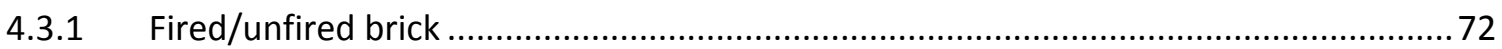

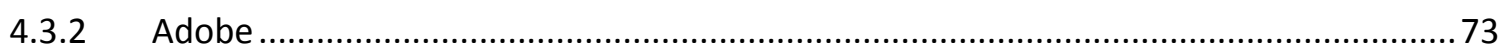

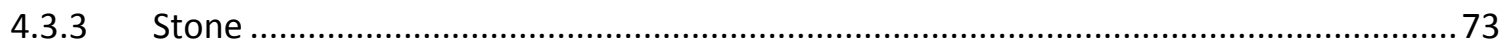

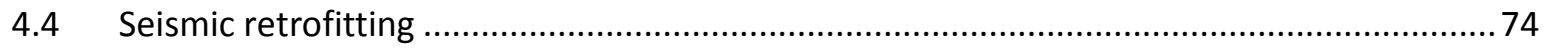

4.4.1 Appropriate retrofitting technologies for low-income housing .................................. 75

4.5 Summary

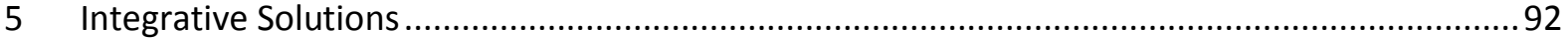

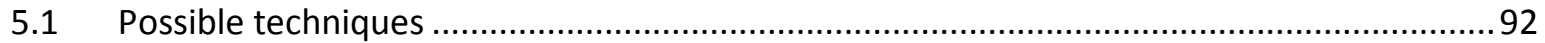

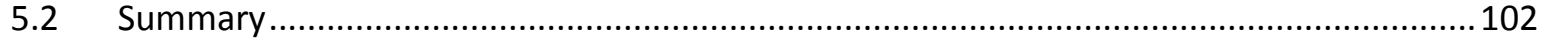

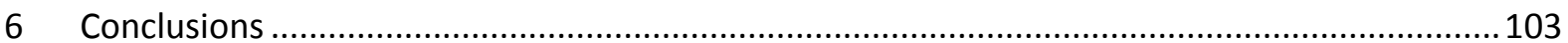

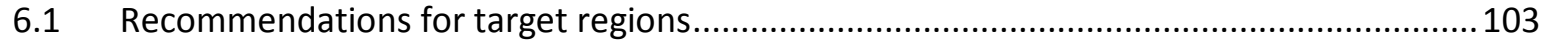

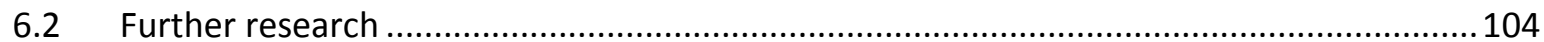

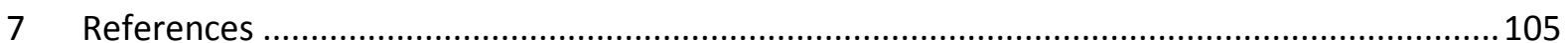




\section{List of Figures}

\section{Chapter 1}

Figure 1.1 Research approach and goal for integrative technologies

\section{Chapter 2}

Figure 2.1 Climatic Zone Map of India (Source: HPCB, 2010)

Figure 2.2 Seismic Zone Map of India (Source: Institute of Seismological Research, 2007)

Figure 2.3 Annual average temperatures of Gangtok, Jammu and Palanpur................................... 25

Figure 2.4 Annual average relative humidity levels of Gangtok, Jammu and Palanpur..................... $\quad 25$

Figure 2.5 Common wall materials usage distribution for Gujarat, Jammu \& Kashmir and Sikkim based on Census of India data (Source: Government of India 2001a, 2001b, 2001c) .......

Figure 2.6 Plan view of typical fired/unfired brick residential building (Source: INTERECT, 1984)

Figure 2.7 SectionAA. A view of a typical fired/unfired brick residential building (Source: INTERECT, 1984).

Figure 2.8 Unfired brick core wall with a fired brick veneer on both side of the wall (Source: INTERECT, 1984)

Figure 2.9 Unfired brick plastered on both sides with a mud and dung mixture (Source: INTERECT, 1984).

Figure 2.10 Possible plan variations (Source: INTERECT, 1984) 34

Figure 2.11 Plan view of a typical adobe residential building (Source: INTERECT, 1984) ................... 36

Figure 2.12 Section AA. A view of a typical adobe residential building (Source: INTERECT, 1984) .... 36

Figure 2.13 Plan view of a typical stone house with a flat roof (Source: INTERECT, 1984) ................ 38

Figure 2.14 Section AA. A section view of a typical stone house with a flat roof (Source: INTERECT, 1984) ......................................................................................................... 38

Figure 2.15 Possible plan variations (Source: INTERECT, 1984) ………...............................................

\section{Chapter 3}

Figure 3.1 Comfort zone for Palanpur ....................................................................................... 49

Figure 3.2 Comfort zone for Jammu .......................................................................................... 49

Figure 3.3 Comfort zone for Gangtok …….........................................................................................

Figure 3.4 Roof ventilation removes trapped heat (Source: Koch-Nielson, 2002) .............................. 53 
Figure 3.5 The movement of air due to temperature generated pressure differences across openings (Source: Koch-Nielson, 2002)

Figure 3.6 Air flow under the floor for cooling (Source: Koch-Nielson, 2002)

Figure 3.7 Heat gain through thermal mass on wall and roof (Source: American Institute of Architects Foundation,1982).

Figure 3.8 Skytherm system with operable insulation (Source: American Institute of Architects Foundation, 1982)

Figure 3.9 Evaporative cooling used in wind tower (Source: Koch-Nielson, 2002)

Figure 3.10 Roof pond with shading (Source: American Institute of Architects Foundation, 1982)

Figure 3.11 Direct heat gain (Source: American Institute of Architects Foundation, 1982)................ 59

Figure 3.12 Indirect heat gain (Source: American Institute of Architects Foundation, 1982).............. 59

Figure 3.13 Isolated heat gain (Source: American Institute of Architects Foundation, 1982)............. 59

Figure 3.14 Bioclimatic chart for Palanpur............................................................................................. 65

Figure 3.15 Bioclimatic chart for Jammu .............................................................................................. 65

Figure 3.16 Bioclimatic chart for Gangtok .........................................................................................

\section{Chapter 4}

Figure 4.1: Breakdown of fatalities attributed to earthquake by cause (Source: Coburn \& Spence, 2002)

Figure 4.2: $\quad$ Inter-relationship of well-being and disasters (Source: Patel, et al., 2006) ..................... 70

Figure 4.3: $\quad$ 'K' arrangement bracing (Source: Desai \& Desai, 2007) ….................................................. 76

Figure 4.4: $\quad$ 'X' arrangement bracing (Source: Desai \& Desai, 2007) …………..................................... 76

Figure 4.5: $\quad$ 'Z' arrangement bracing (Source: Desai \& Desai, 2008) .................................................... 76

Figure 4.6: $\quad$ Collar beam for rafters in pitched roof building (Source: Desai \& Desai, 2008) ............... 77

Figure 4.7: $\quad$ Seismic belt for pitched roof building (Source: Desai \& Desai, 2007) ............................... 77

Figure 4.8: Ensuring continuity of seismic belt with tie-rod connections (Source: Desai \& Desai, 2008)

Figure 4.9: Wire-mesh strengthening (Source: The International Association for Earthquake Engineering, 2001)

Figure 4.10: Shotcreting steel mesh installation with through-wall ties (Source: D'Ayala, et al., 2002)

Figure 4.11: Tie-column \& tie-beam reinforcement (Source: S. Brzev, 2007) ………………….......... 79

Figure 4.12: $\quad$ Seismic belt shear connector (Source: Desai \& Desai, 2007) .............................................. 79

Figure 4.13: Vertical reinforcement shear connector (Source: Desai \& Desai, 2007) ........................... 79 
Figure 4.14: Inserting grout in walls (Source: The International Association for Earthquake Engineering, 2001)

Figure 4.15: Inserting buttresses and pilasters (Source: Desai \& Desai, 2008) ..................................... 80

Figure 4.16: $\quad$ Stitching wall wythes with RC bond element (Source: Desai \& Desai, 2007) .................... 81

Figure 4.17: $\quad$ Stitching wall wythes with RC bond element (Source: Desai \& Desai, 2007) .................... 81

Figure 4.18: $\quad$ Through-stone in wall (Source: Desai \& Desai, 2008) ......................................................... 81

Figure 4.19: $\quad$ Tyre strap reinforcement (Source: Charleson, 2009) …….................................................. 81

Figure 4.20: Post-tensioning elastometric tyre straps on walls (Source: Turer, et al., 2007) ............... 82

Figure 4.21: External bamboo reinforcement (Source: Dowling \& Samali, 2006) ................................... 82

Figure 4.22: Polymer mesh reinforcement (Source: Asian Disaster Preparedness Center, 2010) ........ 82

Figure 4.23: $\quad$ PP-band mesh around the walls (Source: Mayorca \& Meguro, 2008) .............................. 83

Figure 4.24: Connection of new and old walls at T-junction (Source: The International Association for Earthquake Engineering, 2001)

Figure 4.25: Provision of wooden bracing at regular intervals in walls (Source: Das, et al., 2007) ...... 84

Figure 4.26: Using dowels for belt continuity through wall (Source: Desai \& Desai, 2007) ................. 84

Figure 4.27: Tie-beam-to-tie-column connection (Source: S. Brzev, 2007) ............................................ 85

Figure 4.28: $\quad$ Knee-bracing for post-to-beam connection (Source: Desai \& Desai, 2008) ..................... 85

Figure 4.29: $\quad$ Brackets to anchor roof to wall (Source: Desai \& Desai, 2007) .......................................... 85

Figure 4.30: Internal vertical reinforcing bar in corner (Source: Desai \& Desai, 2007) ......................... 86

Figure 4.31: Internal connections when inserting vertical bar (Source: Desai \& Desai, 2007) ............. 86

Figure 4.32: $\quad$ External vertical seismic WWM belt (Source: Desai \& Desai, 2007) .................................. $\quad 86$

Figure 4.33: $\quad$ Appropriate wall opening specifications (Source: Desai \& Desai, 2008) .......................... 87

Figure 4.34: Belt reinforcement at openings (Source: Desai \& Desai, 2007) …..................................... 87

Figure 4.35: Peripheral WWM reinforcement around window opening (Source: Desai \& Desai, 2007)

Figure 4.36: Inserting plinth band above the foundation (Source: S. Brzev, 2007) .............................. 88

Figure 4.37: Inserting RC beams for foundation strengthening (Source: IAEE, 2001) .......................... 89

Figure 4.38: $\quad$ RC strip foundation (alternative arrangement) (Source: S. Brzev, 2007) …...................... 89

Figure 4.39: J Jacketing of masonry column (Source: Desai \& Desai, 2008) ........................................... 89

\section{Chapter 5}

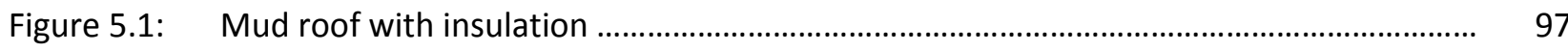

Figure 5.2: Horizontal extension of seismic belt for shading........................................................... 97

Figure 5.3: Section view of a ventilation pipe attached with metal flanges embedded in place of throughstones 
Figure 5.4: Section A -Front elevation

Figure 5.5: Section view of bamboo ventilation pipe.

Figure 5.6: Air flow through the interior with the inlet and outlets on opposite walls for cross-ventilation

Figure 5.7: Wall areas appropriate for replacing throughstones or RC bond elements with ventilation pipes

Figure 5.8: Insulation layer in between wall and wire mesh 100

Figure 5.9: Insulation on wall with wire mesh on one side of wall...... 100

Figure 5.10: Insulation on wall with wire mesh on both sides of wall. 100

Figure 5.11: Plan view of external vertical bamboo reinforcement (on one side and both sides of wall) with additional insulation layer

Figure 5.12: Vertical bamboo reinforcement as air circulation channel. 


\section{List of Tables}

\section{Chapter 2}

Table 2.1: Summary Table of Temperature Range and Humidity Level

\section{Chapter 3}

Table 3.1: Summary table of passive techniques and their applicability.......

Table 3.2: Discomfort indices for Palanpur, Jammu and Gangtok.

\section{Chapter 4}

Table 4.1: Retrofitting technologies for non-engineered construction

\section{Chapter 5}

Table 5.1: Integrative solutions matrix 


\section{Introduction}

This chapter introduces the study. It begins by discussing the challenges and opportunities within the research area. Previous study on seismic resistance and thermal comfort for developing countries is briefly presented and the research gaps are identified. The aims, objectives, scope and methodology of this study are then discussed. Finally, the thesis structure is presented to explain the overall organisation and individual chapter contents.

\subsection{Challenges and opportunities}

In developing countries, masonry construction, which includes brick, adobe and stone construction, is common in residential buildings, especially in rural areas. The simple construction methods, usage of locally available materials, and low construction costs, allow low-income populations to build their own dwellings. In fact, more than 90 percent of the population living in moderate to severe seismic zones of the developing world, work and live in such buildings (Arya, 2000).

However, while masonry construction can be financially beneficial, it is also seismically hazardous. The maximum number of fatalities in developing countries in earthquakes results from the collapse of these buildings, and historically, the low-income population have been most severely affected (Coburn \& Spence, 2002).

The failure lies in the nature of masonry construction which is often constructed by the residents themselves with no professional input. Their ignorance of engineering principles results in houses that are not equipped to tackle seismic forces and do not adhere to the necessary standards set by the building codes in the respective regions. In addition, some places do not have adequate building codes and some do not enforce these standards. Yet, these types of non-engineered construction have been practiced for over a hundred years and are likely to continue to be practiced among the poor whose limited financial capabilities do not permit the implementation of modern aseismic technologies.

Consequently, various low-cost retrofitting techniques have been researched and developed to provide added reinforcement for this type of construction. However, only a very small fraction of the world's developing population has seen their implementation. In addition to the lack of awareness of the danger associated with living in unreinforced houses in seismically active regions, the reluctance to adopt seismic strengthening hinders the dissemination of these life-saving techniques 
among the low-income population. As Meli \& Alcocer (2004) discuss, this is most likely due to the fact that safety is an ethereal concept, not easily understood, and even more difficult to sell to a population with serious unmet needs in their everyday lives.

It is necessary, therefore, to link seismic vulnerability-reduction efforts to other efforts aimed at improving housing habitability, with the hope that it can be better sold if it is accompanied by tangible daily benefits (Meli \& Alcocer, 2004). One such possible 'accompanied daily benefit' is thermal comfort.

For the majority of the low-income population, access to electricity is scarce and expensive, and many do not have the option of using mechanical heating and cooling systems. Their houses are often thermally uncomfortable which has been proven to affect the health and productivity of the occupants. Therefore, the central challenge addressed by this study is the potential for integrating retrofitting techniques with passive thermal comfort strategies for low-income housing in developing countries (with a focus on rural Indian houses for the purposes of this study).

Along with the opportunity to enhance existing seismic retrofitting techniques for additional benefits, this research also addresses the issue of escalating energy requirements and the subsequent increase in carbon emission levels of developing countries by providing alternative passive solutions for thermal comfort.

It is hoped that this research and its future development and implementation will increase the adoption of retrofitting techniques among the low-income population in developing countries.

\subsection{Overview}

\subsubsection{Previous research}

There has been copious research done in the field of seismic retrofitting up to date. Many new retrofitting systems such as diagonal braces, shear walls, base isolation, and so forth, have been suggested.

In previous years, after the revelation of a clear difference in earthquake effects (particularly in the number of casualties and fatalities) among groups of population with distinct income levels (Meli \& Alcocer, 2004), research efforts were directed towards the low-income communities in developing 
countries as they are considered especially vulnerable. As a result, retrofitting techniques applicable for non-engineered constructions in these regions have been developed by various researchers.

Parallel to the issue of seismic resistance, thermal comfort in residential buildings has also been widely researched. Several experiments and field studies indicate the adverse effects of discomfort on human health and performance, as well as the insufficient levels of comfort currently provided in low-income housing (De Dear \& Brager, 2001; Reddy \& Lefebvre, 1993; Toftum, Andersen, \& Jensen, 2009). Concern for rising levels of energy usage in developed and developing countries has also shed light on the need to adopt passive strategies and consequent research and development has followed. Thus, effective methods for modelling human thermal comfort and determining appropriate passive strategies have been analysed and developed. Various low-cost passive technologies have also been investigated; however, a large scale implementation remains to be seen in developing countries.

\subsubsection{The gap}

Although, both seismic strengthening and thermal comfort are well established fields of study, their existence has been distinctively separate as two strands of knowledge; one aims to improve the structural entity while the other aims to improve the enclosed environment. And although researchers like Meli \& Alcocer (2004) have recommended linking seismic strengthening efforts to other activities directed towards housing improvement, there has been no previous work known to the author which concentrates on the integrative potential of seismic retrofitting and thermal comfort.

It is also found that, in some cases, the requirements for maintaining structural integrity conflicts with the practiced indigenous thermal comfort strategies (refer to Chapter 3 for details). This can be considered as part of the reason behind people's reluctance to adopt seismic retrofitting techniques in non-engineered buildings; as attaining one benefit can result in the loss of another. Hence, further work is required to account for the dearth of research in this area, and for developing seismic retrofitting techniques that are in harmony with the thermal comfort needs of the occupants. 


\subsection{Research aim}

To increase the safety and comfort levels in non-engineered housing in developing countries by investigating the potential for integrating seismic retrofitting techniques and passive thermal comfort strategies.

\subsection{Research objectives}

This study has four main objectives:

- Identify the challenges, opportunities and theoretical framework for housing the low-income population in India (Chapter 2).

- Consider the level of thermal comfort in low-income housing and identify appropriate passive thermal comfort strategies for improvement (Chapter 3).

- Consider the level of seismic resistance provided in non-engineered housing and identify appropriate retrofitting techniques for improvement (Chapter 4).

- Explore the possibility of developing integrative techniques which combine seismic retrofitting techniques and passive thermal comfort strategies (Chapter 5).

\subsection{Scope of study}

Although the outcome of this research may be applicable to several other regions that share similar seismic and climatic characteristics addressed in this study, the geographical scope for this study is limited to three particular regions within India. These represent the three major climatic zones out of the five classified in India (HPCB, 2010), since addressing every climate type is beyond the scope.

For the purposes of this study, the nomadic housing types used by some of the low-income population, is not considered. For some this is traditional way of life, such as the Himalayan agropastoralists, while for others it is an inevitable consequence of being displaced and/or homeless. However in either case, it lacks the idea of a permanent structure as a house. Therefore, such non- 
permanent or semi-permanent structures are beyond the scope of this research where the aim is to improve existing permanent rural housing structures for increased level of safety and comfort.

Additionally, since this study is limited to identifying the potential for integration of seismic retrofitting and passive thermal comfort strategies, the thesis scope does not comprise the technical details of the integrative techniques or their practical implementation. This means that the ideas presented are at the conceptual stage and not final; they are intended to act as a starting point for further study. Thus, detailed engineering calculation, feasibility studies, computer simulations, and analysis of culture-responsive design, fall out of the scope of this study.

Due to limitations in availability of funding and time constraints, conducting first hand field surveys of current housing conditions in these regions was not possible. Therefore, the information presented as the basis for analysis is largely dependent on literature sources. However, effort has been made to obtain the most recent and relevant data available. In some cases assumptions have been necessary due to the limitation in scope as well as the lack of the specific information required. These assumptions are explained in the course of the thesis.

\subsection{Methodology}

Essentially, two separate research methods have been utilised in this study: literature review and research-by-design method.

Due to the research being in a nascent field of study, the majority of this thesis comprises of literature review on the subjects of low-income housing, seismic retrofitting, and thermal comfort. This establishes the foundation for the development of this study based on which the context for the study is formalised, followed by the identification of safety and comfort needs and the appropriate strategies for attaining them.

A latter part of the research (namely Chapter 5), involves the exploration of possible integration of seismic retrofitting techniques and thermal comfort strategies via re-design or modifications of existing systems. The knowledge gained through the literature review largely influences the design and conception of these integrative techniques. Each proposed technique and its advantages are then discussed in detail to provide a direction for future research and development. 
In its approach, this research addresses four essential theoretical components of residential building design: safety, comfort, energy efficiency, and affordability. As the diagram (see Figure 1.1) shows, safety and comfort are considered in terms of seismic provisions and thermal comfort, respectively. The integration of these two with an additional aspect of sustainability (represented by the shaded area) owing to the low-cost and energy-efficient nature of the proposed techniques produces affordable and durable housing systems which are also safe and comfortable.

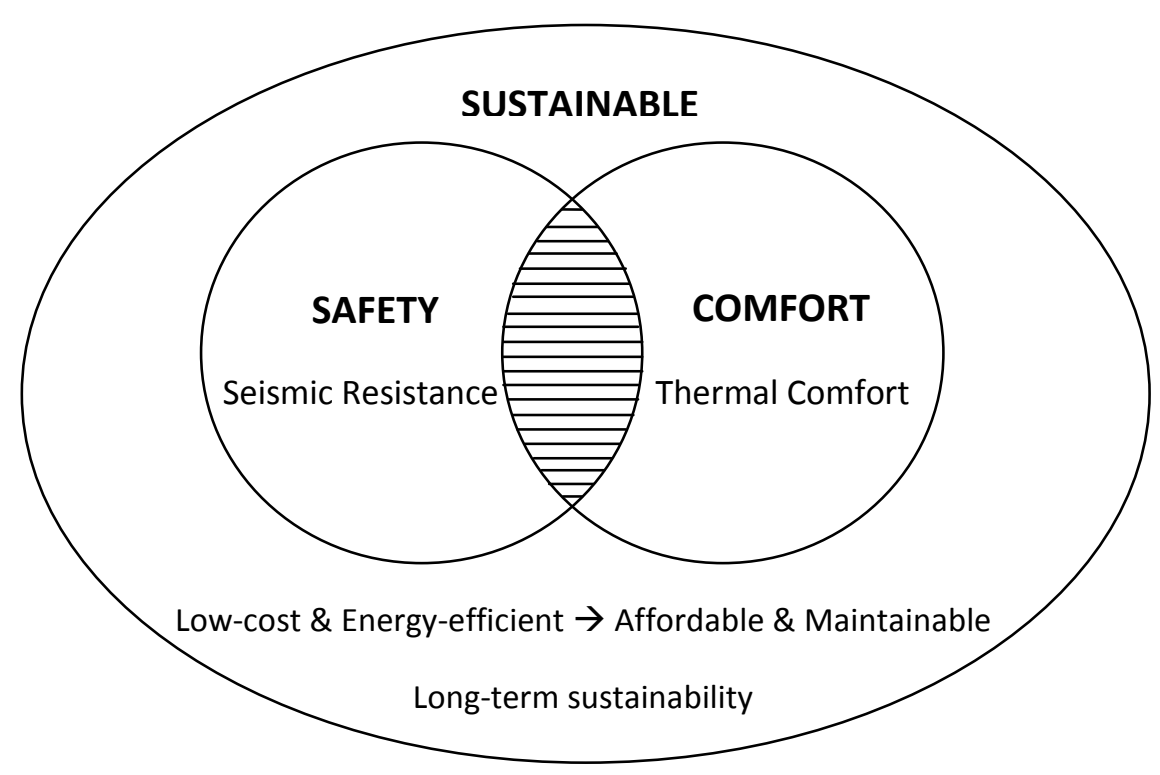

Figure 1.1: Research approach and goal for integrative technologies

\subsection{Thesis structure}

The thesis consists of a further five chapters which are organised sequentially from the initial surveys and identification of problems to the resolution and development of suitable techniques. The thesis organisation reflects the incremental and coalescing nature of the development of this study.

Chapter 2 explores theoretical housing and development issues through literature review. The challenges involved in low-income housing in developing countries are explored with a specific focus on India. The context for the study is set after consideration of the climatic and seismic characteristics of the regions. Popular housing types based on the commonly used construction materials are also explored. 
Chapter 3 reviews the literature on the importance of thermal comfort in the built environment. Investigation of the thermal comfort requirements based on the climatic conditions of each region is followed by the exploration of the best passive strategies for each region.

Chapter 4 reviews the literature on seismic vulnerability of non-engineered buildings, leading to the identification of low-cost retrofitting techniques applicable for the low-income housing types in India.

Chapter $\mathbf{5}$ explores the integrative solutions that have the potential to provide thermal comfort in addition to seismic safety via the research-by-design methodology. Scope for further development is identified and preliminary recommendations for design systems are given.

Chapter 6 concludes by reflecting on the study as a whole. The chapter highlights the key findings of the study, developments of the integrative techniques, future possibilities and the study's significance. 


\section{Housing for the Low-income in India}

This chapter addresses the low-income population of India as the primary target group and consequent beneficiaries of this research. Their socio-economic conditions, lifestyles and housing needs are discussed, followed by the identification of the selected regions for the study (Gujarat, Sikkim, and Jammu \& Kashmir) with consideration to their climate, seismicity, population density, and regional lifestyles. The section then concludes with an overview of the major housing types that are occupied by the low-income groups in these regions, including their construction materials and typical layout.

\subsection{The target group for research}

As the second-most populated country in the world, India has a population of 1.18 billion. While it is regarded as one of the upcoming super-powers of the world economy, about 300 million of its people still live under the government-set poverty line of Rs. 10 (NZD $=0.30^{*}$ ) a day per person (Channa, 2010). Poverty is a pressing concern which hinders the stable growth of the country, and more importantly, it indicates a lack of proper living standards for its citizens.

India has an uneven wealth distribution with the top $10 \%$ of the income group earning $33 \%$ of the income (Naveen, 2003). This results in the nation's poverty being unequally borne by the lower income group which constitutes a large part of the total population. The poor suffer severely in terms of housing conditions which are less than adequate with no protection against wind, rain and cold, and lack even the most fundamental requirements of hygiene (Hirway, 1987; Sengupta, 1975).

The aim of this research is to suggest methods of improving such living conditions in existing houses through techniques for seismic strengthening that will serve the double purpose of ensuring comfort and safety. However, in order to do so, we must first understand the people who live in these houses: how do they live? What can they afford? What are their needs? The following sections attempt to provide a clearer picture of the target group in terms of these questions.

\footnotetext{
* as at December 2010
} 


\subsubsection{Socio-economic conditions}

As established in the previous section, the 'low-income group' is the target population for this study. However, such a general label requires further explanation as to what it means in this context; why such classification is appropriate; and on what basis the classification is established, in order to avoid misuse of the term.

The Indian National Readership Survey categorises the population according to the Socio-Economic Classification (SEC) score based on income, occupation, and education of the chief wage earner of the household (The Times of India, 2005). It consists of five segments A, B, C, D, and E which subsequently relate to the separate status groups. 'High' socioeconomic classes refers to SEC A and $B$, 'mid' socioeconomic class refers to SEC C, and 'low' socioeconomic classes refers to SEC D and E (IndiaRetailBiz, 2006).

So who are the people of 'low' socio-economic classes (SEC D and E)? SEC D consists of those with a school leaving degree who are either skilled or unskilled workers, or petty traders; while SEC E primarily consists of unskilled workers most of whom have little education and nearly $50 \%$ are illiterate (2005 National Readership Survey). Together, this low-income group constitutes nearly half (46.7\%) of the total population of India (The Times of India, 2005).

So then where do they live? All over India is the simplest answer. With the high rates of migration to the cities due to rapid urbanization, it has become difficult to generalise the low-income population as primarily belonging to rural areas (as was the case in the past (Khosla, 1983)). However, some assumptions need to be made in order to make progress with the limited data available. In order to address the most vulnerable housing types commonly inhabited by the low-income population, this study considers the particular types of non-engineered constructions typically found in the rural regions. This is not to say that they are limited to the rural areas; many of the low-income population in urban areas also live in this type of housing (Arya, 2000). Details of these nonengineered construction types are presented in Section 2.3.

The actual income of these lower income groups cannot be pinpointed as the range is variable due to the impermanent nature of employment in the informal labour sector. However, Channa (2010) points out that even the current national floor minimum wage (Rs. 66 (NZD $=1.86^{*}$ ) per day since February $\left.1^{\text {st }}, 2004\right)$, can in no way guarantee a full diet as well as minimum requirements of housing, clothing medicine, and health care. At least Rs. 80 (NZD $=2.25^{*}$ ) per day per person (for just the

\footnotetext{
* as at December 2010
} 
living expenses -without the medical, educational and recreational expenses) is suggested and even this amount is deemed meaningless unless there is a guarantee of at least 250 labour days per year or 25 days per month (Channa, 2010). Observing the gap between ideology and reality, it is clear that the financial conditions of the low-income are insufficient for sustaining oneself let alone the whole family.

\subsubsection{Lifestyles of people}

First, it is necessary to state that there can be no singular lifestyle applicable to all members of the low-income group; such a claim is not viable and does not reflect the numerous complexities that are part of each individual's life and every household's survival. As such, this section only raises some significant factors that may contribute to the lifestyles of the low-income group and have an impact on their residence usage.

According to the Oxford English Dictionary (2009), lifestyle is defined to be "the characteristic manner in which a person lives (or chooses to live) his or her life." The lifestyle of the low-income population is, to a large degree, determined by their economic conditions. Hence, it is more of a lifestyle one has to live; rather than one he/she chooses to live.

Income determines the wellbeing of the individual and the entire family, and the existing discrepancy between what is required and what is provided severely affects the quality of life of the low-income population. For example, the dietary consumption is unbalanced and the food that can be afforded lacks the necessary nutritional content (Channa, 2010). The effects of financial burden can extend to the development of stress related medical conditions (Sethi, 2008). Likewise, access to medical treatments along with education, marriage, and recreation, is also hindered by financial limitations (Channa, 2010; Saigal, 2009).

Depending on where people live and work, they can lead very different lifestyles. The rural environment differs in many aspects from the urban: community associations, pace of life, relative stock prices, and types of employment opportunities available, to name a few. Rural life can be considered relatively slow and routined compared to that of urban where change and the associated uncertainties are an everyday happening. Employment in rural areas is mainly concentrated on agricultural labour which keeps the people outside, though weavers, potters, carpenters, blacksmiths who work indoors are also among the population. In urban areas, the greater part of the 
low-income group commonly perform long hours of labour outside (e.g. construction work, pulling rickshaws, repairing vehicles, menial labour, etc.) as well.

Gender roles in Indian society are largely defined in terms of religion, caste, class and region and may influence the lifestyles of the individuals. Traditionally, the female identity in India is embedded in their roles within the family: their primary responsibilities are caring for the home and nurturing the family, these also include food preparation and serving, cleaning, laundry, and childcare (Dickey, 2000; Maslak \& Singhal, 2008). Therefore, most women live and work within the home environment unlike male earners who are likely to spend the majority of their day outside of their homes.

As is apparent, no clear definition of a singular lifestyle can arise from these considerations since the low-income group is a highly varied population consisting of people from various backgrounds, religions, castes, and regions. One factor common to all low-income group members however, is that they work long and laborious hours for minimal income. Rural and urban environments differ and so does the type of work available. Although the resulting lifestyle differences can mean different needs for housing, addressing these is outside the scope of this study. However, by acknowledging the laborious and generally outdoors lifestyle of the low-income, one can assume that the population has a higher tolerance threshold for thermal discomfort due to their probable physiological acclimatisation to the local climate, and this can affect their comfort requirements. (additional discussion on this issue is presented in Section 3.1.3).

Regardless of lifestyle differences however, houses are required by all and the basic housing needs are common for the majority of people. These are discussed in the following section.

\subsubsection{Housing needs}

'Need' is a subjective term with multiple meanings. Conceptually, a 'need' is perceived and defined by the individual in distress who feels and expresses his/her situation and by the professional who diagnoses it (Yanay \& Griffel, 1985). There may be varying levels of priority assigned to the need and different criteria may be used to assess each need. Analogous to the ambiguous concept of 'need', is the idea of 'comfort'. Maldonado and Cullars (1991) discuss the multivariate meanings that the term can hold depending on the socio-economic context of the individual: it may refer to the minimum resources necessary for living, or it may also refer to the convenience, ease, or habitability enhanced by services. In this sense, there exists a fine line between 'necessity' and 'luxury' (which are relative terms themselves) when addressing comfort. Moreover, 'comfort' can also refer to sentimental, 
physical, and psychological satisfaction and the use of this singular term does not sufficiently explain the implied meaning(s).

Comfort in the context of this research, is the thermal comfort of the inhabitants of the low-income housing types. As discussed further in Chapter 3 (Section 3.3), it is referred to in terms of the tolerance level beyond which an environment induces sensations of discomfort. Both physiological and psychological parameters are considered in determining comfort, and based on the climatic data, 'comfort zones' are produced to account for the possible varying sensations of comfort among individuals of that region.

The 'adequacy' of living standards is another relatively defined term which can vary widely in different nations, cultures, and social circumstances (Kennedy, 2004). An appropriate definition of 'adequacy' of housing needs for this study, is one defined by the 1988 UNCHS Global Strategy for Shelter (GSS) (as cited in Kennedy, 2004): "adequate privacy, sufficient space and security, adequate lighting and ventilation, adequate infrastructure in a location with adequate access to employment, and basic services at a price which is affordable to the user." Although considering all the aspects mentioned here is clearly beyond the scope of this study, those that relate to physical comfort (particularly thermal) and safety provisions against earthquakes are addressed here.

\subsection{Regions chosen for the study}

The regions chosen for the study depend on two key features: 'seismicity' and 'climatic condition'. To ensure certain research variables are controlled in order to increase the reliability and validity of the research (Shuttleworth, 2008), each location chosen is based in Seismic zone IV (Indian Seismic Code IS 1893-2002) to keep the key requirements for the resisting building structure constant. The variable component is the climate which ranges between the extremes: a hot-dry climate in the Gujarat region; a composite climate experienced in Jammu \& Kashmir; and the cold climate of the Sikkim region. The common regions for the study are shown in the climatic and seismic zone maps (Figures 2.1 and 2.2 respectively). 


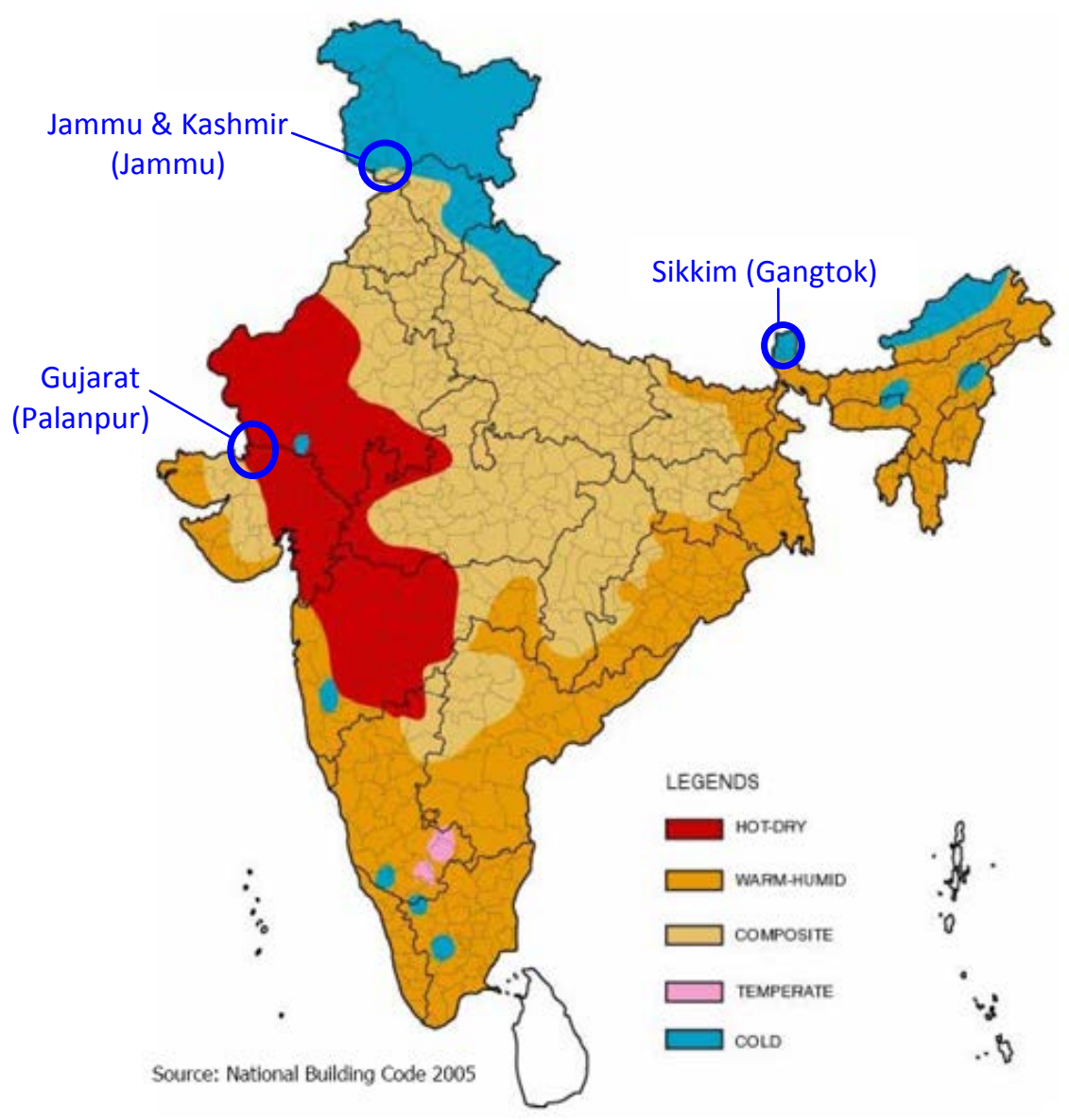

Figure 2.1: Climatic Zone Map of India (HPCB, 2010)

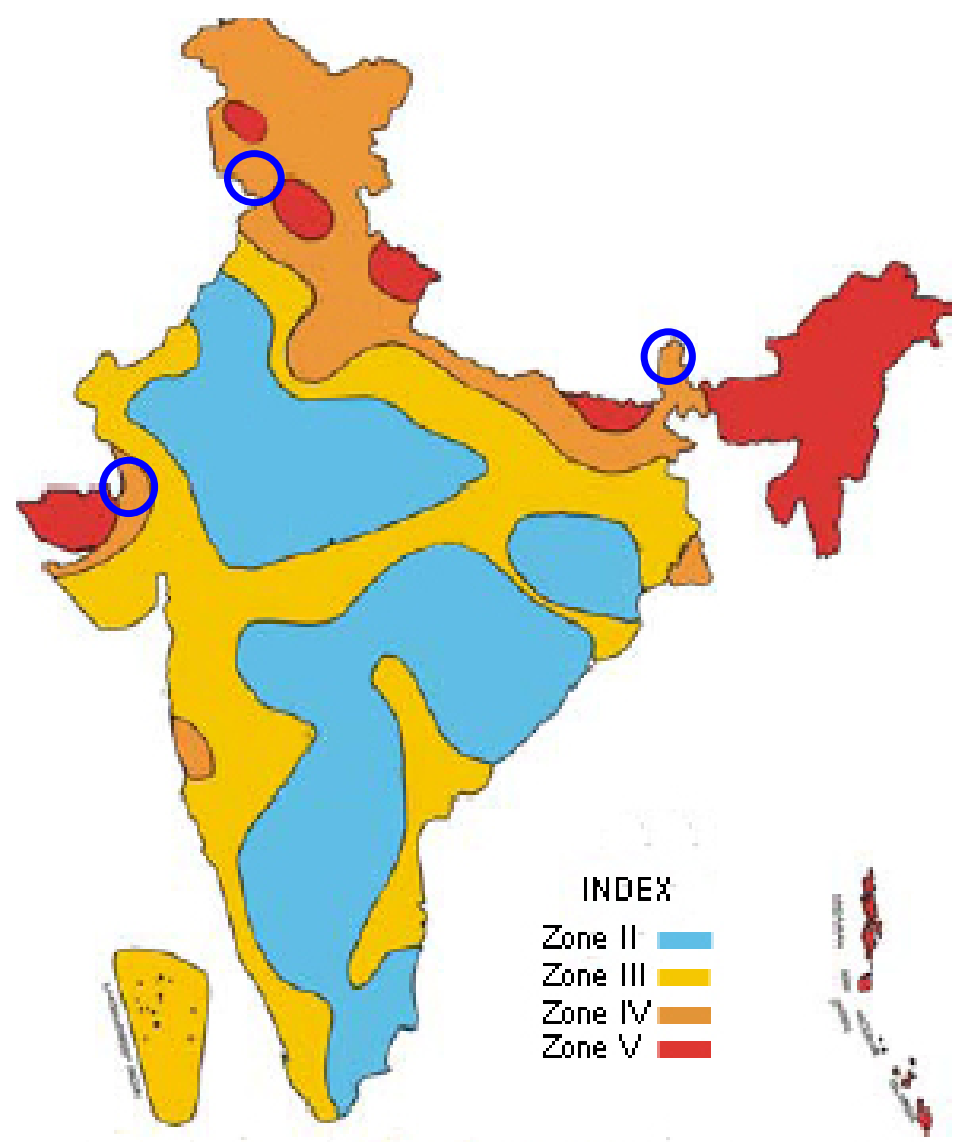

Figure 2.2: Seismic Zone Map of India (Institute of Seismological Research, 2007) 
Particular cities falling in each of the selected climatic zones have been selected in order to yield accurate climatic data and avoid data discrepancies resulting from the varied climatic patterns within the same regions. For example, the state of Gujarat falls in three climatic zones (warm-humid, composite and hot-dry). However, since this research only addresses the hot-dry climate zone for Gujarat, the city of Palanpur which falls in the corresponding climatic and seismic zones, is selected for attaining the climatic data. Similarly, Jammu represents the composite climate found in Jammu \& Kashmir, and Gangtok represents the cold climate in Sikkim.

The current seismic zone map (see Figure 2.2 ) shows that around $60 \%$ (Zone $V=12 \%$, Zone IV=18\%, Zone III $=26 \%$ and Zone II $44 \%$ ) of India is prone to moderate to major earthquakes (Joshi \& Kumar, 2008). Seismic zone IV is identified to be a 'high damage risk zone' by the Indian Seismic code IS 1893-2002 (Bureau of India Standards, 2002), and is equated to VIII of the MSK intensity scale ${ }^{1}$. Description of shaking intensity MSK VIII in terms of building damage is: "Most (about 75\%) well-built structures suffer moderate damage and few (about 5\%) suffer heavy damage. Most ordinary masonry constructions suffer heavy damage, and most rural constructions are destroyed. Occasional breaking of pipe seams occurs; memorials and monuments move and twist; tombstones overturn; and stonewalls collapse" (Murty, 2005). This excerpt reiterates the necessity of this research and provides sufficient reasoning for the selection of zone IV as the targeted zone area for improvement of seismic measures.

The common seismic zone for all three research locations implies that all the retrofitting systems need to withstand the same ground peak acceleration (PGA) (i.e. the maximum acceleration experienced by the ground during shaking), whilst their thermal requirements are different depending upon the local climatic condition. Hence, the variance in the climatic regions chosen allows for maximum exploration of combining and modifying different retrofitting techniques for adequate thermal performance.

The following sub-sections discuss each region to be studied with consideration to their climatic, geographic, and seismic profiles as well as their developments and current housing situations.

\footnotetext{
${ }^{1}$ The MSK Intensity scale 1964 has a range from I (least perceptive) to XII (most severe), and VIII is classified as 'damaging'. The intensity scale is based on three features of shaking -behavioural, structural, and geological effects. (Murty, 2005)
} 


\subsubsection{Geography and climatic profile}

Gujarat, accounting for $6 \%$ of the area (196077 sq. km) of the country, is situated on the west coast of India, near the Thar Desert, making most of the land dry and arid in nature. Though the state experiences various climatic types, Palanpur, located in the hot-dry climatic zone, records high temperatures throughout the year with summers recording average day-time temperatures of around $40^{\circ} \mathrm{C}$. Relative humidity can reach high levels during summer but remains comparatively low overall through other seasons.

The state of Jammu \& Kashmir encompasses the western range of the Indian Himalaya, occupying almost $42 \%$ of the total area of the range (Zurick \& Pacheco, 2006). Though the definite boundaries of the state are still disputed by the neighbouring countries, for the purposes of this study, the territorial boundary defined by the current map of India is used. Various factors influence the climate of the Himalaya including altitude, latitude, orientation and exposure of the mountain slopes to solar radiation. Temperatures in the Himalaya vary inversely with altitude at a rate of about $2{ }^{\circ} \mathrm{C}$ per $300 \mathrm{~m}$ of elevation loss or gain (Zurick \& Pacheco, 2006). The city of Jammu located near the south west of the state falls in the composite climate category with hot summers and cold winters, and fluctuating humidity levels. It also experiences the monsoon with rains lasting from mid-June to mid-September.

Sikkim is a small Himalayan state bound by Nepal, Tibet, Bhutan and the Indian state of West Bengal. Within an area of only 7100 sq. $\mathrm{km}$, the elevations range from $270-8578 \mathrm{~m}$ above mean sea level (Karan, 1989). The climate of the whole state can be recognized as ranging from subtropical to alpine (falling below $-40^{\circ} \mathrm{C}$ in winter) because of the variation in the elevation. However, since the elevated areas of the region are mostly uninhabitable due to their severe conditions and lack of resources, most of the population resides in the southern areas of the state (Karan, 1989). The temperature data for Gangtok (situated in the south) shows a cold to temperate range with average day-time temperatures barely reaching above $22^{\circ} \mathrm{C}$ in summers. Sikkim experiences high humidity levels throughout the year, and the monsoon brings the annual rainfall of $325 \mathrm{~cm}$ all across the state making it one of the wettest states in the Himalayas, and increasing the risk of landslides (Bharatonline.com, 2010).

The corresponding climatic data for each of the selected regions is provided in Table 2.1. 
Table 2.1: Summary Table of Temperature Range and Humidity Level

\begin{tabular}{|c|c|c|c|c|c|c|}
\hline \multirow[t]{2}{*}{ Months } & \multicolumn{3}{|c|}{$\begin{array}{l}\text { Avg. night time - Avg. day time } \\
\text { Temperature Range }\left({ }^{\circ} \mathrm{C}\right)\end{array}$} & \multicolumn{3}{|c|}{ Relative Humidity (\%) } \\
\hline & Palanpur & Jammu & Gangtok & Palanpur & Jammu & Gangtok \\
\hline January & $12.0-28.0$ & $4.0-19.0$ & $4.2-12.6$ & 50 & 76 & 50 \\
\hline February & $14.0-31.0$ & $7.0-22.0$ & $5.5-14.1$ & 43 & 71 & 58 \\
\hline March & $19.0-36.0$ & $11.0-28.0$ & $8.7-18.3$ & 34 & 64 & 62 \\
\hline April & $24.0-40.0$ & $16.0-35.0$ & $11.5-21.0$ & 35 & 48 & 66 \\
\hline May & $27.0-42.0$ & $22.0-40.0$ & $13.6-21.7$ & 45 & 40 & 69 \\
\hline June & $27.0-38.0$ & $25.0-39.0$ & $16.0-22.2$ & 60 & 54 & 76 \\
\hline July & $26.0-33.0$ & $26.0-35.0$ & $16.6-22.0$ & 78 & 75 & 81 \\
\hline August & $25.0-32.0$ & $25.0-35.0$ & $16.5-22.4$ & 80 & 78 & 82 \\
\hline September & $25.0-34.0$ & $23.0-34.0$ & $15.5-21.8$ & 73 & 74 & 79 \\
\hline October & $21.0-36.0$ & $16.0-32.0$ & $12.3-20.9$ & 56 & 65 & 68 \\
\hline November & $17.0-33.0$ & $10.0-28.0$ & $8.7-17.8$ & 49 & 67 & 57 \\
\hline December & $13.0-30.0$ & $5.0-21.0$ & $5.6-14.4$ & 51 & 74 & 47 \\
\hline
\end{tabular}

(Sources: Weather 2, 2010; WeatherReports, 2010)*

* Two sources have been used for the climatic data values presented here. This is due to the fact that the data for Gangtok presented in the Weather2 database is very different (too cold) to the range of temperatures presented on the WeatherReports database even though the data for the other regions largely coincide. This difference is possibly due to the large elevation variation in Sikkim. However, since it is known that people mainly live in the southern areas which are of lower elevation, and since this area is closer to the warm-humid zone, the data set used is the one with slightly warmer temperature ranges.

The mean temperatures for each month taken from the temperature range presented in Table 2.1 and presented in Figure 2.3 confirm the climatic classification of the selected regions as hot-dry, composite and cold and provide a visual comparison in terms of high low temperature levels throughout the year. Relative humidity levels of the regions are also presented in Figure 2.4 and show obvious differences such as the overall high humidity for Gangtok and its gradual change compared with the drastic differences between high and low figures of Jammu and Palanpur depending on the seasons. 


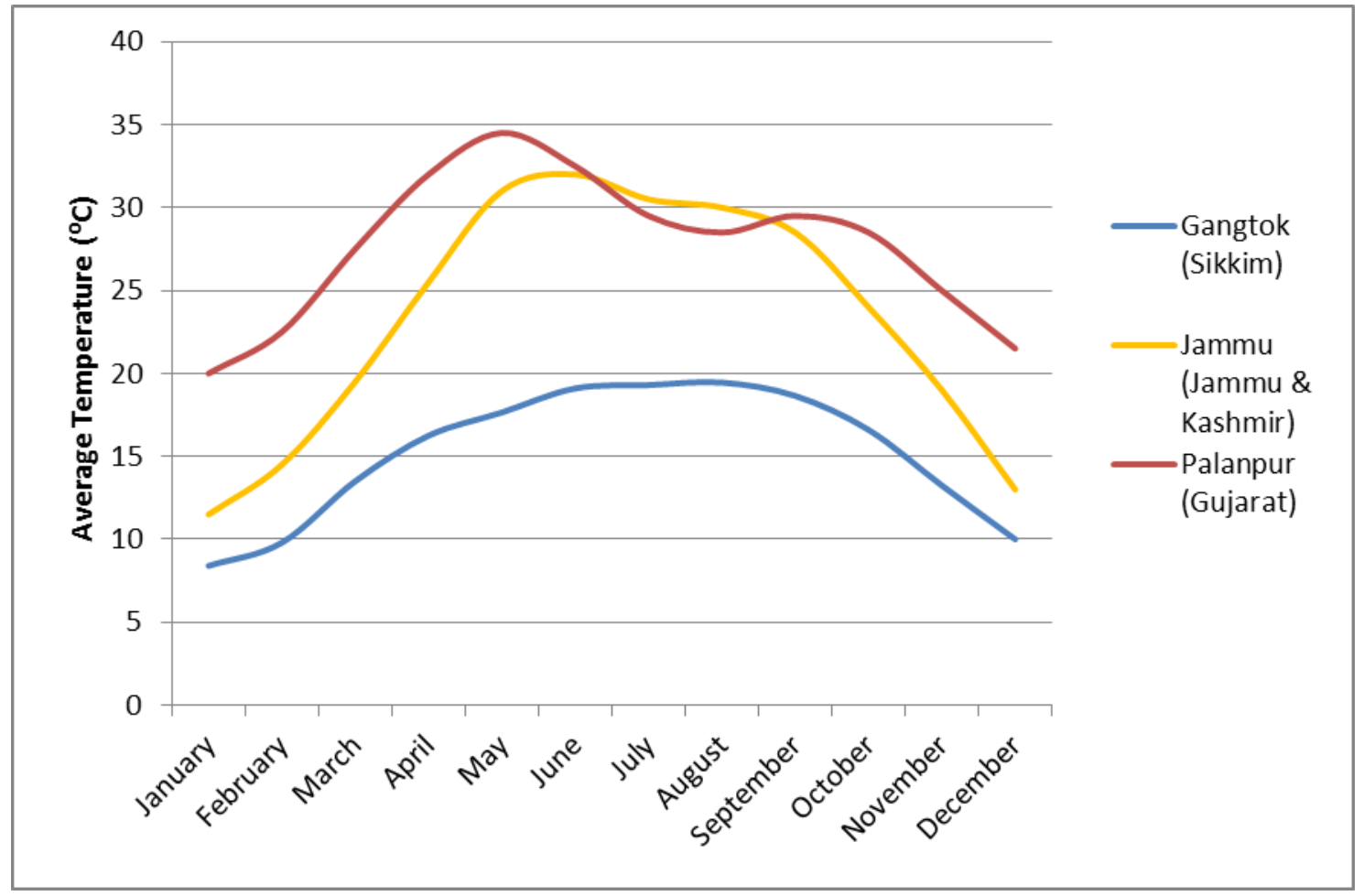

Figure 2.3: Annual average temperatures of Gangtok, Jammu and Palanpur

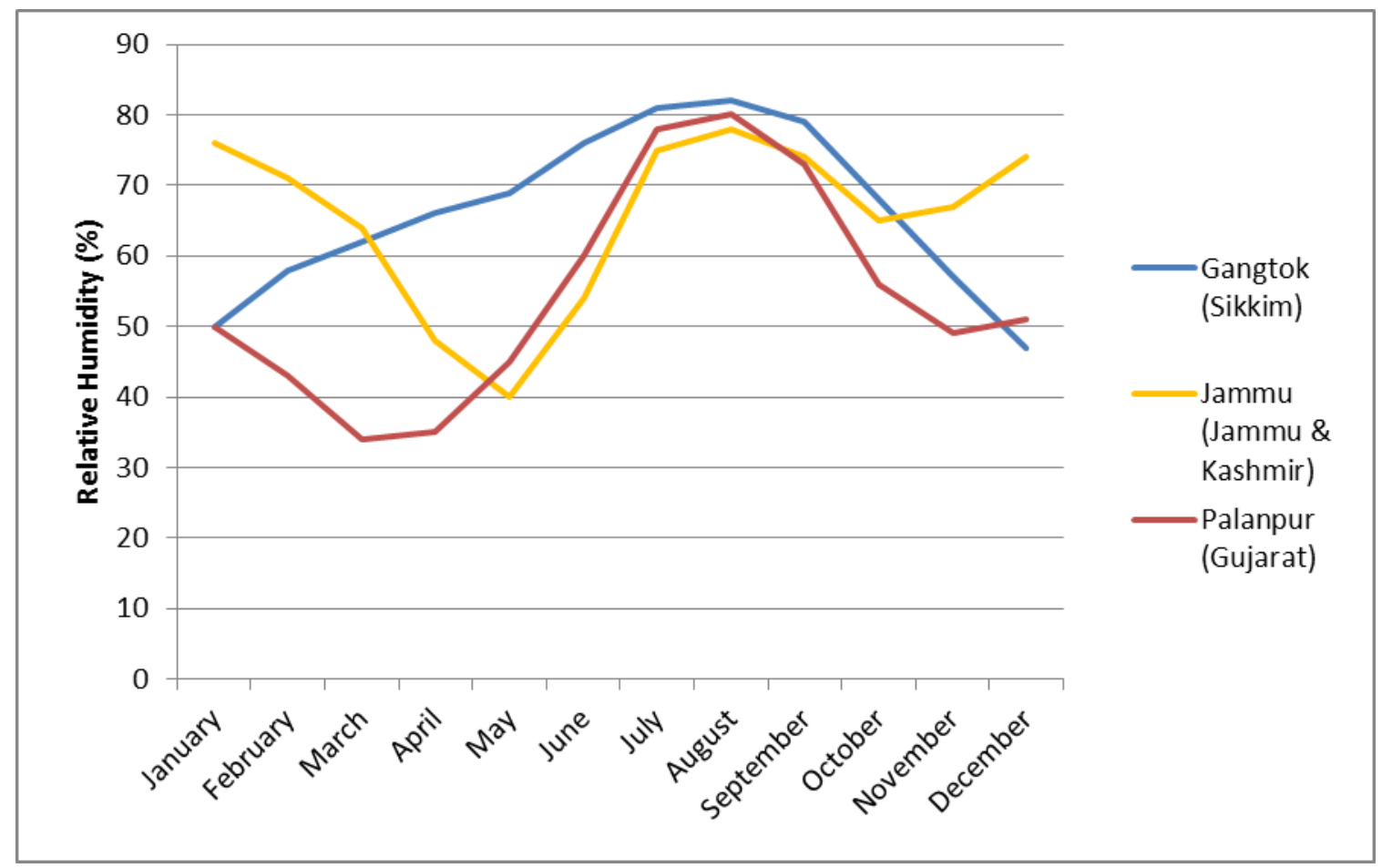

Figure 2.4: Annual average relative humidity levels of Gangtok, Jammu and Palanpur 


\subsubsection{Seismic profile}

According to the seismic zoning map (see Figure 2.2), Gujarat falls in all four different seismic zones, and is one of the most seismically prone intercontinental regions of the world (Yadav, Tripathi, Rastogi, \& Chopra, 2008). Zone IV covers a narrow fringe of the northern peninsula and the remaining part of Kachchh that is not in Zone V. Yadav et al.(2008) list 28 recorded occurrences of earthquakes with a magnitude greater than 5.0 in the region, during the period of $1819-2006$. The 2001 Bhuj earthquake was particularly devastating for the region, killing at least 19,200 people with 166,000 others injured, and destroying approximately 348,000 houses with an additional 844,000 damaged (RMS, 2007).

The Himalayas is one of the youngest mountain ranges on earth and it continues to grow today amid widespread and frequent earthquakes, making northern India a tectonically dangerous place to live. The Jammu and Kashmir state falls in both Zone V and Zone IV seismic zones, resulting in high risk area. Eight major earthquakes measuring over 7.5 on the Ritcher scale have occurred in the Himalayas in the past century, and the most recent earthquake in the Kashmir was in 2005 (7.6 magnitude on the Ritcher scale) with 80,000 resulting casualties (Kayal, 2008).

Likewise, the mountainous Sikkim region is underlain by several thrust faults. All districts of Sikkim lie in Zone IV and eight earthquakes of around 5.0 or higher in magnitude have been recorded in the region from 1934-2007 (ASC, 2008). Seismologists indicate that the microearthquake data in the Sikkim Himalaya reveals active faults in the region and suggest that any such active fault can trigger a large earthquake (Kayal, 2008). Moreover, Bilham et al. (2001), states that one or more great earthquakes are overdue in large fraction of the Himalayan arc, threatening millions of people in the region (as cited in Kayal, 2008).

\subsubsection{Housing profiles}

The following housing profiles are based on the data available through the latest Census of India to date which was conducted in 2001. It gives a clearer picture of the socio-economic conditions of the people in terms of their housing, affordable services, and most of all, their living conditions.

It is worth noting that the census data for housing is separated by state and does not specify data for particular localities, it also does not differentiate the data in terms of income levels but rather as 
'rural' and 'urban' population. The census data only shows the general figures of the whole population of the state and their housing conditions, and these are used here.

\subsubsection{Gujarat}

51 million people live in Gujarat accounting for almost 5\% of India's total population of which 37\% belong to the urban areas whilst $63 \%$ live in rural areas (Government of India, 2001a). The Census data also reveals that $46 \%$ of the working population in Gujarat is engaged in agriculture (i.e. cultivators and agricultural labourers) which includes $68 \%$ of the rural population. It is considered to be one of the richest states in terms of per capita income of the country, and yet its level of poverty, especially rural, is also relatively high -and where rural poverty is low, the urban poverty is high (Parikh, 1996).

The most relevant points have been selectively identified from the State Housing Profile data (Government of India, 2001a) for the purposes of the study and presented in the following summary.

- $49 \%$ of the population live in one room houses and about $32 \%$ live in two room houses.

- Rural households generally have more members per household compared to urban households. The usual household size range varies between 4-8 members per household.

- The most common materials for wall construction are burnt brick followed by mud, then stone.

o Urban houses are mostly made of burnt brick (75\%) while only $8 \%$ are of mud/unburnt brick.

o Rural house figures show equal numbers of mud, unburnt brick houses and burnt brick houses.

- There is a high percentage of privately owned houses, especially in rural areas (93\%).

- Separate kitchen within the house is usually available in this region, with $69 \%$ of the houses providing them, though $24 \%$ may need to cook within their regular rooms.

\subsubsection{Jammu \& Kashmir}

Jammu \& Kashmir, with almost 8 million residents, has the largest population of any Indian state in the western Himalaya. The great majority of migrants in the state settle in relatively new towns and cities. These places are growing at a very rapid rate, in most cases without sufficient infrastructure 
or planning. Population growth rates of 2 to $3 \%$ a year are common in the Himalaya, and in some areas, such as the outer foothills, annual growth rates exceed $4 \%$ (Zurick \& Pacheco, 2006). The majority of the Kashmiri population is involved in agriculture while the cities accommodate the emerging industrial sectors.

The state encompasses the disputed territory with Pakistan and China, and the long conflict since 1947 has played a large part in the deteriorating conditions of the environment, the increase in poverty rate, and the growing risk of living in a war zone. Accurate population measurements and housing data are also not possible due to the inability to carry out surveys in the disturbed regions, but the following summary is based on the available Census housing data for the state of Jammu \& Kashmir (Government of India, 2001b).

- The majority of the people live in houses with 1-3 rooms.

- The sizes of households in Kashmir are generally larger compared to the other regions.

o The majority has 6-9+members per household.

- The commonly used wall materials are mud/unburnt brick, burnt brick, and stone, but there are significant differences between the usage of materials between the rural and urban population.

o $81 \%$ of the urban houses are of burnt brick while only $10 \%$ are of mud, unburnt brick, and $3 \%$ of stone.

o Rural also uses burnt brick the most but there is less difference between percentages distribution of the materials

- More than $80 \%$ of the people in both rural and urban settings own their own houses

- A separate kitchen within the house is usually available, with $80 \%$ of the total houses recorded to have them.

\subsubsection{Sikkim}

Sikkim is the least populous state in India with a population of 0.54 million according to the 2001 Census. The population below the poverty line as recorded in the 2001 Census is approximately 37\%, and most of the human population residing in the southern foothills of Sikkim engages in agriculture. The population growth rate in Sikkim is very high which is one of the main causes of the region's environmental degradation, and the spread of agriculture on to steeper slopes and marginal land has also heightened the level of vulnerability in the event of an earthquake (Karan, 1989). 
The following summary based on the state census data (Government of India, 2001c), highlights the most relevant points regarding housing conditions in Sikkim.

- Most of the population lives in one or two rooms houses whether in rural or urban areas.

- Both rural and urban households have a high number of people per household and the overall range is between 4-8 members per household.

- Rural houses show higher percentages of locally available materials used for wall construction such as grass, thatch, bamboo and wood, while $60 \%$ of the urban houses are made of concrete.

- In Sikkim, $69 \%$ of the rural population own their own houses while $60 \%$ of the urban population rent their houses.

- A separate kitchen within the house is usually available with $85 \%$ of the total houses providing them.

The above housing profiles for each of the regions have identified important factors which provide a better insight to the living conditions of the population. Similarities can also be noticed across the regions. For example, it is clear that the majority of the houses usually do not have more than one or two rooms which have to accommodate large family units (consisting of 4-9 members per household). Similarly, the high percentage of the rural population with 'owned houses' is common to all the regions. This scenario, especially in rural areas where poverty is typically thought to be an issue, indicates that most people are likely to construct their own houses, which in turn indicates that these houses must be of low standard due to the lack of technical knowledge and built without proper consideration of engineering principles. It can therefore be safely assumed that there would be a high percentage of non-engineered housing in each of these regions. Accordingly, the following section addresses these housing types based on the commonly used construction materials across the selected regions.

\subsection{Housing types}

Based on the 2001 Census housing data, this section outlines the typical housing types found in the regions of Gujarat, Jammu \& Kashmir and Sikkim. The concept of non-engineered construction is explained, followed by the analysis of commonly used construction materials in the selected regions, and finally the typical housing types are illustrated in plan and section to provide an idea of the construction types addressed in this research. 


\subsubsection{Non-engineered construction}

According to Arya (2000), "non-engineered buildings" are defined as those that are spontaneously and informally constructed in various countries in the traditional manner without any or little intervention by qualified architects and engineers in their design. These construction types are often built using inexpensive locally available materials by the owners themselves or with the involvement of the neighbours in the construction process. These residences are usually built based on prior experiences (passed down through generations) rather than engineering knowledge, and as a result they do not adhere to the building codes, are often unreinforced, and therefore highly vulnerable to seismic forces. Their weaknesses are further described in Chapter 4 (Section 4.3).

As established previously, most of the low-income population in developing countries live in nonengineered houses. Papanikolaou \& Taucer (2004) also observe that these structures are prevalent not only in rural areas but also in the periphery of large urban centres. Most casualties during earthquakes has occurred due to the collapse of these non-engineered buildings that are still being built in the moderate to severe seismic zones of the developing world (Arya, 2000). Their widespread use without any awareness of its danger makes the low-income population in seismic regions even more vulnerable to earthquake occurrences.

\subsubsection{Construction materials}

Based on analysis of the 2001 Census state data for the construction materials used for walls in residential housing (see Figure 2.5), the most common non-engineered housing types can be identified.

From the graph it is clear that burnt brick is the most used wall material followed by mud and unburnt brick in both Gujarat and Jammu \& Kashmir. For Sikkim, the most commonly used materials differ from that of the other regions. The popular use of wood or bamboo is likely to be due to abundance of natural resources available to the region. These perform considerably better than other construction materials in earthquakes and are not in need of major seismic retrofitting. The reconnaissance report of the February 2006 Sikkim earthquake also confirms this, stating that there were no reports of any significant damage to wooden construction (Kaushik, Dasgupta, Sahoo, \& Kharel, 2006). Hence, for the purposes of this study, wooden and bamboo constructions are not considered. 
Concrete also appears to be used extensively as a wall material in Sikkim -over $20 \%$ of the houses use it. This is probably due to the habitable area of this state being small and the majority of it being developed as cities and towns. However, since concrete is not extensively used in the other two regions, it cannot be considered as a commonly used wall material for all of the selected locations. In this sense, stone is comparatively well used as a common wall material across all three regions and better suited for this research.

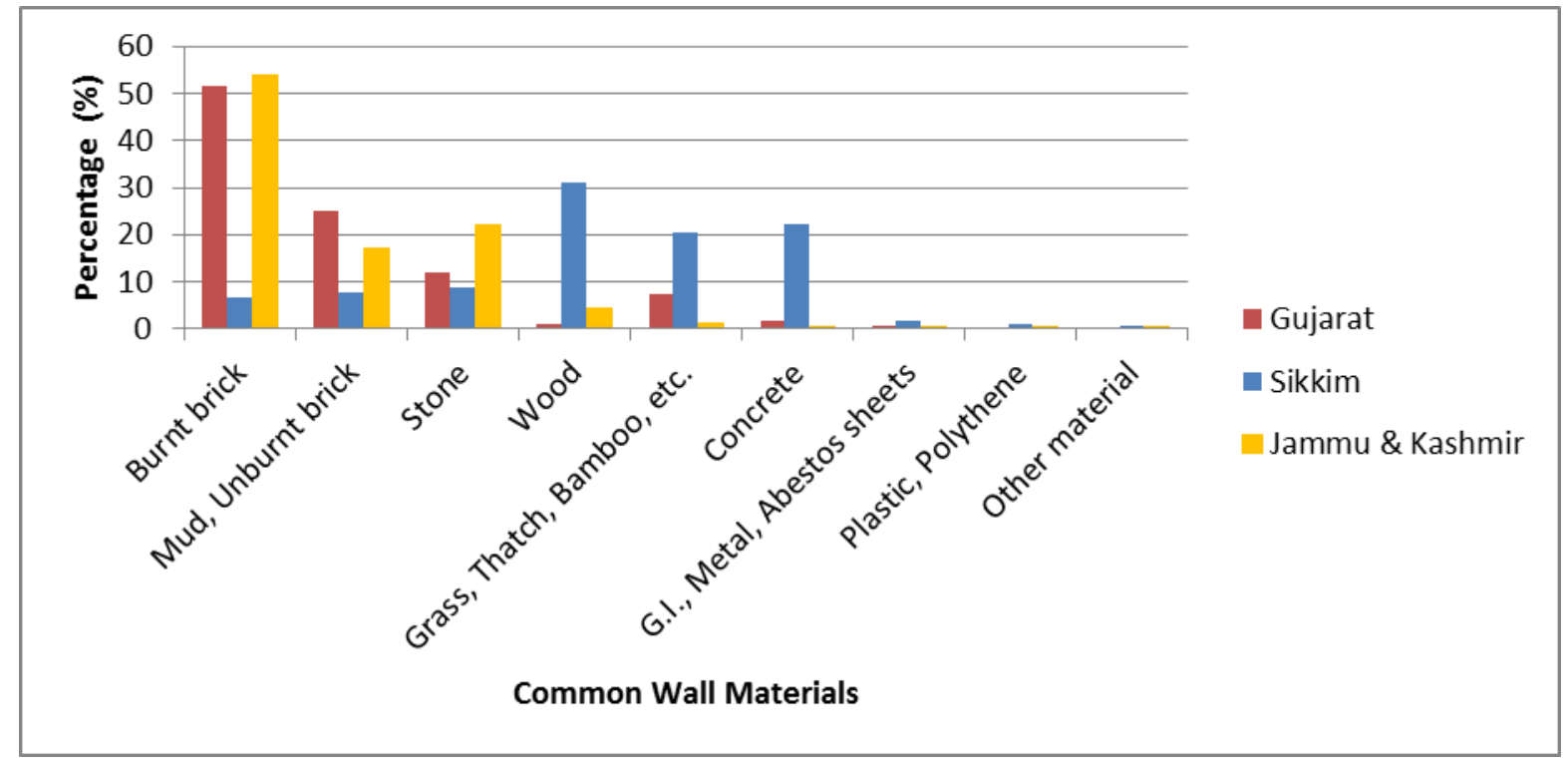

Figure 2.5: Common wall materials usage distribution for Gujarat, Jammu \& Kashmir and Sikkim based on Census of India data (Government of India, 2001a, 2001b, 2001c)

Therefore, based on the above reasons and the overall usage of the different materials across the regions, the three most commonly used wall materials are identified to be: burnt and unburnt brick, mud and stone construction.

\subsubsection{Typical house plans}

This section presents typical house plans and section drawings for non-engineered construction types based on the findings for common wall materials used across the regions. These unreinforced masonry construction types are categorised as follows: "Fired/unfired brick", "Adobe" and "Stone". A point to note is that most of these construction types are found throughout India and are not limited to the selected regions only. Similar types of construction are found in other developing countries. 
It is necessary to acknowledge that although 'typical' house plans are presented below, individual houses can differ depending on the requirements of the owner and their financial limitations. Hence, although a selection of possible variations is also presented, the house plans presented here should only serve to provide an idea of the unreinforced construction types to be considered in this study.

Another point to note is that it is common for low-income housing types to have the bathrooms separate from the main structure and this is the case for all of the plans presented here.

\subsubsection{Fired/unfired brick}

Brick housing is the most popular construction type across the three regions (as illustrated in Figure 2.5), and has been practiced for hundreds of years in India. Fired brick buildings utilise regular-sized masonry units made of clay mud which are burnt in a kiln. These housing types can be made with or without mortars; but when mortars are used, they are either mud-based or cement-based (INTERTECT, 1984). The typical wall compositions as outlined in the survey conducted by INTERTECT (1984) on the vernacular housing in seismic zones of India, are as follows:

(1) $30 \mathrm{~cm}$ wide unfired brick with fired brick veneer on the outside in mud mortar, plastered inside with a mud and dung mixture (total wall thickness is $40-45 \mathrm{~cm}$ ) (see Figures 2.6 and 2.7).

(2) Unfired brick 'core' wall in mud mortar $30 \mathrm{~cm}$ wide, a fired brick veneer inside and out in mud mortar, and plastered inside and out with a mud and dung mixture (total wall thickness is $60-70 \mathrm{~cm}$ ) (see Figure 2.8 ).

(3) $30 \mathrm{~cm}$ wide unfired brick in mud mortar plastered on both sides with a mud and dung mixture (see Figure 2.9).

A variety of roofing systems can be adopted, but hipped roofs constructed of wood or bamboo rafters at $25 \mathrm{~cm}$ centres are predominant including tiled roofs supported on wood trusses, asbestos or steel sheets on steel trusses, and reinforced concrete slabs (INTERTECT, 1984).

The information above is presented based on the building found in the northern region of the state of Bihar. However, as the World Housing Encyclopedia report reveals, this type of unreinforced brick masonry construction can be commonly found in both rural and urban areas of Northern India (Kumar, 2002b). The following diagrams, though not to scale, provide an idea of the typical brick houses found in India. 


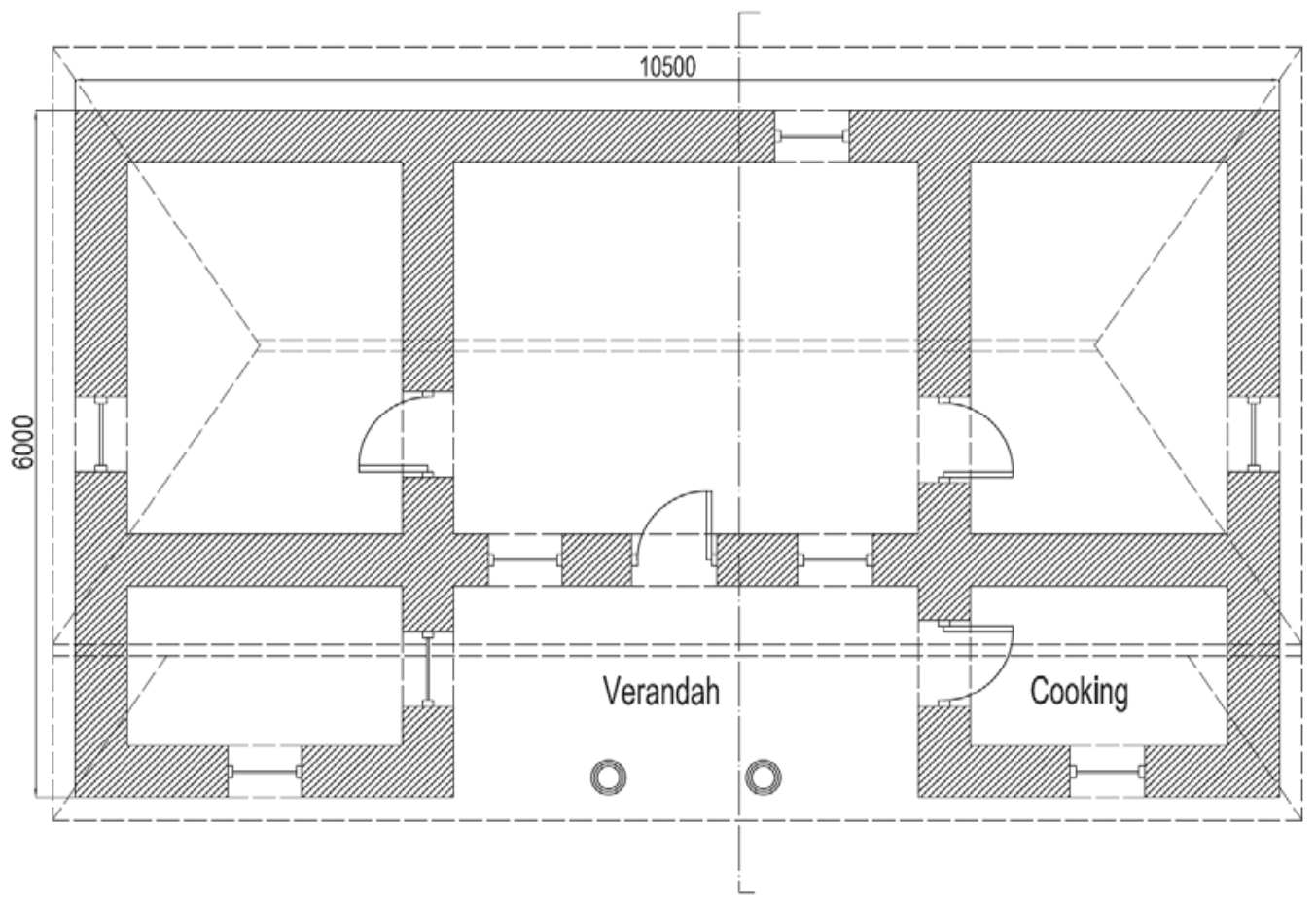

Section A-A

Figure 2.6: Plan view of typical fired/unfired clay brick house (based on INTERECT, 1984)

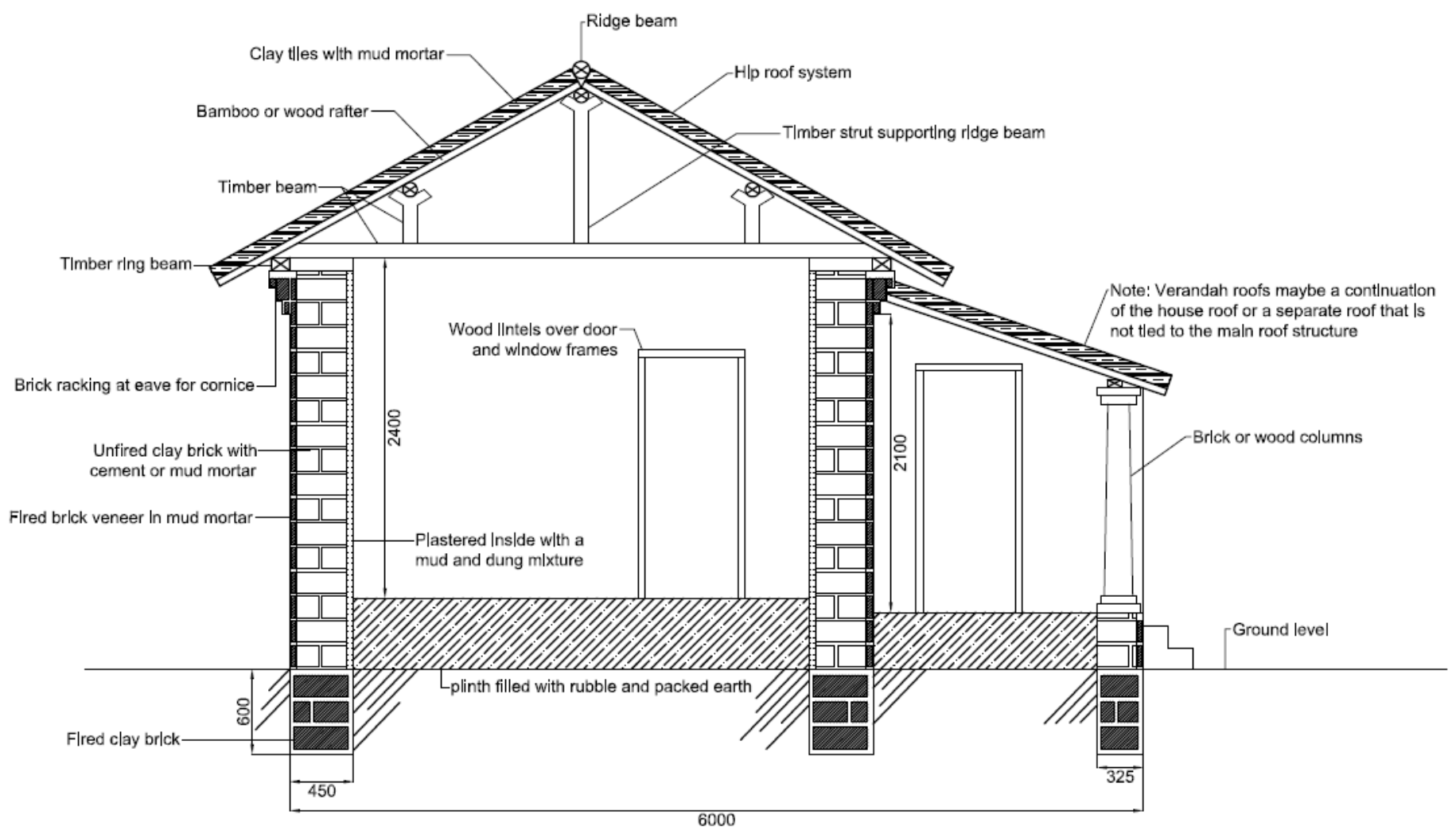

Figure 2.7: Section A-A (based on INTERECT, 1984) 


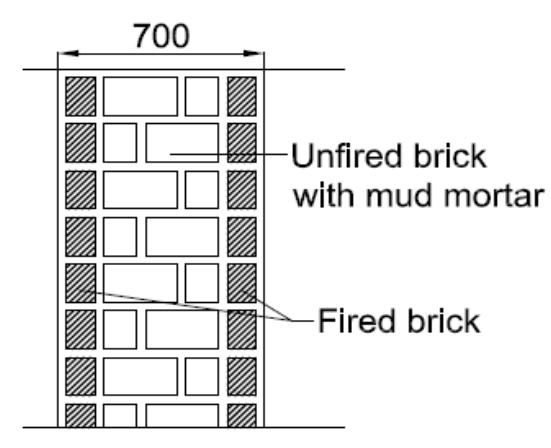

Figure 2.8: Unfired brick core wall with a fired brick veneer on both side of the wall (based on INTERECT, 1984)

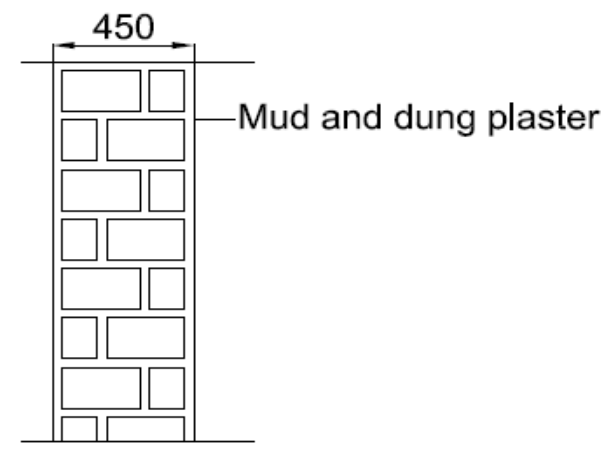

Figure 2.9: Unfired brick plastered on both sides with a mud and dung mixture (based on INTERECT, 1984)

These types of buildings are typically found on flat terrain and do not share common walls with adjacent buildings; if adjacent buildings exist, they are usually separated by a distance of 3 metres (Kumar, 2002b). In terms of the plan, the buildings are generally rectangular. The typical plan dimensions of these buildings are $6 \times 10.5$ metres (as shown in Figures 2.6 and 2.7) and one storey high (usually 3 meters) (INTERTECT, 1984; Kumar, 2002b). However, these dimensions can vary depending on the requirements and economic conditions of the owners. The commonly found configuration variations of these houses are presented in Figure 2.9. It can be noted that there are very few exits that lead directly to the outside in these types of houses.
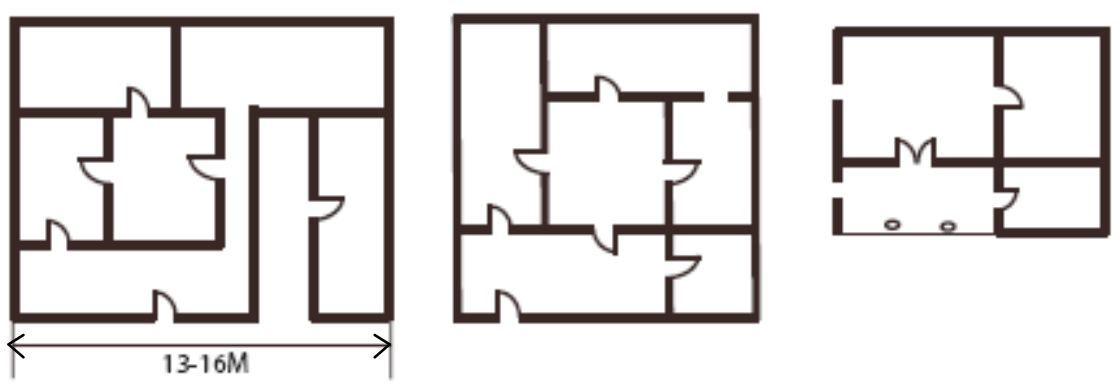

Figure 2.10: Possible plan variations (based on INTERECT, 1984)

The style and size of wall openings have changed with time and recently constructed buildings usually have smaller doors and window sizes as compared with older buildings. However, since they have more windows and doors, the total area of openings is greater in newer constructions (Kumar, 2002b). It is also common to find openings located at wall corners which increase the risk of collapse in the event of an earthquake. In addition, the roofing elements are usually not interconnected and the roof structure is not properly anchored to the wall. These structural deficiencies and others are discussed in further detail in Chapter 4. 


\subsubsection{Adobe}

Adobe or mud is the most commonly used material for housing construction in the developing world. The most popularly used adobe construction method utilises sundried blocks of earth (mixed with water and straw) joined with mud mortar. In India, the walls, consisting of $12 \times 25 \times 30 \mathrm{~cm}$ mud blocks, are usually plastered with a mud and dung mixture. This type of building construction has been practiced for over 200 years and continues to be practiced today (Kumar, 2002a). Figures 2.10 and 2.11 show the plan and section views of a typical adobe building in India.

Though the above illustration is based on the INTERTECT survey of the Maharashtra state, this type of building is said to be found throughout India except in high rainfall areas of the Northeastern part of the country (Kumar, 2002a). It is worth noting that this statement also coincides with the low Census figures for mud usage in the Sikkim state (as seen in Figure 2.5), indicating that mud houses are uncommon in that particular region though widely used in the other two.

This type of adobe construction is more common in the rural areas than in the urban. It usually houses the poorest of the low-income group. Similar to the brick construction, these construction types are also typically found in flat terrain and do not usually share common walls with adjacent buildings. Though the dimensions of the houses vary depending on the number of occupants and the economical capabilities of the owner, they are usually rectangular in plan. The foundations are constructed of stone in mud mortar below ground, and the plinth above ground is filled with rubble and packed earth (INTERTECT, 1984). Hipped roofs are typically constructed of round wood or bamboo rafters with square wood tie beams at $1.7 \mathrm{~m}$ spacing, resting on a continuous square wood ring beam; and roofing materials are usually handmade or manufactured ("Mangalore") clay tiles.

The main load-bearing system consists of mud walls which carry the roof load, though in some cases, wooden posts are provided at the wall corners and at intermediate locations. The wooden posts and walls are not structurally integrated, and therefore the loads are shared by the walls and the frame. There are very few openings (doors and windows) in these buildings (Kumar, 2002a). And overall there are various seismic deficiencies due to the weak construction materials. 


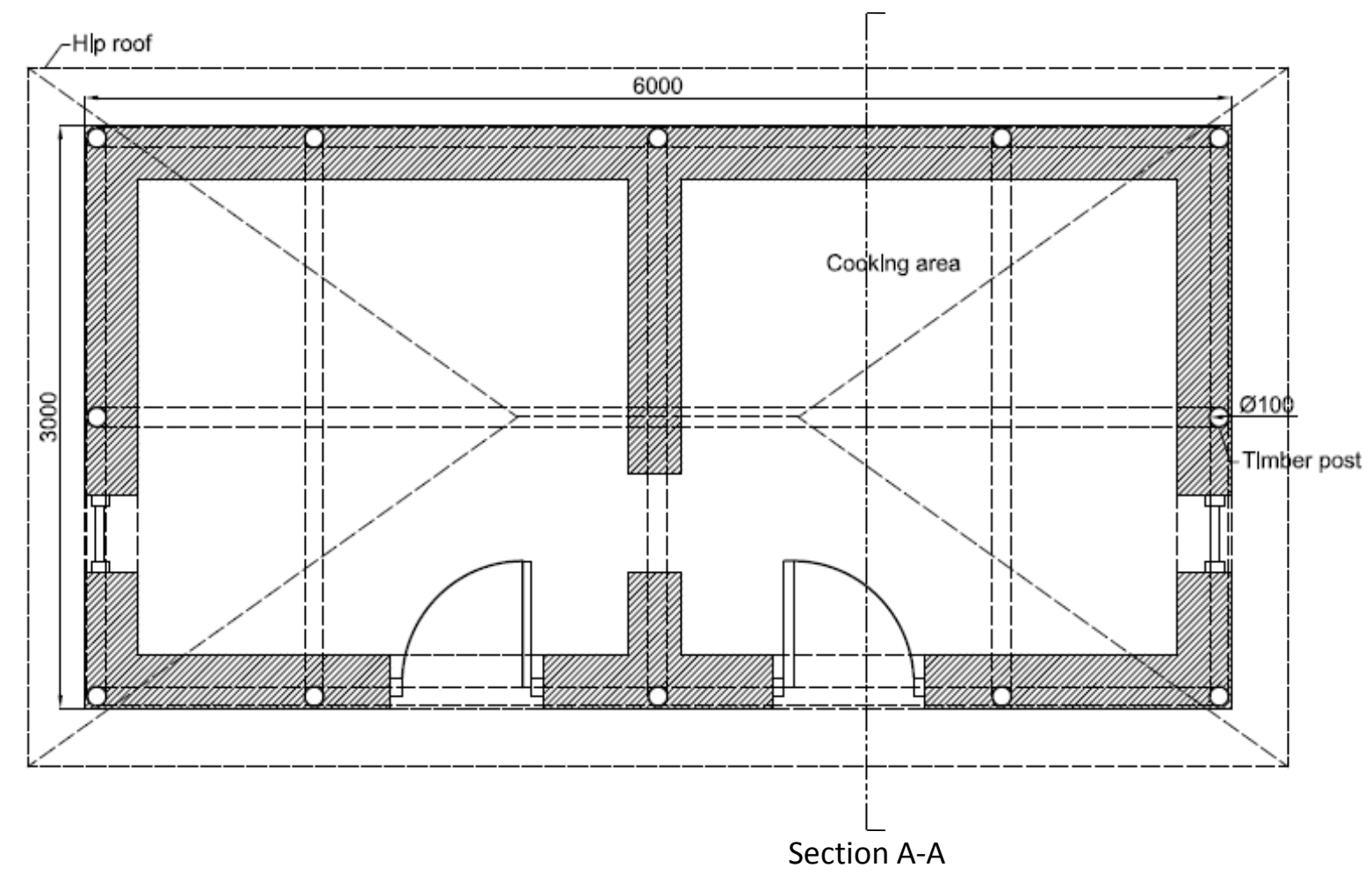

Figure 2.11: Plan view of a typical adobe residential building (based on INTERECT, 1984 p.47)

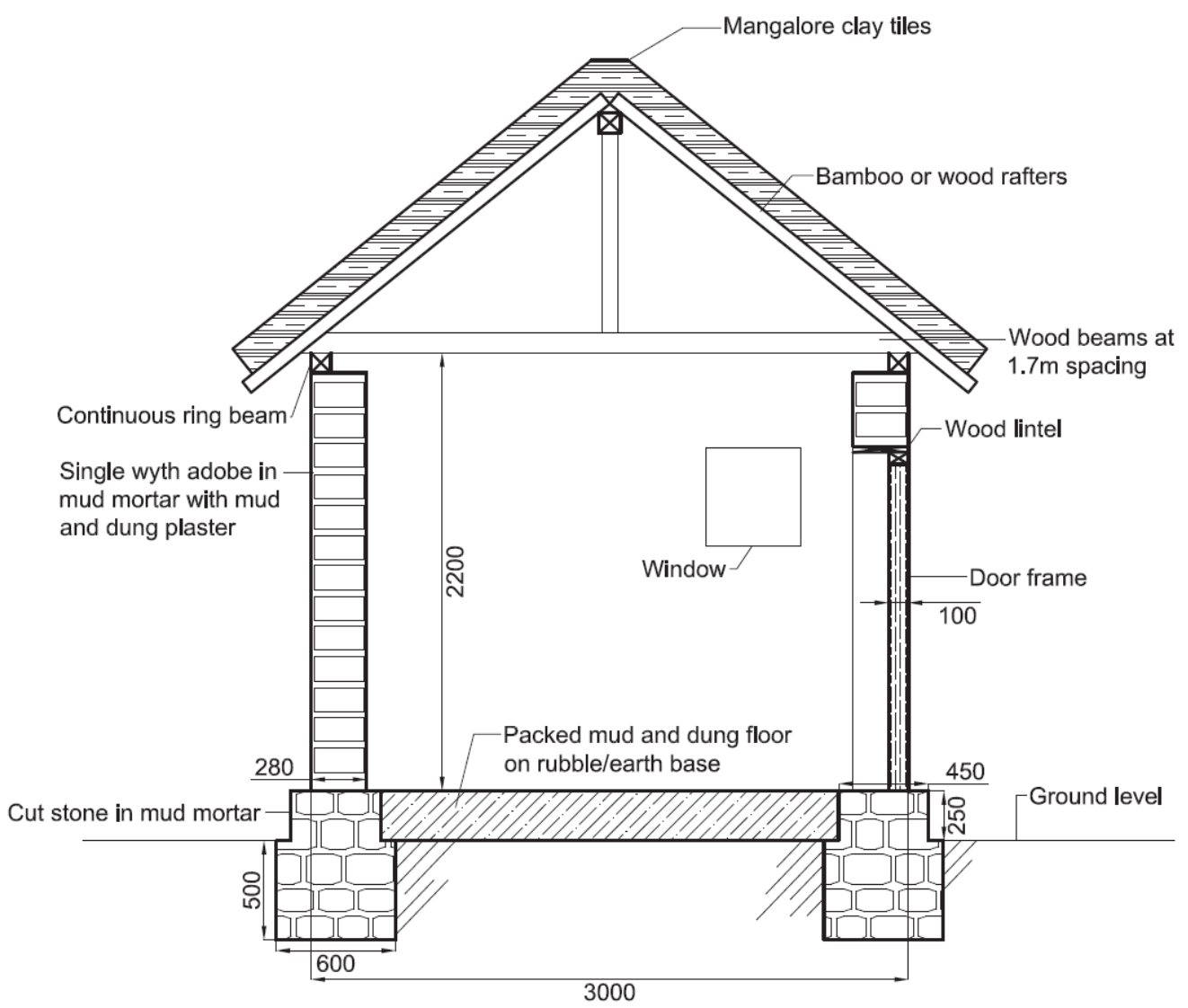

Figure 2.12: Section AA. A view of a typical adobe residential building (based on INTERECT, 1984 p.46) 


\subsubsection{Stone}

Stone is commonly used in all of the three selected regions as a wall construction material, and particularly in Jammu \& Kashmir. In this type of construction, cut or random stone with slate wedging is used for the walls; no mortar is used and the walls are plastered with mud and dung mixture inside and out (INTERTECT, 1984). The foundations are also of cut or random stone but they are in mud mortar. The roof structure typically consists of four perpendicular pancake layers of timber beams with a solid sheathing of small round wood, which is then covered with small branches in a thick layer before the thatching is placed followed by a mud and crushed stone topping (INTERTECT, 1984). The following Figures 2.12 and 2.13, illustrate the typical type of rural stone housing that is found all over India.

The houses are mainly built around a central courtyard and can be expanded horizontally by building additional rooms; but usually they are of regular or square shape (see Figure 2.14 for the variations). Typically there are very few small door and widow openings, and it is estimated that the total window and door widths constitute approximately 15-25\% of the total wall length (S. N. Brzev, Greene, \& Sinha, 2002). The lack of multiple doors may be good for security reasons; however, it also means there is only one escape to the exterior during earthquakes.

This type of building is usually occupied by extended families. The number of inhabitants in the building during the day is estimated to be 5-10, while in the evening and night it is 11-20 (S. N. Brzev, et al., 2002). These high rates of occupancy coincide with the 2001 Census data for Jammu \& Kashmir (which has the highest stone construction rate) in Section 2.2.3.2.

According to Brzev et al. (2002), this type of housing is cheap to construct and therefore the ratio of housing unit price to annual income is 1:1. However, though it may be cheap, this type of nonengineered stone construction is extremely vulnerable in earthquakes because of its heavy roofs and poorly constructed walls. Delamination of walls is common and results in full collapse of the structure. Further details on seismic deficiencies are discussed in Chapter 4. 


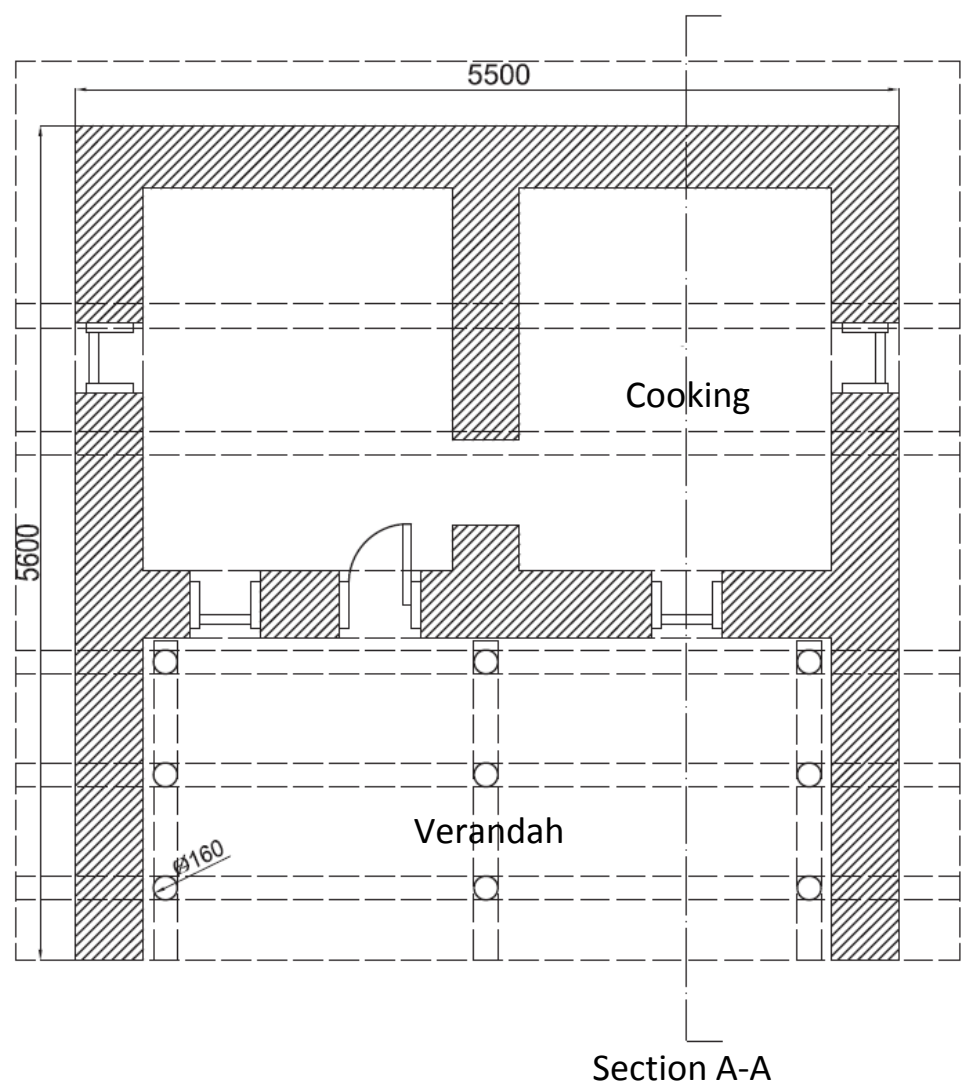

Figure 2.13: Plan view of a typical stone house with a flat roof (based on INTERECT, 1984 p.81)

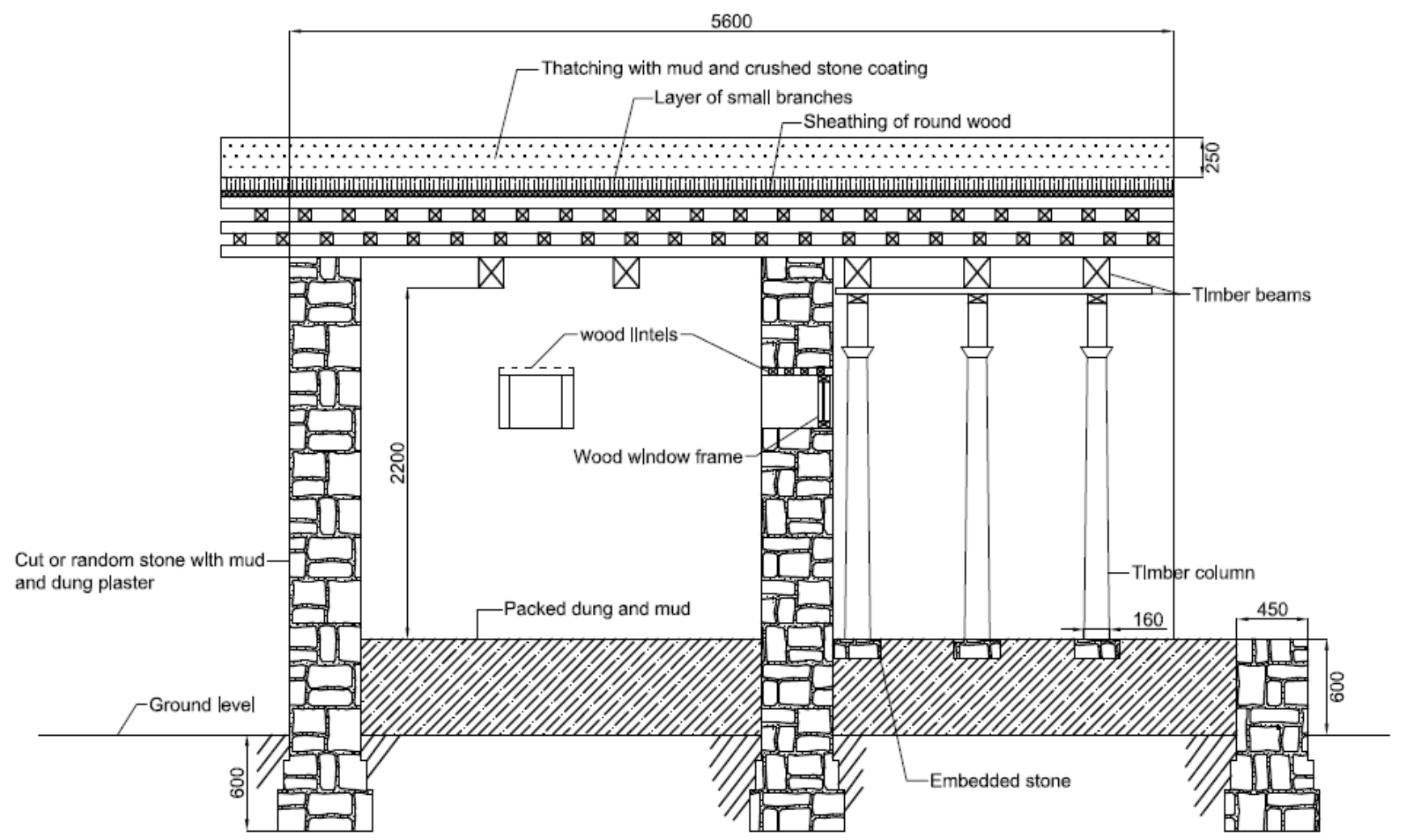

Figure 2.14: Section AA. A section view of a typical stone house with a flat roof (based on INTERECT, 1984 p.80) 

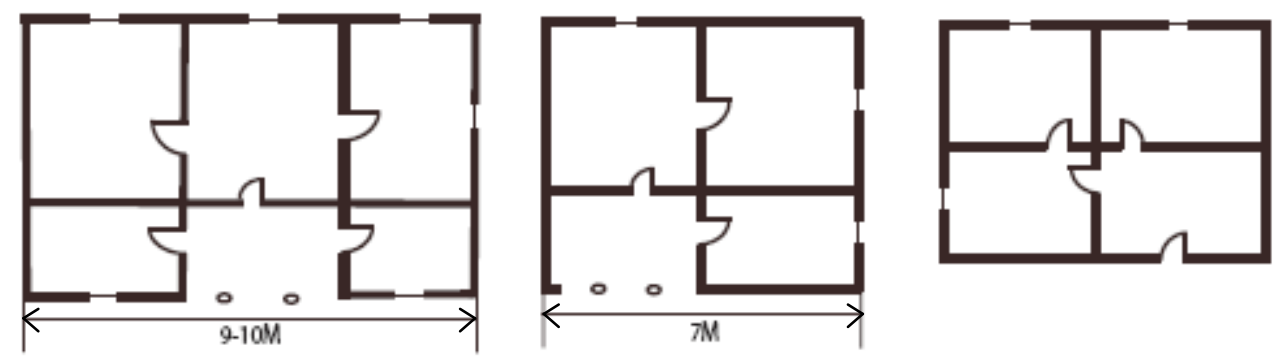

Figure 2.15: Possible plan variations (based on INTERECT, 1984 p.81)

\subsection{Summary}

The living conditions of the low-income population in India are inadequate due to their inability to afford the necessities of housing. It is therefore clear that the low-income population living in the seismic zones of India are highly vulnerable to earthquakes, not just because of their location but also due to the type of affordable non-engineered housing that they inhabit.

The three major types of non-engineered housing commonly found in Seismic Zone IV areas considered in this study, on the basis of most popular construction materials, are: unreinforced brick, adobe and stone buildings. These buildings are constructed all across India and also in the three selected regions (Gujarat, Jammu \& Kashmir and Sikkim) which belong to three disparate climatic zones (hot-dry, composite and cold, respectively) selected for this study. 


\section{Importance of Thermal Comfort in the Built Environment}

This chapter addresses thermal comfort and what it means in the specific context of the low-income population. The effects of discomfort are discussed in order to emphasise the necessity of maintaining comfort in houses. Following this, the existing models of thermal comfort are examined and the most appropriate model for use in this study is identified. On its bases the comfort zones for each region are mapped and analysed. After a brief examination of current housing conditions and comfort levels of the low-income population, different passive strategies are reviewed and through analysis of the monthly climatic lines and the discomfort index, the most appropriate passive strategies to consider in this study are identified.

\subsection{Experiencing the environment}

We experience the environment through our sensory organs. Our eyes allow us to navigate through space and perform tasks at hand. Our ears offer an omni-directional perception which can illuminate spatial properties of the surroundings. If it is particularly strong, the most persistent memory of a space can also be its smell (Pallasmaa, 2005). Our skin not only reads the texture, weight and density of matter (Pallasmaa, 2005), but also senses the change in humidity level, air movement and air temperature of the surroundings through the thermal sensors located over the whole body surface (Szokolay, 2004). As a result, several realms of sensory experience interact and fuse into each other to provide a singular understanding of the environment.

Consequently, the sensations experienced via these sensory organs evoke different bodily responses depending on the conditions of the environment. Thermal comfort, the focus of this study, is one such condition that is essential for habitability in a given environment. If not maintained it can have adverse effect on human health, performance, and productivity. The following sections will examine these thermal comfort aspects and the responses that they arouse in detail.

\subsection{Definition of thermal comfort}

The standard definition of thermal comfort is "that condition of mind which expresses satisfaction with the thermal environment" (ANSI/ASHRAE 55-2004). Alternatively, since our physiological and psychological responses are usually only triggered in cases of 'discomfort', 
comfort can be understood to mean the absence of thermal (heat/cold) discomfort (Givoni, 1998). Though on one hand comfort is a subjective psychological phenomenon and not directly related to the physical environment or physiological state (Parsons, 2003), the phenomenon does evoke a human response to the physical environment which can affect the physiological and psychological state of the person.

The four basic environmental variables that affect human response to thermal environments are air temperature, radiant temperature (heat exchange by radiation), humidity (the amount of moisture/water vapour in the air) and air movement (direction, speed and time of air flow). Combined with the metabolic heat generated by human activity and clothing worn by a person, they provide the six fundamental factors that define human thermal environments (Parsons, 2003).

\subsubsection{Physiological responses}

According to Givoni (1998), the main physiological human responses to thermal change are sweat rate, heart rate, inner body temperature, and skin temperature. In order to feel comfortable, humans must maintain an internal body temperature within a narrow range of $36.5^{\circ} \mathrm{C}$ to $37^{\circ} \mathrm{C} \mathrm{(Koch-}$ Nielsen, 2002), and the skin temperature within a range of $31^{\circ} \mathrm{C}$ to $34^{\circ} \mathrm{C}$ (Szokolay, 2004). If the body temperature deviates from this thermal equilibrium, one experiences 'discomfort', and the above mentioned physiological responses are triggered in order to release or generate heat and restore the internal core temperature.

Perspiration can be taken as an example of the most common form of physiological response to thermal discomfort. It occurs when the surrounding temperature (i.e. air and surface temperature) is above $25^{\circ} \mathrm{C}$ (Koch-Nielsen, 2002), but the extent to which heat is lost by evaporation (i.e. perspiration) also depends on the clothing worn, the temperature, the humidity level and the amount of air movement. Opposite of this mechanism is shivering; while perspiration works to decrease the core temperature and cool the skin surface, shivering is triggered to increase the declining core body temperature in a cold environment. As is clear from the above, these thermoregulatory processes are the immediate physiological responses our body initiates to cope with thermal discomfort. 


\subsubsection{Psychological and behavioural responses}

As established previously, thermal sensation is a psychological perception, and therefore, the discomfort experienced when the internal body or skin temperature is above or below the thermal equilibrium is a psychological response. The recognition of this discomfort then in turn triggers the physiological responses, as well as various behavioural actions.

Behavioural adjustment is identified as being the most effective response for people to maintain their thermal comfort (Williams, 1996). According to Parsons (2003), our behaviours to resolve a thermally uncomfortable situation can be categorized into personal, technological, and cultural adjustments. Personal adjustment includes actions that directly influence the body, such as moving to more desirable thermal conditions, changing posture, and removing or putting on more clothing. Technological adjustment includes actions that are aimed at manipulating the environment; for example, lighting fires and turning on mechanical heating and cooling systems. And lastly, the cultural adjustments include traditions which have been developed to cope with the extreme environmental conditions such as having siestas in midday heat.

It can be assumed that the target population of this study being low-income would not rely much on technological adjustments due to the financial limitations which prevent them from being able to afford the appropriate technology. Their psychological perception of thermal discomfort is also likely to have a high tolerance threshold which is discussed later in Section 3.4.

\subsection{Effects of discomfort}

The effects of discomfort can range from a slight headache to sudden death; affecting people's health as well as performance and productivity. It is, therefore necessary to understand the nature and extent of these effects in order to comprehend the importance of maintaining comfort in the built environment.

\subsubsection{On health}

Our body maintains several physiological mechanisms to cope with thermal discomfort, but in extreme conditions, thermal discomfort can lead to the impairment of these metabolic processes. For example, the evaporation of sweat from the skin cools the body and plays an active role in 
human thermoregulation. However, high humidity can retard this mechanism of heat loss (Egan, 1975). Koch-Nielsen (2002) observes that relative humidity above $90 \%$ can make one feel clammy and damp, and therefore, lower humidity level is usually preferred. However, on the other hand, relative humidity of less than $20 \%$ is likely to cause discomfort because of excessive dryness of the air. This may cause lips to crack, eyes to become irritated, and the throat to become sore (KochNielsen, 2002). Hence, the need to maintain an adequate humidity level through effective ventilation systems is evident.

Similarly, discomfort caused by air motion can lead to draught if there is unwanted local cooling of the body. It can also lead to stuffiness if the interior wind speeds are below $0.1 \mathrm{~m} / \mathrm{s}$. Therefore, the suggested wind speed limit for daytime is of up to $2.0 \mathrm{~m} / \mathrm{s}$ when air motion is required and $1.0 \mathrm{~m} / \mathrm{s}$ for night comfort (Koch-Nielsen, 2002).

More serious consequences of discomfort are heat stress and cold stress. Heat stress occurs when the body's thermoregulation system is strained in its attempt to increase heat loss; it can lead to delirium, dryness of skin, heat illness and even death resulting from stroke if those exposed are neither behaviourally nor psychologically acclimatized to the heat (Parsons, 2003). Cold stress is the opposite extreme of heat stress. Fall in body and skin temperature can cause muscles to become stiff and therefore movements become clumsy. There may also be a clouding of consciousness (e.g. confusion and sometimes apathy), loss of sensory information (e.g. blurring of vision), unconsciousness, and eventually the risk of death. Though these health effects are caused by extreme conditions, it is clear that the primary cause for them is discomfort caused by the unsuitable thermal environment.

\subsubsection{On performance and productivity}

In general, exposure to discomfort leads to loss of capacities for physical and mental work. The physiological responses triggered by discomfort may impact the physical performance and hence decrease productivity of the task at hand. For example, shivering can cause distraction and sweating may affect the grip of the hand. Moreover, there may be loss of concentration, clouding of consciousness and psychological strain on the mind in thermally stressful environments. It is noted that people's performance under thermal stress is about $11 \%$ lower than their performance at normal thermal conditions (Auliciems \& Szokolay, 2007).

In addition to decreased cognitive performance, behavioural changes can also be observed as a 
result of discomfort. Studies report antisocial behaviours, increased anxiety levels, and apathy being caused by thermal discomfort (Auliciems \& Szokolay, 2007).

In both cases, it is important to consider how acclimatised the people are to the environment and what their tolerance limit for handling the discomfort is before it becomes a strain on the body. Once the discomfort level is beyond the capacity to cope, the effects can range from minor hindrance in terms of productivity, to short-term and long-term illnesses and even death. This corroborates the importance of maintaining optimal thermal comfort in indoor environments in order to avoid adverse effects on human health and performance.

\subsection{Acclimatisation}

The process of acclimatisation is defined as:

"A complex set of physiological and psychological readjustments that take place when the organism is exposed to stress. The manifestations of heat acclimatisation include the increase of blood volume which increases the effectiveness of vasodilation, an enhanced efficiency of heat loss by sweat, both in terms of volumes and composition and in accord with adaptation theory, a readjustment of temperature preference towards the stress stimulus." (Auliciems \& Szokolay, 2007).

The tangible results of acclimatisation include decreased sensations of discomfort and improved work performance under thermal stress. Due to the nature of its prolonged seasonal process where the full attainment results from everyday thermal experiences, the effects of acclimatisation can be applied to the low-income population who, in addition to their vigorous work requirement, known to speed up the acclimatization process (Auliciems \& Szokolay, 2007), also lack the scope to modify indoor air conditions via mechanical HVAC systems.

Researchers have shown that there is a large difference between the acceptable comfort ranges of people with and without HVAC systems (Indraganti, 2008), and between those of indoor and outdoor occupations (Auliciems \& Szokolay, 2007). In both cases, the latter population (i.e. without HVAC systems and of outdoor occupation) find a broader range of thermal conditions acceptable, coinciding with the characteristics of the low-income majority. There are also temperature preferences that can arise due to the geographical location of the region (e.g. coastal vs. inland population), as well as gender and age differences in the tolerance threshold for thermal discomfort among individuals (Auliciems \& Szokolay, 2007). However such considerations are beyond the scope of this study. 
The terms "acclimatisation" and "adaptation" are often interchangeably used even when their implied meanings may be different. This can create issues when referring to the adaptive model of thermal comfort (explained in Section 3.5.2). For purposes of this study, "acclimatisation" refers to the physiological or psychological adjustments through which a person may come to prefer or accept a different set of skin temperatures or sweat rates for comfort, while "adaptation" also includes the active adjustments (behavioural, technological or cultural) undertaken by a person to restore comfort as identified in Section 3.2.2.

\subsection{Models of thermal comfort}

Having discussed the variable range of comfort conditions that can be experienced by individuals, it is necessary to consider thermal comfort models which help establish guidelines, giving a better indication of appropriate indoor thermal conditions. The two major existing models are the Static and Adaptive models.

\subsubsection{Static model}

The static model is based on the principle that a person is a passive recipient of thermal stimuli. It assumes that a given thermal environment affects the human body exclusively by "the physics of heat and mass exchanges at the surface of the body, while the maintenance of a constant internal body temperature necessitates some physiological responses"(De Dear, Brager, \& Cooper, 1997). This model is based on studies conducted under laboratory conditions, and enables one to predict thermal comfort limits based on the assumption that thermal sensations are proportional to the magnitude of the physiological responses such as skin temperature and sweat rate (De Dear, et al., 1997; Humphreys \& Nicol, 1998).

This principle has led to the development of the currently used ASHRAE Standards (ANSI/ASHRAE 55-2004) for building design (Humphreys \& Nicol, 1998) which has promoted the universal application of indoor climate standards across all building types. Sharma and Tiwari (2007) note this to be the case in India also, where the existing indoor design temperatures are set at $26^{\circ} \mathrm{C}$ for cooling seasons and $21^{\circ} \mathrm{C}$ for heating seasons irrespective of which region the building is to be built in. Minimal recognition of the outdoor climatic context (apart from the seasonal clothing adjustment) and the adaptive capabilities of the building occupants, along with the increased 
reliance on mechanical cooling are highlighted as the major shortcomings of the static model (De Dear, et al., 1997; Humphreys \& Nicol, 1998). Accordingly, the static model's relevance to naturally ventilated buildings where conditions are inherently much more viable has been questioned (De Dear, et al., 1997).

\subsubsection{Adaptive model}

In contrast to the static model of thermal comfort, the adaptive model considers behavioural adaptation as well as psychological and physiological acclimatisation of the occupants. It is based on the principle that "if a change occurs such as to produce discomfort, people react in ways that tend to restore their comfort" (Humphreys \& Nicol, 1998). It recognises that a person is not a passive receiver (as is the case in the static model) but rather an active participant within the thermal environment.

The adaptive model follows the reasoning that indoor temperatures are dependent on outdoor temperatures, especially in naturally ventilated buildings, and therefore calculates the optimal indoor temperature based on the mean outdoor air temperatures. It takes into account the adaptive capabilities of humans; for example, the ability to expect and tolerate different temperatures during different times of the year, as well as actively engage in opening or closing of windows, changing posture, and so forth (Humphreys \& Nicol, 1998; Tuohy, Humphreys, Nicol, Rijal, \& Clarke, 2009) The optimal temperature for a given time is determined by looking at the mean outdoor temperatures of each month of the year, and field-studies in this area have led to suggestions for region-specific (instead of universal) thermal comfort standards.

Likewise, Sharma and Tiwari (2007) also find the static model to be unsuitable since it is non-flexible in the Indian context; the country, having a highly variable climate from region to region and within a region, needs variable indoor temperature standards that take into account the outdoor climate. Accordingly, this study follows the adaptive principle to determine the appropriate indoor thermal conditions for each of the target regions (using psychrometric charts) based on their mean outdoor temperatures (explained further in Section 3.5.4).

\subsubsection{Psychrometric charts}

Psychrometric charts provide the means of analysing the climatic characteristics of a given location 
in terms of human comfort. It allows the annual graphical representation of patterns of the main climatic factors, as well as the thermal performance of buildings, which can help determine the appropriate design strategies in order to maximise indoor comfort for a particular region. It presents a concurrent combination of temperature and humidity at any given time, which can then help specify strategies to maximise indoor comfort when the building's interior is not mechanically conditioned. All such charts are structured around, and refer to, the "comfort zone" (Givoni, 1992).

Primarily, the following information can be read from the psychrometric chart: the dry bulb temperature (DBT) -the most common measure of temperature represented by the vertical lines; absolute humidity $(\mathrm{AH})$-the amount of moisture in the air represented by the horizontal lines (not shown in the diagrams for clarity since it is not relevant); saturation line -the maximum amount of humidity that air can hold for a particular temperature represented by the outer most curve; relative humidity $(\mathrm{RH})$-the percentage of humidity in the air relative to the saturation line represented by the other curves. Additionally, other information such as wet-bulb temperature, dew-point temperature, and moisture precipitation can also be read from the psychrometric chart, but these are not explained in detail here as they are not essential for understanding the comfort zone.

\subsubsection{Comfort zone}

In order to understand how to improve the thermal conditions of the houses in the target regions, it is first necessary to understand the thermal range in which the local population would feel comfortable. The comfort zone, represented on the psychrometric chart, specifies boundaries of air temperature and humidity within which the majority of persons would not feel thermal discomfort, either of heat or of cold, in an indoor environment. The graphic depiction of these ranges allows one to determine which conditions result in discomfort and what strategies to use in order to retain the thermal conditions within the comfort zone.

The widely used ASHRAE comfort zone (based on the static model) is largely developed for mechanically controlled residential and commercial buildings, and is therefore not appropriate as a guideline for maintaining thermal comfort in low-income residences across the developing world. Therefore, the appropriate indoor comfort zones for each of the target regions of this study have been determined based on the adaptive model of thermal comfort and apply to the naturally ventilated buildings usually inhabited by the low-income population. It considers the wide diurnal climatic range that is experiences by the people in the houses as well as their capacity for acclimatisation. 
There is no previous work known to the author which has determined the comfort zones based on the adaptive model for these specific target regions. Hence, to deduce the comfort zones, the method suggested by Szokolay (2004) using outdoor the climatic data available was used (this is shown below). A point to note is that since the comfort zone plotted on the chart varies with the climate, strictly speaking, it would be different for each month. However, for purposes of visual simplicity, only the values for the warmest and coldest months in each of the regions have been used here in order to represent the range applicable for the two extremes.

The procedure to obtain the comfort zone boundary values is outlined in Szokolay (2004, p. 22) and involves:

1) Find the thermal neutrality $\left(T_{N}\right)$ for both the warmest and the coldest month using the equation: $\mathrm{T}_{\mathrm{N}}=17.6+0.31 \times \mathrm{T}_{\mathrm{O} . \mathrm{AV}}$ [where $T_{\mathrm{O} . \mathrm{AV}}=$ the mean temperature of the month]

2) Find the limits as $T_{U}=T_{N}+2.5^{\circ} \mathrm{C}$ and $T_{L}=T_{N}+2.5^{\circ} \mathrm{C}$ [where $T_{U}=$ upper temperature limit; $T_{L}=$ lower temperature limit]

3) Mark these on the $50 \% \mathrm{RH}$ (relative humidity) curve. For the side boundaries of the comfort zone, either follow the slope of SET lines ${ }^{2}$ or note the AH (absolute humidity) for these two points (referred to as $\mathrm{T}_{\text {LSET }}$ and $\mathrm{T}_{\text {USET }}$ here respectively).

4) To find the base line intercepts use:

$$
\begin{aligned}
& \text { For } T_{L}: T_{L}+0.023 \times\left(T_{L}-14\right) \times T_{\text {LSET }}=T \text { (intercept) } \\
& \text { For } T_{U}: T_{L}+0.023 \times\left(T_{U}-14\right) \times T_{\text {USET }}=T \text { (intercept) }
\end{aligned}
$$

5) Draw the side boundaries. The humidity limits (top and bottom) are at 12 and $4 \mathrm{~g} / \mathrm{kg}$ respectively.

Below are the comfort zones (see Figures 3.1, 3.2, 3.3) for each of the target regions determined using the above procedure and the climatic data previously presented in Chapter 2.

\section{Palanpur Comfort Zones}

\footnotetext{
${ }^{2}$ The SET (Standard Effective Temperature) lines are drawn on the psychrometric chart and coincide with DBT (dry bulb temperature) at the $50 \% \mathrm{RH}$ curve. The slope of the SET lines indicates that at higher humidities the temperature tolerance is reduced, whilst at lower humidities higher temperatures are acceptable. The slope coefficient of the SET lines is taken as $\mathrm{X} / \mathrm{Y}$ or DBT/AH $=0.023 \times(\mathrm{T}$ or L -14$)$ which gives the deviation from the corresponding vertical DBT line for each $\mathrm{g} / \mathrm{kg} \mathrm{AH}$. The SET thus defined combines the effect of temperature and humidity, the two most important determinants.
} 


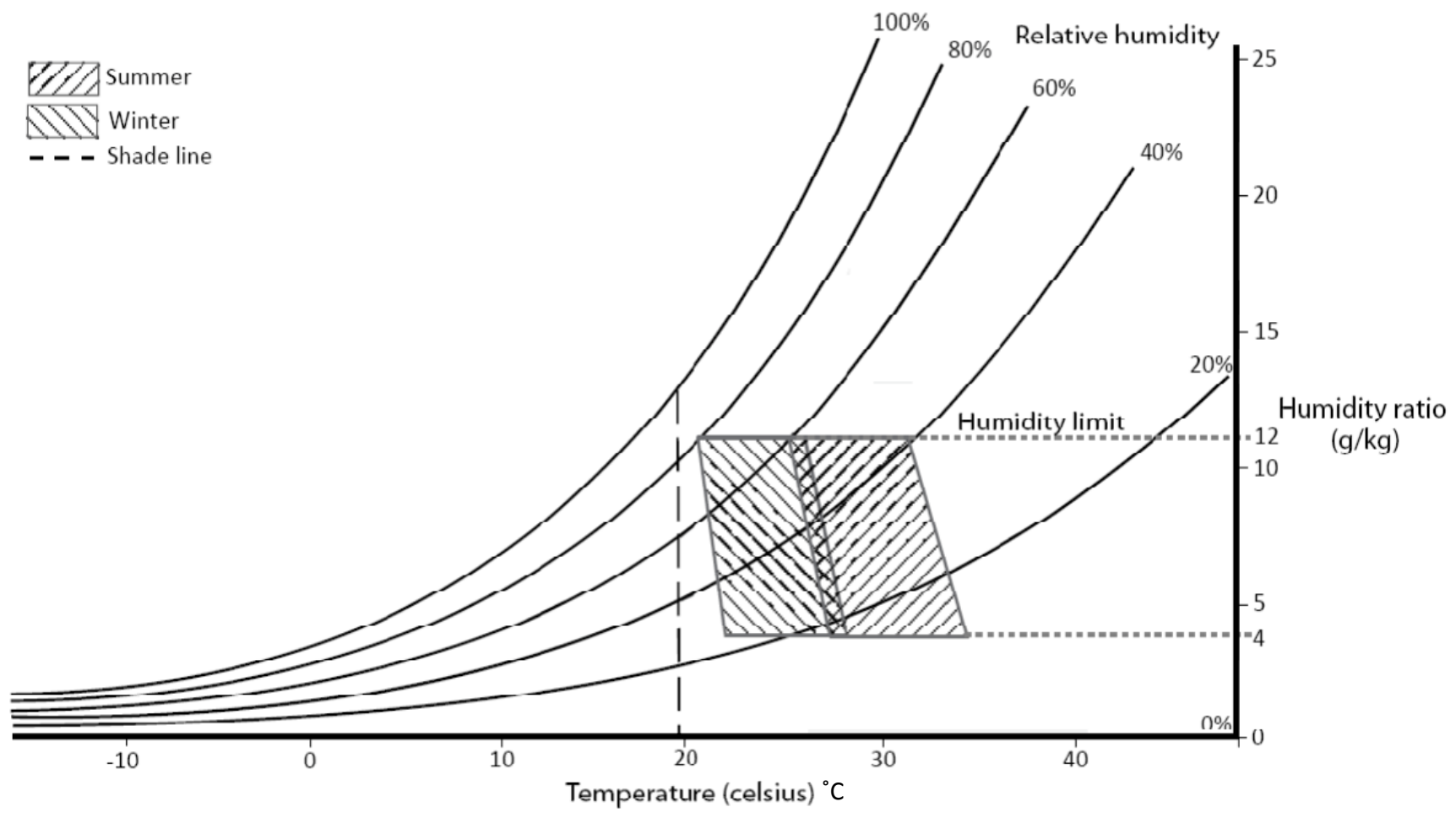

Figure 3.1: Comfort Zone for Palanpur

The above representation based on the Palanpur data shows that for winter, the comfort conditions can range from $22.6^{\circ} \mathrm{C}$ to $29.3^{\circ} \mathrm{C}$. For summer, the comfort range would be from $28.3^{\circ} \mathrm{C}$ to $35.9^{\circ} \mathrm{C}$.

\section{Jammu Comfort Zones}

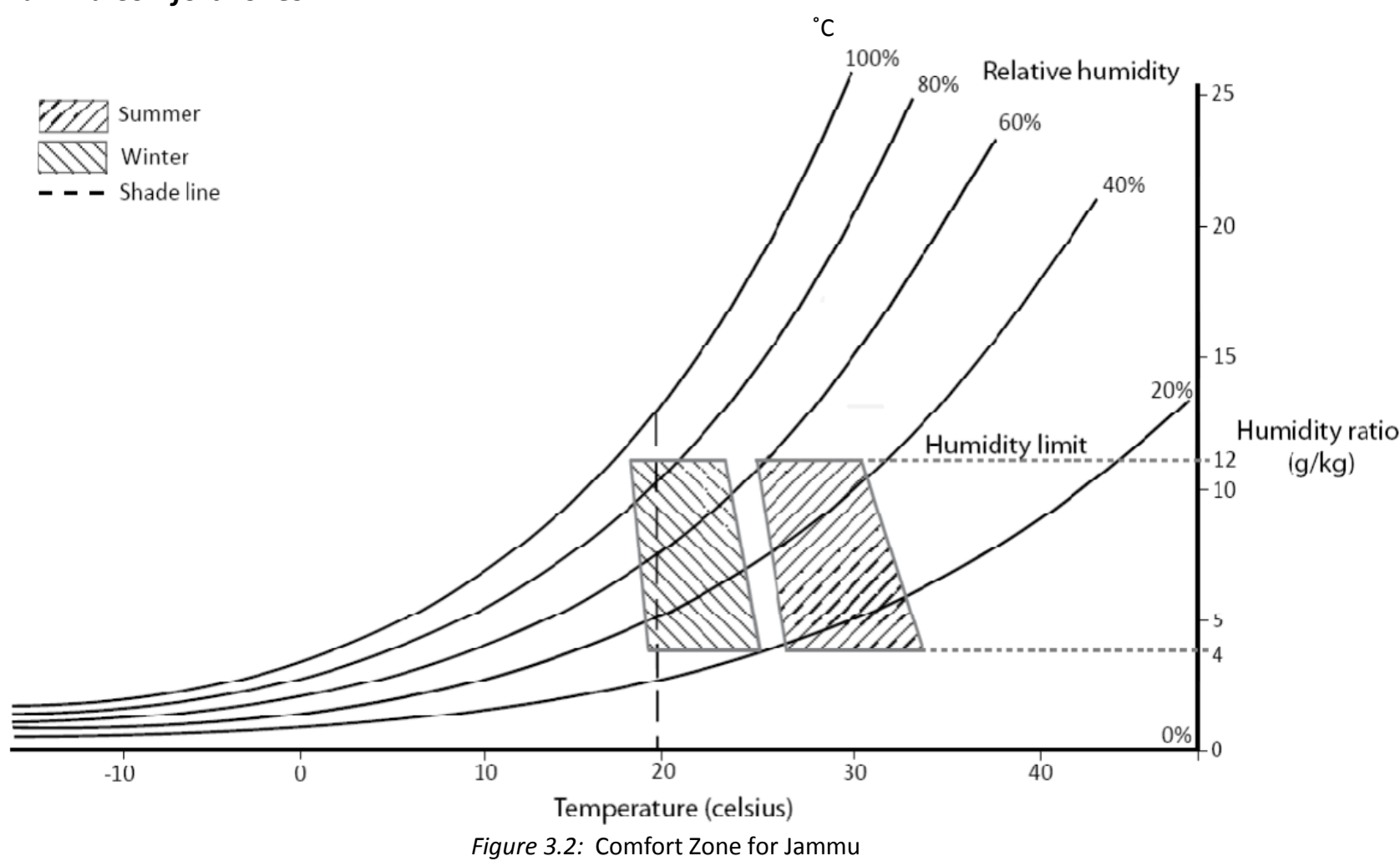

The above representation based on the Jammu data shows that for winter, the comfort conditions can range from $19.4^{\circ} \mathrm{C}$ to $25.7^{\circ} \mathrm{C}$. For summer, the comfort range would be from $27.5^{\circ} \mathrm{C}$ to $34.9^{\circ} \mathrm{C}$. 


\section{Gangtok Comfort Zones}

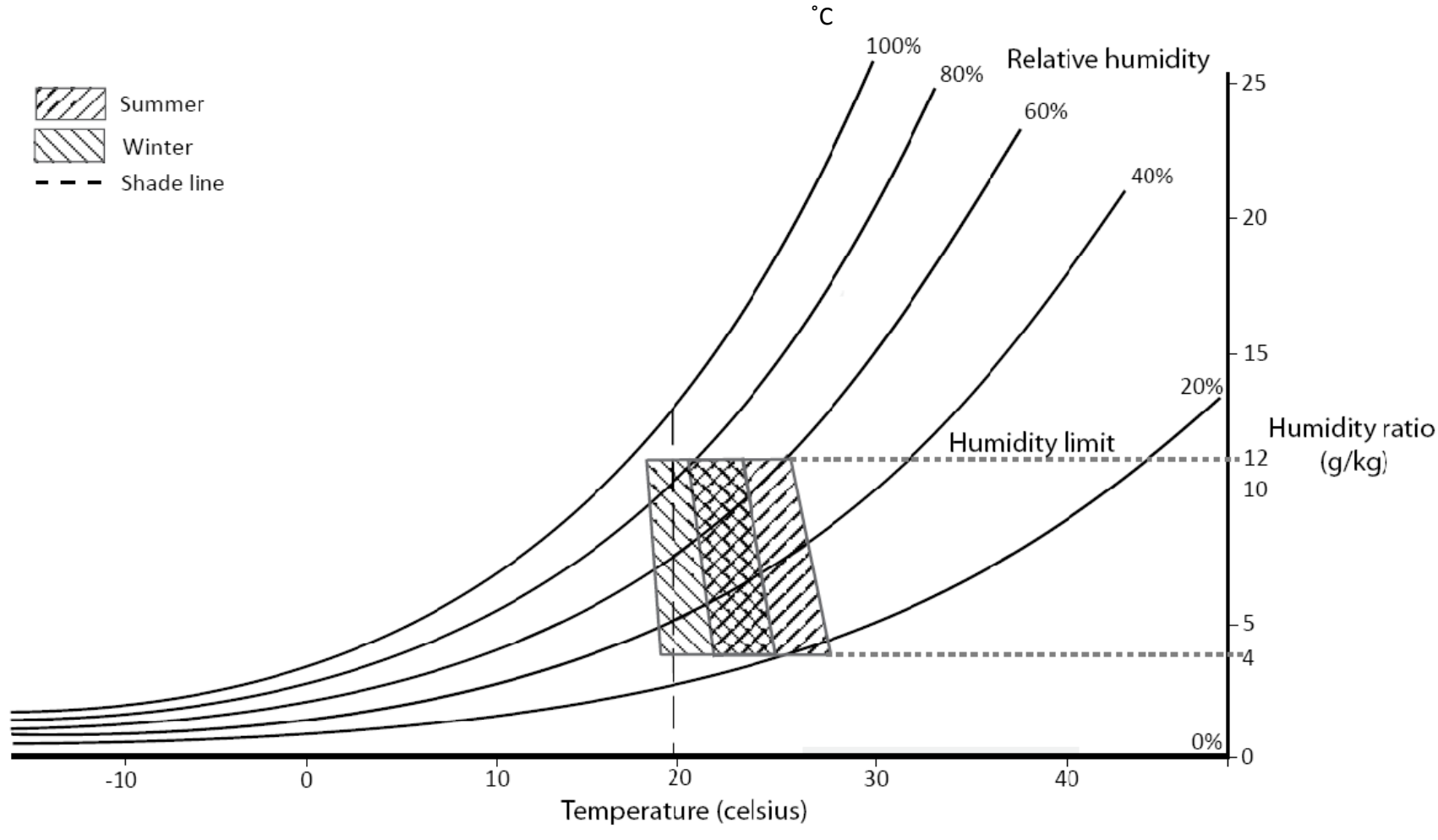

Figure 3.3: Comfort Zone for Gangtok

The representation based on the Gangtok data shows that for winter, the comfort conditions can range from $19.3^{\circ} \mathrm{C}$ to $25.6^{\circ} \mathrm{C}$. For summer, the comfort range would be from $22.2^{\circ} \mathrm{C}$ to $28.9^{\circ} \mathrm{C}$.

It is apparent from the above that while Gangtok shows the least seasonal variation (cold climate), Jammu shows a big difference between winter and summer comfort. Observations such as this can be valuable for determining the appropriate thermal improvement strategy to be used for the buildings. Another point to reiterate is that the comfort zones illustrated here are not definite; perceptions of discomfort and tolerance level will vary among individuals. Furthermore, since these comfort zones are based on the adaptive model for naturally ventilated buildings, adaptive action will be required on the part of the inhabitant to feel comfortable and maintain these conditions.

\subsection{Energy implications of comfort}

The ideal indoor comfort zones for people living in each of the target locations have been identified above, but the means of achieving these comfort levels is another important consideration. In developed countries, the goal is usually achieved by an energy intensive process which has resulted in the high rates of energy consumption and increasing carbon emission levels. In developing countries, while energy use remains one-third of that of the developed countries, it is increasing 
rapidly as resources become more available which indicates a major issue for the future. On the other hand however, access to energy resources still remains very limited among the low-income and the rurally situated households in developing countries. The 2001 Census data indicates that some 85 million households in India were without access to electricity, 92\% of which were in rural areas (Ailawadi \& Bhattacharyya, 2006). This shows the reason why not to use energy intensive methods for thermal comfort; not only because of its unsustainable nature but also because of its limited availability to low-income residents.

So what are the alternatives? In developed countries, several passive technologies have been developed to encourage energy efficient housing. However, many of these sophisticated technologies such as photovoltaic panels and small-scale wind turbine power systems have a high installation cost which prevent people from obtaining them even in the developed world. Thus, these technologies are not appropriate for the low-income population as they are not only unaffordable, but also widely unavailable. Therefore, in order to resolve the issue of thermal discomfort for this study's target population, simple passive solutions which can reduce energy costs and be easily implemented with low installation costs need to be considered (these are discussed in detail in Section 3.8).

\subsection{Current level of comfort conditions provided in low-income housing}

Before considering the appropriate passive strategies for thermal comfort it is necessary to first understand the current level of comfort conditions in India to thus justify why improvement is necessary. As the above section states, electrical systems are often not an option for the low-income households. Therefore, with only minimal scope for thermal adjustment within the building envelope, the discomfort can often exceed the manageable limit.

However, this is not to say that all aspects of the low-income housing are inappropriate for thermal comfort. Indigenous construction methods that have been developed over the years often make the houses well adhered to the local environment. For example, mud houses are effective for the hot and arid climates as they prevent the heat from reaching the interior during the daytime hours due to the mud's thick layer with insulative properties.

Yet sometimes even these passive technologies are not sufficient as is shown in Reddy \& Lefebvre's study (1993), which examined rural inhabitants based in a hot-dry region living in mud houses (similar to the typical house presented in the previous chapter). Reddy \& Lefebvre (1993) note that 
though the mud houses provided sufficient thermal insulation against the extremely high daytime temperatures, at night the people moved outdoors to sleep since the outdoor temperature was cooler than the interior. This would be the result of the daytime heat finally reaching the interior through the insulation during the evening, hence resulting in a high indoor temperature. It is thus apparent that discomfort remains an unresolved issue in low-income housing even with effective indigenous construction methods; in fact it is so severe that the inhabitants are forced to move out of their homes to attain comfort.

Another issue with the application of indigenous construction techniques is that in today's society where there is a high demand for housing, these techniques are often applied without consideration to the climate in which it was developed. This results in a house that is unsuitable for the local climate in which it is placed, rendering all its thermally advantageous features redundant. These types of houses are almost as inefficient as those constructed solely with the cost factor in mind and without any consideration to the climate.

One other problem of serious concern is the means used by the low-income households to achieve some degree of interior thermal comfort. Natural fuels such as kerosene are popularly used in areas where electricity is unavailable, for not only cooking but also for heating purposes. However, researchers have shown that the indoor air pollution caused by these biomass fuels can have adverse health implications for the inhabitants (Mishra, 2003; Parikh \& Laxmi, 2000). This calls for better thermal comfort strategies to be implemented in these houses to provide passive means for comfort as well as to reduce unwanted indoor air pollution.

\subsection{Passive design strategies}

Previous sections in this chapter have discussed why passive strategies, as opposed to energy active strategies, are better for the low-income population. Therefore, this section concentrates on the particular passive strategies that can be applied to the target locations.

\subsubsection{Natural ventilation}

The simplest passive strategy for cooling is through ventilation. When the indoor temperature, under still air conditions is too warm, daytime ventilation can provide comfort through high indoor air speeds. Introducing outdoor air can increase the upper limit of the comfort zone beyond that 
under still air conditions (Givoni, 1994), and therefore such comfort ventilation may be desirable even when the outdoor air temperature is higher than the indoor air temperature.

The technique is particularly appropriate for high humidity regions; as even if indoor temperature is elevated due to the introduction of hot outdoor air, the higher air speed can increase the rate of sweat evaporation from the skin thus minimizing discomfort felt with wet skin (Givoni, 1994). Hence, comfort ventilation is best for warm and humid regions and is best applicable in seasons when the outdoor maximum air temperature does not exceed about 28 to $32^{\circ} \mathrm{C}$, depending on acclimatization and comfort expectations of the population (Givoni, 1994). Thus it can be applied to all of the target regions because of their high humidity during the summer season.

There are various passive techniques that have been developed to improve the ventilation of a building. All of them utilise the principle of stack effect in their designs. Since hot air rises, techniques such as the implementation of a wind tower or including cavities and inlets in the roofs and walls, are designed to remove the trapped heat out to the exterior and keep the interior cool (see Figures 3.4 and 3.5). The cooling potential of the floor can be utilised by elevating it off the ground to allow air movement underneath (see Figure 3.6). This however can be conflicting with seismic requirements to maintain the wall to foundation connections for better performance.

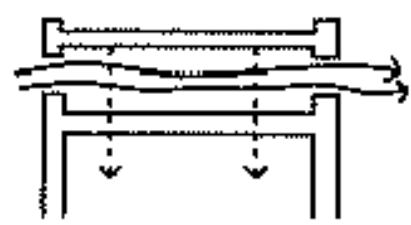

Figure 3.4: Roof ventilation removes trapped heat

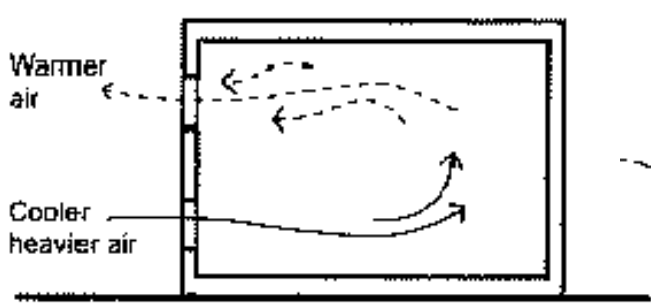

Figure 3.5: the movement of air due to temperature generated pressure differences across openings

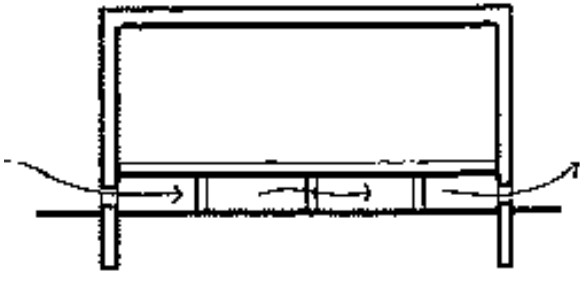

Figure 3.6: Air flow under the floor for cooling

Landscaping is also an effective way to provide ventilation via the planting of trees and shrubs. However, as such techniques are not linked with the structural entity of the house and therefore provide no scope for integration with seismic retrofitting; these are not considered in this study.

\subsubsection{Thermal mass}

Thermal mass provides heat storage which can be used to passively heat and/or cool the interior. As mentioned previously, adobe houses particularly make good use of the mass effect, absorbing the 
exterior heat during the daytime and releasing it into the interior during night time via radiation, convection and conduction. When the warmth of the previous day is exhausted, the walls which had cooled during the night now absorb heat, keeping the interior of the house cool throughout the daytime (Janzen, 2010). Thermal mass also prevents large temperature fluctuations which can arise due to the rise and fall of the exterior temperature swings between night and day as is the case in a hot-dry climate.

The typical stone construction shown in Chapter 2 also uses this idea of thermal mass with its thick masonry walls and 500-800 mm thick mud overlay in order to avoid the interior heating up during hot summer months (Brrzev, et al., 2002). However, too thick of a mud layer on the roof should be avoided to maintain the structural integrity of the building. Also, although high thermal mass can be advantageous for hot regions as the build up of heat is delayed, it is disadvantageous during the winter and in cold regions as it requires a very long warm-up period (Auliciems \& Szokolay, 2007).

The best way to employ thermal mass is to maximise the surface area of the thermal mass facing the interior; the greater the area of thermal mass, the greater its ability to store heat and maintain a uniform temperature without the use of mechanical cooling or heating (Szokolay, 2004) (see Figure 3.7). The right combination of insulation (see Section 3.8.8) to slow heat flow, and thermal mass to moderate temperature variations, can create a home that is both energy efficient and comfortable (Saturn Resource Management, 2008).

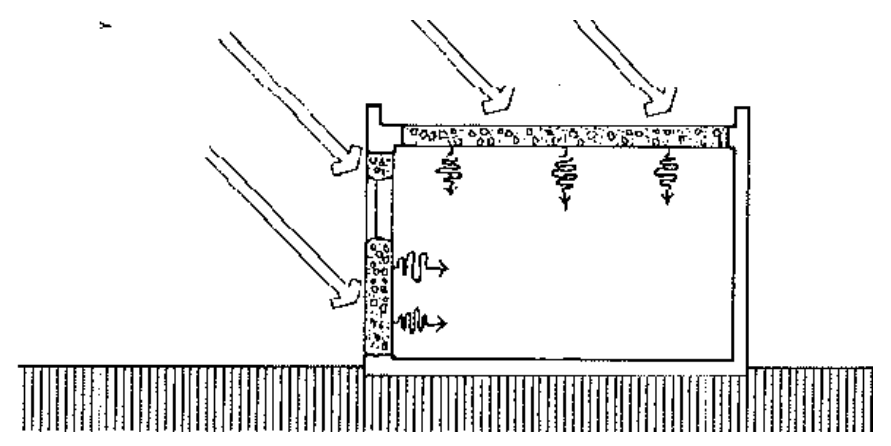

Figure 3.7: Heat gain through thermal mass on wall and roof (AIAF, 1982)

\subsubsection{Nocturnal ventilation}

Nocturnal ventilation dissipates excess heat from the building materials by ventilating a building during the night hours (when the exterior temperature is low) and closing it during day-time to minimize the incoming of external heat loads. When a building is ventilated at night, its structural 
mass is cooled by convection from the inside, which bypasses the thermal resistance of the building envelope (Chandra, 1995), and is therefore faster and more effective.

This type of cooling is most effective for regions where the diurnal temperature range in summer is large enough to enable significant reduction of the indoor temperature below the outdoor maximum. It is in fact preferable to natural ventilation as a building design strategy in regions where the daytime temperatures in summer are above the upper limit of the comfort zone even with allowable wind speed of 1.5 to $2.0 \mathrm{~m} / \mathrm{s}$ (Givoni, 1994). Thus, according to Chandra (1995) and Givoni (1994), nocturnal ventilation is applicable in hot dry/arid regions where daytime temperatures are around $30-36^{\circ} \mathrm{C}$ and the night temperatures are at or below $20^{\circ} \mathrm{C}$, as well as composite climates where major part of summer is hot dry. Daytime ventilation is not desirable in this situation, even if it could provide conditions acceptable in the daytime, because additional heat will be stored in the structural mass and raise the indoor temperatures at night (Givoni, 1994).

In regions with daytime temperature above $36^{\circ} \mathrm{C}$, night ventilation alone is not sufficient to maintain the indoor temperature at an acceptable level, and therefore, it is recommended that other passive cooling systems, such as thermal mass, also be considered in conjunction.

\subsubsection{Radiant cooling}

Any ordinary surface open to, or facing, the sky loses heat by emission of long wave radiation towards the sky and can be regarded as a heat radiator. Consequently, the exterior surfaces of all buildings begin to be cooled by radiation to the sky as soon as sun goes down and this cooling continues until the sun rises again (Chandra, 1995). The roof is the most preferred building element for radiant cooling due to its maximum surface exposure to the sky. However, usually, roofs are insulated to minimise heat gain in summer and heat loss in winter, which minimises the actual cooling that a building can utilise from the nocturnal radiation occurring at the external surface of the roof.

The simplest radiant cooling system concept is that of a heavy and highly conducting roof (e.g. made of dense concrete) exposed to the sky during night, but highly insulated externally during day by means of operable insulation to minimise heat gain from solar radiation and hotter ambient air (Chandra, 1995). Another system is the Skytherm system which uses a horizontal roof made of structural steel deck plates. On top of this, plastic bags filled with water are placed along with insulation panels which can be moved to cover or expose the bags in a similar way to the conducting 
roof (see Figure 3.8). Since the cooled water bags are in direct thermal contact with the metal deck, the ceiling serves as a cooling element over the whole space below. During the winter, the operation of the insulation can be reversed between day and night to provide indirect heating. However, both the radiant systems are not seismically safe due to the heavy load on the roof as well as being expensive to install.

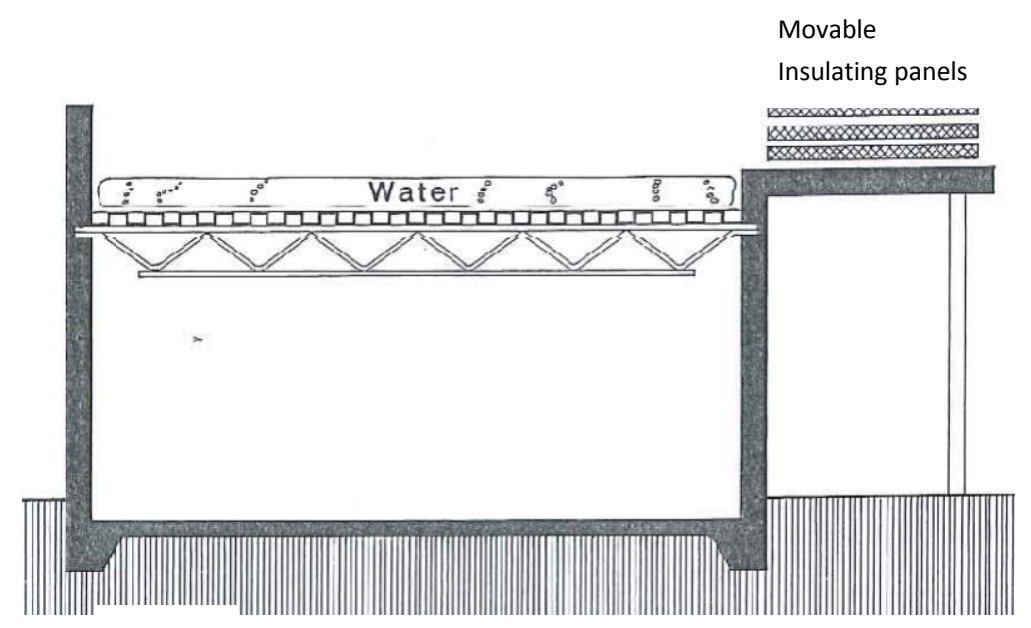

Figure 3.8: Skytherm system with operable insulation (AIAF, 1982)

\subsubsection{Evaporative cooling}

Evaporative cooling, is literally, as the words suggest, cooling by evaporation of water. Evaporative cooling systems can be direct or indirect each having different advantages and disadvantages. In direct evaporative cooling systems, dry bulb temperature of the interior falls but the moisture content of the air rises. Therefore these are appropriate for hot regions with low humidity levels. Among direct evaporative cooling systems are evaporative cooling towers developed by Cunnigham and Thompson as well as the "shower" cooling tower system developed by Givoni that humidify the ambient air (Givoni, 1994). These are based on the wind tower concept combined with either wetted mats or water sprays inside the tower to cool the hot air as in flows into the building (see Figure 3.9). However, these are too complicated for installation in the target regions of this study due to the cost and specific expertise required. 


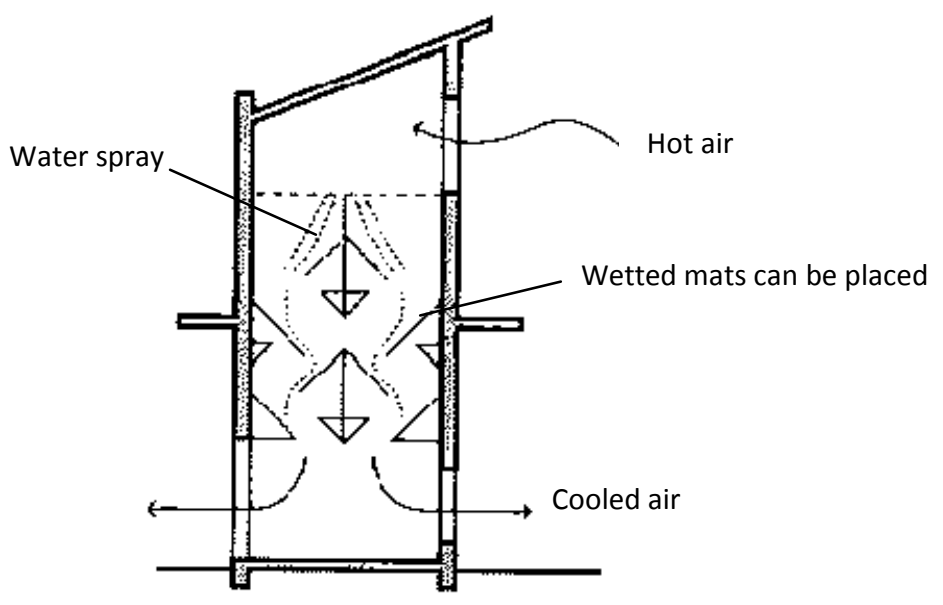

Figure 3.9: Evaporative cooling used in wind tower (Koch-Nielson, 2002)

A more widely adaptable technique according to Chandra (1995), is using wetted pads of fibre like khas khas (vetiver roots) which can be effective if placed on windows facing strong winds, as natural evaporative cooling occurs. The hot-dry and the composite zones (where a major part of summer is hot and dry), is suitable for this type of cooling.

Evaporative cooling can also be an indirect process where the roof of the building can be cooled so that the interior remains cool. The advantage of using this indirect system is that the humidity level of the interior does not increase since evaporation only occurs on the external surface. Hence this technique can be applied to high humidity regions also.

The two major strategies for indirect evaporative cooling are: wetting the roof or having a shaded pond over it. A strategy to wet the roof, similar to the khas khas technique, is using mats made of double layered empty jute bags laid in close contact with the roof (Jain (1991) cited in Chandra, 1995). The mattings remain soaked in water throughout day and night during the summer season, and the water trapped in the bags or mattings evaporates continuously subsequently cooling the ceiling below. A disadvantage is that its operation relies on water availability as well as manual labour for spraying the mats at regular intervals if an automated sprinkler is not installed. The second option of a roof pond system is similar to the radiant cooling system mentioned previously. It needs to be shaded and naturally ventilated over an uninsulated roof to be effective for cooling (see Figure 3.10). However, along with being not as effective and difficult to adopt under Indian conditions (Chandra, 1995), having a roof pond adds to the seismic mass, reducing earthquake resistance, as well as has high installation cost which is unaffordable for the low-income households. 


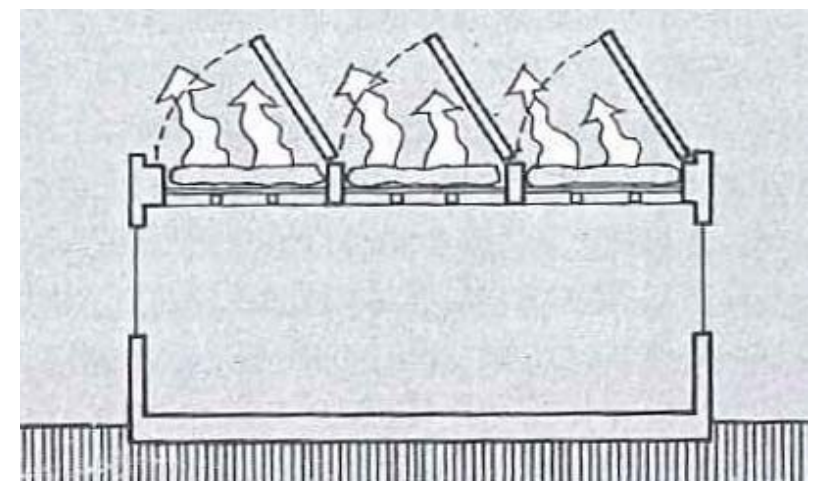

Figure 3.10: Roof pond with shading (AIAF, 1982)

\subsubsection{Earth cooling}

The earth mass under, around, and above a building can act as a natural cooling source for buildings in most climatic regions. Even if the "natural" temperature of the soil in summer is too high for it to serve as a cooling source, as is the case in hot regions, different strategies can be applied to cool the soil. These include covering the exposed soil with a layer of mulch, raising the building off the ground and allowing water that was provided by rains or irrigation to evaporate from the shaded soil surface, and installing buried pipes or tunnels embedded in the soil as heat exchangers (Givoni, 1994). However, since these techniques are either detached from the building structure or too complicated, they are not suitable to consider for integration with seismic retrofitting.

\subsubsection{Passive solar heat gain}

Passive solar heat gain can be attained in three different ways (see Figures 3.11, 3.12 and 3.13): direct, indirect, or isolated. Indirect heat gain systems the sunlight enters the space, is converted to heat at absorbing surfaces, and is dispersed throughout the space. In indirect heat gain systems, sunlight is absorbed and stored by a mass interposed between the glazing and the conditioned space. The conditioned space is partially enclosed and bounded by the thermal storage mass so that a direct thermal transfer is achieved between the mass and the space. In isolated heat gain systems, there is a distinct physical and thermal separation between the thermal storage and the heated space. Solariums, greenhouses, and atriums are common examples of such a system. 


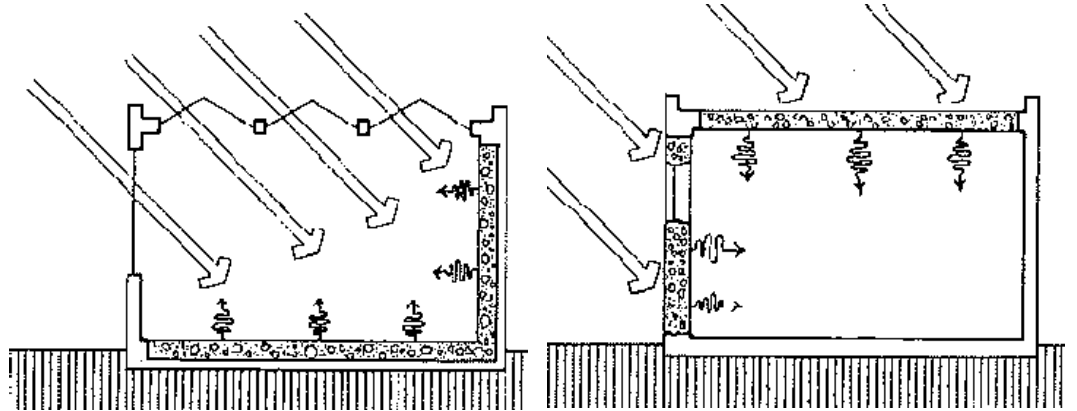

Figure 3.11: Direct heat gain (AIAF, 1982)

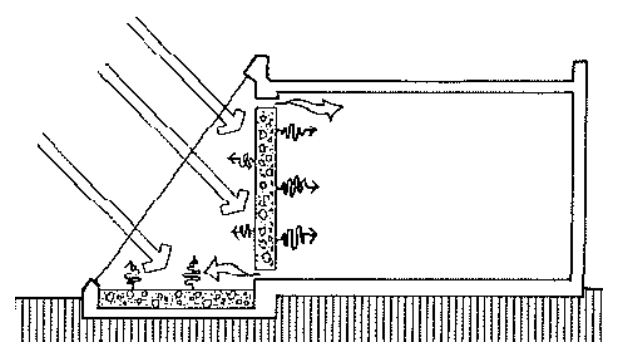

Figure 3.12: Indirect heat gain (AIAF, 1982)
Figure 3.13: Isol 1982)

For direct gain systems, a south facing heat collector area (in northern hemisphere) such as a window is recommended, along with the conditioned spaces exposed directly behind, and absorber/storage floors and walls (American Institute of Architects Foundation, 1982). Along with the heat collecting area, an insulative layer can also help to reduce the temperature fluctuations that may occur between day and night due to heat escaping from the window.

The two basic types of indirect gain systems are thermal storage walls and roof ponds, both of which have already been discussed. Thermal storage walls for the heat gain system can be composed of masonry and be painted black for better absorption of sunlight. The roof pond system can act as a passive solar heat gain system by removing the shade placed above the pond. However, as previously mentioned, the roof pond system and heavy masonry roofs are unadvisable for seismic regions due to its undesirable effect on seismic performance.

Isolated gain systems often need to have a separate collection area within the interior which is covered in glass. The extensive use of glass is uncommon in low-income housing due to the lack of financial resources; so most form of heat gain would be through thermal mass. Hence isolated systems are not considered as an applicable feature for integration.

\subsubsection{Insulation}

Where thermal mass refers to the ability of a material to store heat energy, insulation refers to the ability of a material to slow down the transfer of heat energy. Insulation can therefore be taken as a 'barrier' to resist the surrounding conditions whether it is heat or cold. Insulation is also effective when used in conjunction with thermal mass. Ideally masonry has layers of external insulation to 
help lock in the heat it gains from the sun in order to keep the interior cool (Janzen, 2010). In winter it can be used to trap the heat within the interior and reduce heat energy escaping via the walls.

Typically in a modern home insulative material used are fibreglass, foam, loose fill, and/or reflective materials (Janzen, 2010). However, most low-income households do not have insulative materials in their houses. National Academy of Sciences (1974) suggests some technologies that can be used for roofs which include materials with insulative properties. One such material type is foamed plastic -a lightweight cellular substance produced by introducing gas bubbles into plastic compounds during manufacture. 'Spray-in-place bamboo/foam composites' can also be used where the structural wall material or the base of the roof is bamboo/thatch by spraying the foam on both sides of a bamboo mat to provide thermal insulation and give a unitized sealed roof (National Academy of Sciences, 1974). Other suggestions include plastic resins containing monomers which can be combined with locally available reinforcement and fillers to form roofing sheets that would be lightweight and weather resistant. These insulation types may be able to be integrated with the seismic retrofitting techniques attached to walls (see Chapter 4 for details).

\subsubsection{Shading}

Solar gain through windows is a major component of the total heat gain of a building, and therefore minimizing this through the use of shading is important for all types of hot climates. Shading devices can be primarily classified into two types: operable and fixed shading.

Operable shading can be applied either on the inside or the outside of the window. External shading devices include shutters, rotable fins, horizontal plates, retractable venetian blinds or canvas awnings; while internal shading devices include venetian blinds, roller blinds and curtains. Compared to external operable shading, the internal operable shading devices are less efficient since they only intercept the sun's rays after the rays are transmitted indoors through the window (Givoni, 1994). Therefore, for hot regions, and especially for houses with large windows, external operable shading is advised.

For using fixed shading devices, Givoni (1994) recommends horizontal overhangs above the southern windows for buildings in the northern hemisphere (applicable to the target locations) which can provide complete shading during the midsummer seasons and permit solar penetration in the winter. Fixed horizontal overhangs above the eastern and western windows are also more 
effective for summer shading although they cannot provide complete shading in these orientations (Givoni, 1994).

Additionally, vertical fins can also protect the northern windows in summer from the low sun in the morning and later afternoon (Givoni, 1994). Since shading can be attached to the structure, it has integrative potential with the retrofitting techniques.

\subsubsection{Colour}

Colour of the building's envelope can also help decrease or increase the heat gain of a building. The basic colours for consideration are black and white, one which absorbs most of the radiation and one which reflects most of it, respectively. The colour of the roof is most important due to its large surface area and continuous exposure to the sun. Givoni (1994) notes that the difference in maximum external surface temperature between a white and black roof in a desert location can be $30-40^{\circ} \mathrm{C}$. Therefore, white roofs are always recommended for hot climates as they have lower diurnal temperatures than the ambient air even in midsummer days with clear skies (Givoni, 1994). The colour of the wall can also have some effect on the indoor temperature though not as much as the roof. However, since colour does not affect the structure, it cannot be considered as an option for integration.

It is apparent from the above strategies that although they are all effective for improving thermal comfort, many strategies include techniques that are not directly attached to the building structure itself (i.e. colour of surfaces and positioning of walls for passive solar gain). Although these techniques do not have any integrative potential for combining with seismic retrofitting (and therefore not relevant for this study), they can still be incorporated separately for thermal comfort improvement. Some techniques are also too complex or unsuitable for the seismically vulnerable zones (i.e. earth cooling, heavy conducting roofs, and roof pond systems) and hence are not pursued further. However, the principle of each type of technology is useful nonetheless, and some can definitely be developed further for application to the house types in question. Table 3.1 summarises the information presented in this section. 
Table 3.1: Summary table of passive techniques and their applicability

\begin{tabular}{|c|c|c|c|c|c|c|}
\hline \multirow{2}{*}{$\begin{array}{l}\text { Passive } \\
\text { systems } \\
\text { discussed }\end{array}$} & \multicolumn{2}{|c|}{ Function provided } & \multirow{2}{*}{$\begin{array}{l}\text { Integrative } \\
\text { Potential }\end{array}$} & \multicolumn{3}{|c|}{ Target regions applicable to } \\
\hline & Heating & Cooling & & $\begin{array}{l}\text { Hot-dry } \\
\text { (Palanpur) }\end{array}$ & $\begin{array}{l}\text { Composite } \\
\text { (Jammu) }\end{array}$ & $\begin{array}{l}\text { Cold } \\
\text { (Gangtok) }\end{array}$ \\
\hline $\begin{array}{l}\text { Ventilation } \\
\text { (daytime \& } \\
\text { nocturnal) }\end{array}$ & & $\begin{array}{l}\text { direct } \\
\text { cooling by } \\
\text { air motion }\end{array}$ & $\checkmark$ & $\begin{array}{l}\checkmark \text { (day time }= \\
\text { esp. for May, } \\
\text { June, Sept.; } \\
\text { night time = } \\
\text { Jan.-March \& } \\
\text { Oct. }- \text { Dec.) }\end{array}$ & 2 & $\begin{array}{l}\checkmark \text { (can be } \\
\text { applied since } \\
\text { there is high } \\
\text { humidity } \\
\text { even though } \\
\text { its cold) }\end{array}$ \\
\hline Thermal mass & $\begin{array}{l}\checkmark \text { delays the } \\
\text { time for heat } \\
\text { to escape the } \\
\text { interior }\end{array}$ & $\begin{array}{l}\checkmark \text { delays } \\
\text { the time } \\
\text { for heat to } \\
\text { reach the } \\
\text { interior }\end{array}$ & $\checkmark$ & $\checkmark$ & $\checkmark$ & $\checkmark$ \\
\hline $\begin{array}{l}\text { Radiant } \\
\text { system } \\
\text { (conducting } \\
\text { roof, roof } \\
\text { pond, water } \\
\text { bags on roof) }\end{array}$ & $\checkmark$ & $\checkmark$ & & $\begin{array}{l}\text { (low } \\
\text { cloudiness is } \\
\text { required, } \\
\text { which might } \\
\text { be hard to get } \\
\text { in regions } \\
\text { other than } \\
\text { Palanpur) }\end{array}$ & $\checkmark$ & $\checkmark$ \\
\hline $\begin{array}{l}\text { OEvaporative } \\
\text { cooling } \\
\text { (wetting the } \\
\text { roof, shaded } \\
\text { roof pond) }\end{array}$ & & $\checkmark$ & & $\checkmark$ & $\checkmark$ & \\
\hline Earth cooling & & $\checkmark$ & & $\checkmark$ & $\checkmark$ & \\
\hline $\begin{array}{l}\text { Passive solar } \\
\text { heat gain }\end{array}$ & $\begin{array}{l}\checkmark \text { (south } \\
\text { facing heat } \\
\text { collector for } \\
\text { northern } \\
\text { hemisphere) } \\
\end{array}$ & & & & & $\checkmark$ \\
\hline Insulation & $\begin{array}{l}\checkmark \text { keeps the } \\
\text { heat trapped } \\
\text { inside }\end{array}$ & \begin{tabular}{|l|}
$\checkmark$ if on the \\
exterior \\
surface, \\
resists heat \\
from going \\
in \\
\end{tabular} & $\checkmark$ & $\begin{array}{l}\checkmark \checkmark \text { (for } \\
\text { summer) }\end{array}$ & $\begin{array}{l}\checkmark \text { (for } \\
\text { summer) }\end{array}$ & $\begin{array}{l}\checkmark \text { (for } \\
\text { winter) }\end{array}$ \\
\hline Shading & & $\begin{array}{l}\text { (on } \\
\text { southern } \\
\text { windows) }\end{array}$ & $\checkmark$ & $\checkmark$ & $\checkmark$ & \\
\hline Colour & $\begin{array}{l}\text { (black } \\
\text { colour for } \\
\text { absorption) }\end{array}$ & $\begin{array}{l}\text { white } \\
\text { colour for } \\
\text { reflection) }\end{array}$ & & $\checkmark$ (white) & $\checkmark$ (white) & $\checkmark$ (black) \\
\hline
\end{tabular}




\subsection{Passive design strategies}

This section uses the psychrometric chart, introduced previously, to map the monthly climatic data for each of the target regions and further analyse it in order to identify the passive design strategies explained above that could be applied to each situation.

\subsubsection{Climate analysis}

The representation of a comfort zone by itself lacks specific information to allow for thermal performance improvement. It only indicates the conditions necessary for comfort; not the means to attain it. Hence, a useful strategy is to conduct climate analysis using climatic lines superimposed on the comfort zone charts. Additionally, the use of discomfort indices can provide a way to quantify the data and find the discomfort conditions that are most pronounced, leading to a better understanding of passive climatic control strategies.

The simplest representation of climate analysis is done using 12 monthly climatic lines superimposed on the comfort zone shown on the psychrometric chart. In the case of naturally ventilated buildings, since the indoor conditions are expected to be relative to the outdoor conditions, mapping the outdoor climate on the comfort zone chart can show the amount of adjustment required to bring the conditions within the comfort zone. Szokolay (1990) and Yang, et al. (2005) have used this approach where "the two end-points of each of the 12 climatic lines are given by the mean minimum temperature coincident with the corresponding relative humidity and the mean maximum temperature again coincident with the corresponding relative humidity" (Yang, et al., 2005). Due to the limitation in the available humidity figures for the locations investigated, here, the average monthly relative humidity figures (as shown in Chapter 2) have been used. Since the length of the climate line is based on the maximum and minimum temperature values, it is not affected by this alternative method. The only difference is the lack of gradient for the line depicted. However, observing the climatic analysis for five regions in China presented in Yang, et al. (2005), it is apparent that the gradient factor is negligible in most cases and, therefore, it can be assumed that using the average value would be sufficient for the purpose of this analysis.

Once the 12 climatic lines are superimposed on the psychrometric chart, "the extent of the area covered by the climatic lines in relation to the comfort zone (i.e. the number of lines below, within and above the comfort zone) can give a good indication of the prevailing climatic conditions during each of the 12 months presented" (Yang, et al., 2005). In addition, as Yang, et al. (2005) show, the 
representation of the climatic lines also help indicate the extent of the likely environmental control problems envisaged as well as any appropriate design solutions that could be considered.

Below are the climate analysis charts (see Figures 3.4, 3.5, 3.6) for each of the target locations of Palanpur, Jammu and Gangtok. The 12 monthly climatic lines (numbers alongside of the lines the corresponding month) have been superimposed and the aggregate lengths of the climatic lines outside the comfort zone indicate the magnitude of over- and/or under-heating. Likewise, those that fall above and below the humidity comfort boundaries represent, respectively, the level of dehumidification and humidification required to achieve indoor thermal comfort conditions.

The design strategy lines shown in colour on the charts are also a helpful indicator for deducing which technique to use in order to minimise the discomfort factor. The strategy lines are based on the psychrometric bioclimatic chart model developed by Givoni and Milne (cited in Lechner, 2009), and are relative to the comfort zone. Active strategies would be required for the climatic lines that fall completely outside of the design strategy lines, however since this study concentrates on the passive strategies, those are not considered. Also a point to note is that normally, the lines for the high thermal mass with and without night ventilation strategies extend horizontally to the bottom left-most edge of the winter comfort zone, and the line for the comfort ventilation strategy extends vertically down at about $33^{\circ} \mathrm{C}$ and follows horizontally to meet the bottom right-most edge of the summer comfort zone. However, since these lines already fall within the respective comfort zones of the target locations, they have not been further extended in the diagrams below -as it is only necessary to consider which strategies to use when the conditions are outside of the comfort zones.

The results of the climatic chart analyses and the table for discomfort indices are discussed together in section 3.9.2. 


\section{Palanpur Climatic Analysis}

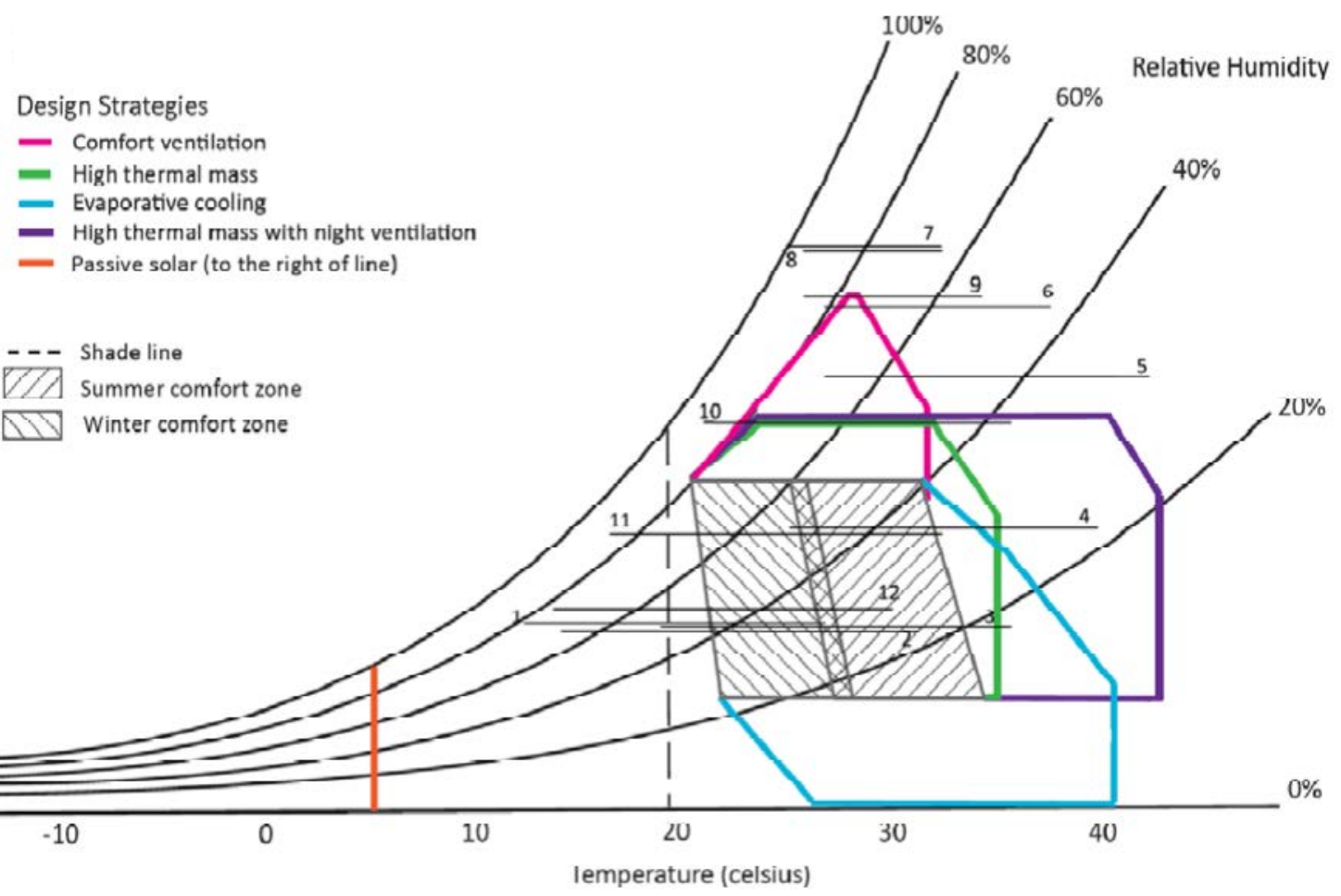

Figure 3.14. Bioclimatic chart for Palanpur

\section{Jammu Climatic Analysis}

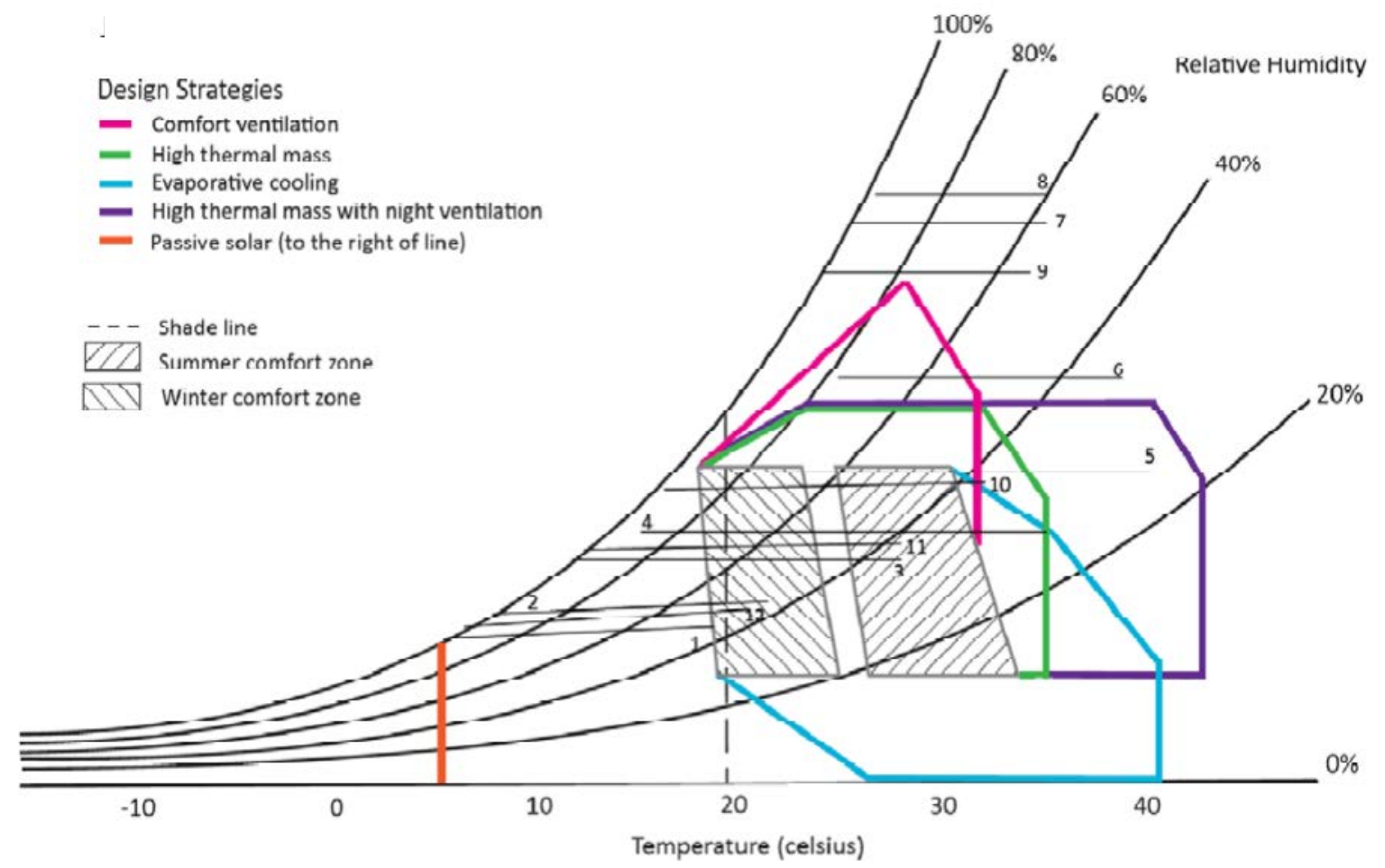

Figure 3.15. Bioclimatic chart for Jammu 


\section{Gangtok Climatic Analysis}

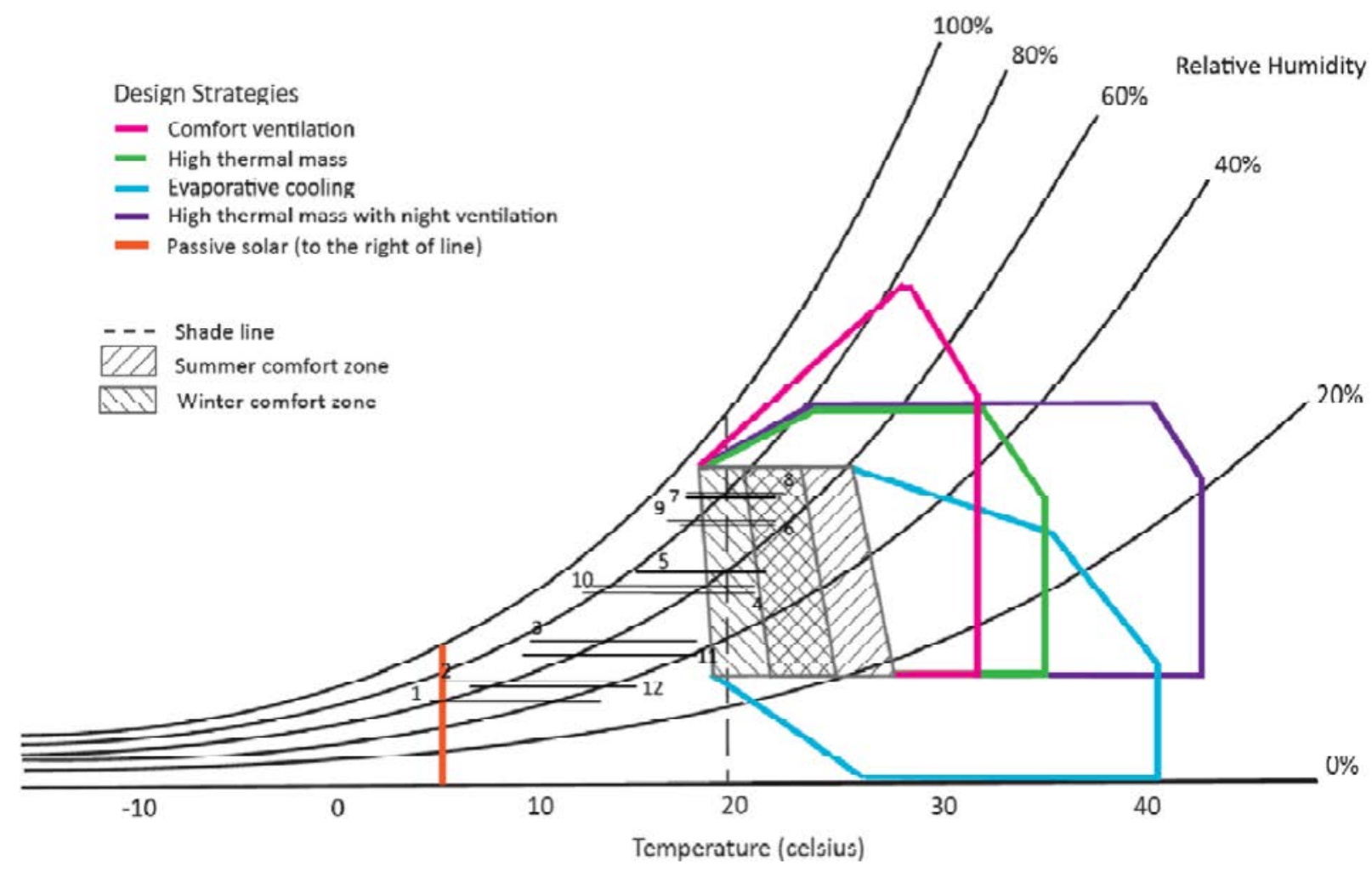

Figure 3.16. Bioclimatic chart for Gangtok

\subsubsection{Climate analysis and discomfort indices}

In addition to the climatic analysis, a total of four discomfort indices have been developed following Yang, et al. (2005)'s approach. These are namely hot, cold, humid and dry and defined as follows:

Hot Index = Lot $/$ Ltotal

Cold Index = Lut $/$ Ltotal

Humid Index $=$ Loh $/$ Ltotal

Dry Index = Luh $/$ Ltotal

[Where Lot $=$ length of the monthly climatic lines over the comfort temperature zone.

Ltotal $=$ total length of the monthly climatic line

Lut $=$ length of the monthly climatic line under the comfort temperature zone.

Loh = length of the monthly climatic line over the humidity comfort boundary.

Luh = length of the monthly climatic line under the humidity comfort boundary.] 
As a way of quantifying the visual data (see Table 3.1), these discomfort indices can give a general picture of the overall climate characteristics of the local outdoor environment. A large discomfort index (say greater than 0.5 ) would indicate the likelihood of the climatic control problem. And consequently, referring back to the climate analysis charts, one can determine which design strategy to use.

Table 3.2: Discomfort indices for Palanpur, Jammu and Gangtok

\begin{tabular}{|c|c|c|c|c|c|c|c|c|c|c|c|c|c|c|}
\hline $\begin{array}{c}\text { Name of } \\
\text { City }\end{array}$ & $\begin{array}{l}\text { Discomfort } \\
\text { Indices }\end{array}$ & Jan & Feb & Mar & Apr & May & Jun & Jul & Aug & Sep & Oct & Nov & Dec & $\begin{array}{l}\text { Ann } \\
\text { ual }\end{array}$ \\
\hline \multirow{4}{*}{$\begin{array}{l}\text { Palanpur } \\
\text { (Gujarat) }\end{array}$} & Hot & 0.00 & 0.00 & 0.14 & 0.54 & 0.81 & 0.82 & 0.59 & 0.65 & 0.65 & 0.35 & 0.03 & 0.00 & 0.38 \\
\hline & Cold & 0.63 & 0.43 & 0.14 & 0.00 & 0.00 & 0.00 & 0.00 & 0.00 & 0.00 & 0.00 & 0.30 & 0.46 & 0.16 \\
\hline & Humid & 0.00 & 0.00 & 0.00 & 0.00 & 1.00 & 1.00 & 1.00 & 1.00 & 1.00 & 1.00 & 0.00 & 0.00 & 0.50 \\
\hline & Dry & 0.00 & 0.00 & 0.00 & 0.00 & 0.00 & 0.00 & 0.00 & 0.00 & 0.00 & 0.00 & 0.00 & 0.00 & 0.00 \\
\hline \multirow{4}{*}{$\begin{array}{l}\text { Jammu } \\
\text { (Jammu } \\
\& \\
\text { Kashmir) }\end{array}$} & Hot & 0.00 & 0.00 & 0.00 & 0.18 & 0.51 & 0.71 & 0.87 & 1.00 & 0.69 & 0.08 & 0.00 & 0.00 & 0.34 \\
\hline & Cold & 1.00 & 0.80 & 0.42 & 0.16 & 0.00 & 0.00 & 0.00 & 0.00 & 0.00 & 0.12 & 0.39 & 0.88 & 0.31 \\
\hline & Humid & 0.00 & 0.00 & 0.00 & 0.00 & 0.00 & 1.00 & 1.00 & 1.00 & 1.00 & 0.00 & 0.00 & 0.00 & 0.33 \\
\hline & Dry & 0.00 & 0.00 & 0.00 & 0.00 & 0.00 & 0.00 & 0.00 & 0.00 & 0.00 & 0.00 & 0.00 & 0.00 & 0.00 \\
\hline \multirow{4}{*}{$\begin{array}{l}\text { Gangtok } \\
\text { (Sikkim) }\end{array}$} & Hot & 0.00 & 0.00 & 0.00 & 0.00 & 0.00 & 0.00 & 0.00 & 0.00 & 0.00 & 0.00 & 0.00 & 0.00 & 0.00 \\
\hline & Cold & 1.00 & 1.00 & 1.00 & 0.73 & 0.53 & 0.23 & 0.19 & 0.13 & 0.32 & 0.71 & 1.00 & 1.00 & 0.65 \\
\hline & Humid & 0.00 & 0.00 & 0.00 & 0.00 & 0.00 & 0.00 & 0.00 & 0.00 & 0.00 & 0.00 & 0.00 & 0.00 & 0.00 \\
\hline & Dry & 1.00 & 1.00 & 0.00 & 0.00 & 0.00 & 0.00 & 0.00 & 0.00 & 0.00 & 0.00 & 0.00 & 1.00 & 0.25 \\
\hline
\end{tabular}

Based on the climatic analyses charts and the discomfort index calculations of the 12 climatic lines for each region, the following can be understood:

Palanpur shows a dry index of zero for the whole year while a humid index of 1.00 is recorded for a continuous period of 6 months indicating that dehumidification is required for $50 \%$ of the year. This may be due to the fact that although the location falls in the 'hot-dry' area, it is situated very close to the composite zone, and therefore an uncharacteristic high humidity can be experienced. Since climatic lines that fall beyond the passive strategy zones indicate the necessity of active cooling or heating, the combination of high temperature and humidity levels in Palanpur show air-conditioning as an effective strategy for thermal comfort. However, as this study is limited to the consideration 
of passive strategies, comfort ventilation can be used to decrease the level of discomfort even if it cannot eliminate it. Similarly, the high thermal mass with or without night ventilation can also be used effectively cool the house. Heating requirement for Palanpur is minor, in fact the least of all the other locations, and could be achieved by passive means.

Jammu, like Palanpur, shows a dry index of zero for the whole year which is understandable for a composite climate. Short mild winter with long hot, humid summer is characteristic of Jammu. The summer period or cooling season runs mainly from May to October during which a humidity index of 1.00 and high values for the hot index have been recorded. The climatic analysis chart shows that comfort ventilation is a possibility for decreasing the discomfort for the milder conditions although it may not suffice for the more extreme conditions. December through to end of March in the discomfort index table show high cold index values which can be improved through passive solar strategies according to the chart.

For Gangtok, both the hot and humid index is zero for the whole year which is expected for a cold region. The prevailing climate is mild winter with practically no summer period. Most of the climatic lines are either within the comfort zone or inside the passive solar design strategy zone, and for about $65 \%$ of the year space heating is required. Although the duration of space heating is long, the magnitude of heating required is relatively small due to the mild winter conditions during most of the year.

\subsection{Summary}

This chapter has justified the importance of maintaining indoor thermal comfort by looking at the effects that discomfort can cause on human health and performance. The natural physiological and psychological responses to discomfort are also discussed as well as acknowledging the adaptive capabilities and acclimatisation which are particularly relevant to the low-income population. After reviewing the existing thermal comfort models, the adaptive model is selected for the study, and based on the outdoor climatic data, the comfort zones for each region have been identified. Climatic analysis and discomfort index calculation have also been carried out to provide a better idea of which strategies would be most appropriate. Energy implications of thermal comfort and the need for passive strategies are also discussed and the implementable passive technologies are identified along with their integrative potential which will be investigated in detail in Chapter 5 . 


\section{Seismic Retrofitting for Non-Engineered Housing}

This chapter discusses the necessity of seismic provisions for non-engineered buildings. Taking the housing types previously introduced in Chapter 2, the structural deficiencies of these buildings and consequent damages likely to result from these deficiencies are identified. The current attitudes toward safety in developing countries are briefly discussed. And finally, the appropriate techniques for reinforcing these existing housing types through retrofitting are identified in order to form the foundation for the next chapter which discusses the modification of these techniques for enhancing thermal comfort.

\subsection{Effects of earthquake disasters}

The causes of earthquake fatalities are varied. They can include deaths from fires following earthquakes, from tsunamis generated by off-shore events, from rock-falls, landslides and other hazards triggered by earthquakes (Coburn \& Spence, 2002). However, as many past studies have shown (S. N. Brzev, et al., 2002; Murty, 2005; Papanikolaou \& Taucer, 2004), the principal cause of fatalities in most large-scale earthquakes is the failure of structural and non-structural elements leading to the collapse of buildings. In fact, according to Coburn \& Spence (2002), about 75 percent of fatalities attributed to earthquakes are due to building collapse.

This is even more accentuated in developing countries where the majority of residential buildings is non-engineered masonry construction (see Figure 4.1). Due to the inherent weakness of the materials used and fundamental construction flaws, these structures present a higher risk of collapse, indicating serious consequences. In the 1993 Killari earthquake of Maharashtra, over 8,000 people died, most of them buried under the rubble of traditional stone masonry dwellings. Likewise, a majority of over 13,800 deaths during the 2001 Bhuj earthquake in Gujarat is attributed to the collapse of masonry buildings (Murty, 2005). 

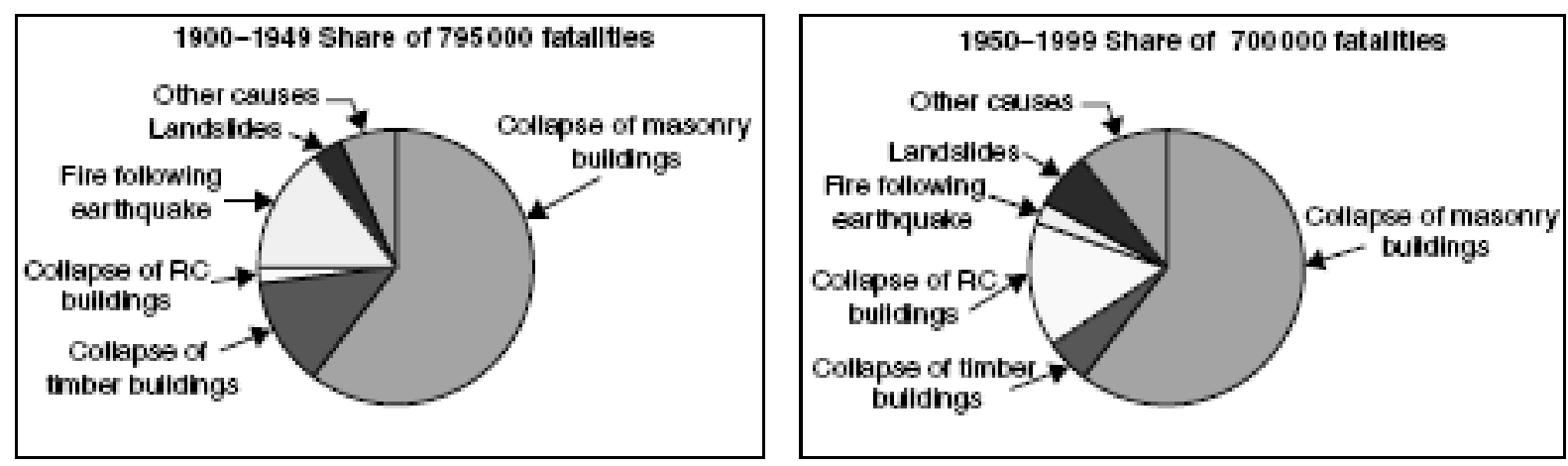

Figure 4.1: Breakdown of fatalities attributed to earthquake by cause (Coburn \& Spence, 2002)

\subsection{Attitudes towards safety in developing countries}

Disasters (not limited to earthquakes) can be not only fatal but also affect the well-being of the affected population and therefore delay the process of recovery. The chart (see Figure 4.2) shows the inter-relationship between disaster and well-being. On one hand, a disaster affects the well being of the community/household through altering the status of their physical, economic, social and environmental conditions, while the population's asset decides the severity of disasters' impact on the community and their coping capacities (Patel, et al., 2006). As can be observed from the chart, the target population of this study, characterized by its poor capital assets is likely to be severely impacted, which can result in the well-being of the population being destroyed. Therefore, any type of disaster preparedness planning to reduce impact of disaster at the time of disaster and enhance the quality of life in normal time should essentially take in to consideration impact on physical, economic, social and environmental- well being of the community (Patel, et al., 2006).

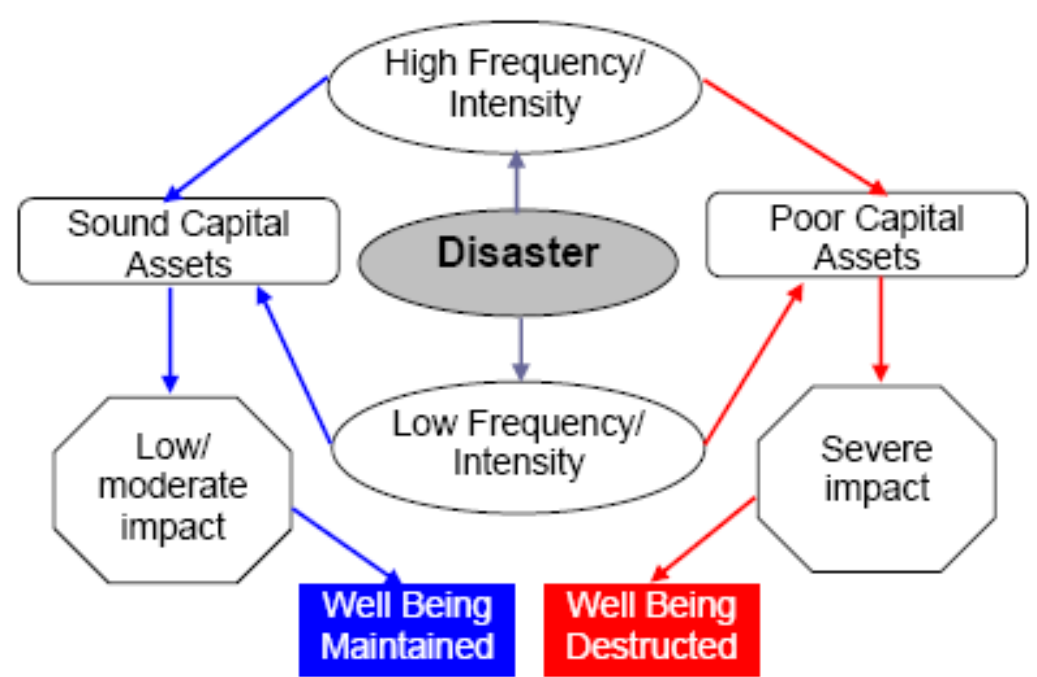

Figure 4.2: Inter-relationship of well-being and disasters (Patel, Patel, \& Hemani, 2006) 
According to Sena (1991), disasters can be seen as the product of two factors: 'risk' and 'vulnerability'. An event will be a risk only if it happens in a community which is vulnerable to this particular event. Sena (1991) identifies several vulnerabilities that can exist in earthquake damageprone regions. Physical vulnerability is applicable to all regions that are situated in disaster-prone areas, but particular to the regions discussed in this study, and developing countries in general, are the technical vulnerability (lack of building knowledge), educative vulnerability (lack of awareness), economic vulnerability (lack of money to invest in proper structures).

The economic vulnerability is classified as the base of all vulnerabilities (Sena, 1991). The inability to afford the available technology is the basis for all unsafe houses. Additionally, the notion of planning for the future is also not very common among low-income populations who struggle to survive in the present with numerous inadequacies.

Technical and educative vulnerabilities are linked to each other with the common problem being that earthquakes have large return periods, making it difficult to learn from them via a trial-anderror method in short time spans without the tools offered by modern engineering research and design. Hence, even after damaging earthquakes, the same types of non-engineered buildings continue to be constructed. In addition to this, the weak or non-existent regulatory environments which characterise the rapid urbanisation of developing countries, a subsequent lack of enforcement of design and construction standards, a lack of effective technical and professional leadership, and an uneducated workforce, has led to seismically vulnerable building stocks (Charleson, 2008).

Social vulnerability may or may not be a factor contributing to the reluctance to construct seismically resistant structures in these regions. People living in certain locations may not own the land on which their houses are built, but rather live as part of squatter settlements. These settlements are at risk of being cleared by the state at anytime resulting in displacement of the population. In these environments, people can be reluctant to invest in their houses for long term habitation.

The above factors explain why India and other developing countries are unable to maintain an adequate level of safety in their buildings. Many circumstances create vulnerable societies as well as vulnerable structures indicating a high risk factor which needs to be resolved. 


\subsection{Current level of seismic provisions provided in low-income housing}

Despite the high risk from earthquakes, non-engineered masonry building types will continue to be built due to their low cost and readily available materials. Therefore, it is essential that the structural safety be improved. Thus this section aims to first understand the common structural deficiencies and typical modes of failures of these housing types of fire/unfired brick, adobe, and stone (introduced in Chapter 2), and then presents possible improvements.

\subsubsection{Fired/unfired brick}

Masonry buildings are brittle structures and one of the most vulnerable of the entire building stock under strong earthquake shaking. The walls are most vulnerable to damage caused by horizontal forces due to earthquake. Horizontal inertia force developed at the roof transfers to the walls acting either in the weak direction (perpendicular to its plane) or strong direction (along the wall's length). Since usually the walls are not tied together, the walls loaded in their weak direction tend to topple. To ensure good seismic performance, all walls must be joined properly to the adjacent walls to function together like a box. In this way, walls loaded in their weak direction can take advantage of the good lateral resistance offered by walls loaded in their strong direction. Furthermore, walls also need to be tied to the roof and foundation to preserve their overall integrity.

The roofing elements are often not interconnected and the roof structure is not properly anchored to the wall in most cases. This increases the risk of roof collapse. Similarly, the frequency and size of wall openings are also important. If a house has too many windows and doors or if the areas of the individual openings are great, there is a high risk of collapse. Also, it is common to find openings located at wall corners which increase the risk of collapse in the event of an earthquake.

The quality of building materials, especially the masonry units and mortar, is also very important as they influence the earthquake performance of a masonry wall. Burnt clay bricks are most commonly used but these bricks are inherently porous and tend to suck water away from the adjoining mortar which results in poor bond between brick and mortar. Similarly, mud mortar is very weak as it crushes easily when dry, and therefore has very low earthquake resistance. Thus cement sand mortar with lime is recommended instead for better performance.

The overall vulnerability of this type of construction (as in Figures 2.6, 2.7 and 2.8) with the most commonly observed deficiencies mentioned above is classified to be in a range of medium to high; 
indicating moderate to very poor seismic performance in the event of an earthquake (Kumar, 2002b). However if the relevant improvements are made, the risk of collapse can be significantly reduced.

\subsubsection{Adobe}

Although over a $30 \%$ of the world's population lives in adobe houses, they are not safe in seismic areas because of their heavy walls which have low strength and brittle behaviour. During strong earthquakes, due to their large mass, these structures are unable to resist the high levels of seismic forces, and therefore they fail abruptly. Typical modes of failure during earthquakes are the same as other unreinforced masonry buildings and include severe cracking and disintegration of walls, separation of walls at the corners, and separation of roofs from the walls, leading to collapse.

In the house plan shown in Chapter 2 (see Figures 2.10 and 2.11), while the provision of wooden columns at regular intervals is a seismically resilient feature, there are several serious seismic deficiencies which contribute negatively. These include poor lateral resistance, no lintel bands, improper proportions of openings, poor interconnection of roofing elements and wall-to-wall connection, and lack of sufficient distance between corners and openings. The overall rating of the seismic vulnerability of the housing type is high to medium-high which indicates a poor to very poor rate of seismic performance in event of an earthquake (Kumar, 2002a).

Ensuring better connection between the roofing elements through bracing and ties, as well as incorporating peripheral reinforcement around openings is advisable. Wall reinforcement by filling cracks with good fibre-reinforced mortar and stitching of corner cracks with bamboo ties are also recommended and applicable to all types of masonry construction not limited to adobe (WHE -mud house with pitched roof).

\subsubsection{Stone}

Though it may be cheap, this type of non-engineered stone construction is extremely vulnerable in earthquakes because of its heavy roofs and poorly constructed walls. The thick stone masonry walls built using rounded stones are bound with mud mortar and filled with random rubble in between the wythes. With stones placed in a random manner and absence of proper connection between the two wythes of the wall, delamination tends to occur in the walls and increases the risk of collapse. 
Other seismic deficiencies include the absence of header stones at corners and junctions, vertical separation joints at wall corners and junctions, inadequate post-to-beam connections, and a heavy mud roofs to name a few.

The overall seismic vulnerability of common stone masonry construction (see Figure 2.12 and 2.13) is classified as high to medium-high, (same as the non-engineered adobe construction) and means that the seismic performance of this type of stone construction will be poor to very poor during an earthquake unless it is improved with the techniques recommended here, and presented in Table 4.1 in detail.

Most deficiencies are similar to those relevant to brick masonry buildings and the same solutions for ensuring box-like behaviour can be applied here. Additionally, to ensure proper bond in masonry courses, there should be through-stones or reinforced concrete bands embedded in the wall wythes. The unsupported length of walls between cross-walls should be limited to $5 \mathrm{~m}$, and for longer walls, buttresses should be provided for support. Wall thickness should not exceed $450 \mathrm{~mm}$, and as with the brick houses, the use of cement-sand mortar or lime-sand mortar is recommended (Desai \& Desai, 2008).

As this section emphasises, there are major seismic deficiencies in these houses that require improvement if they are to be made seismically resistant. Although, these may not be sufficient to meet the requirements of the safety levels stated in the seismic code, improving the wall-to-wall, wall-to-roof, wall-to-floor connections, and perhaps strengthening the foundations will increase the building's collapse time. This will allow people the opportunity to escape from the building before it collapses.

\subsection{Seismic retrofitting}

Seismic retrofitting offers many advantages over reconstruction. Firstly, taking into consideration the economic vulnerability of the low-income population, the cost of demolition and removal of debris from demolition can be eliminated and the total cost of the improvements can also be reduced since there is no need to redo the whole building. Also, retrofitting can be done in a phased manner depending upon the availability of funds and time. So it is not necessary to retrofit the whole structure at once. This also eliminates the need for a temporary shelter since the retrofitting can be done part-by-part without hindering everyday life too much. Hence, seismic retrofitting is 
recommended for strengthening existing buildings in high risk regions unless they are in a dilapidated condition.

However it is essential that the retrofitting technology be appropriate and affordable for the people. Technologically advanced retrofitting techniques which involve a high level of intervention are not applicable as the capital investment required for the upgrade could easily exceed the initial cost of the building. Similarly, if the interventions significantly restrict or reduce the liveable area, some people may not want to seismically retrofit.

\subsubsection{Appropriate retrofitting technologies for low-income housing}

The table below presents the retrofitting solutions that are appropriate and low cost for nonengineered buildings in developing countries. The solutions are categorized in terms of the different structural elements and connections that are deficient. These are: roof construction; wall and column reinforcement, wall-to-wall, wall-to-roof, and foundation-to-wall connections; wall openings; and foundation strengthening. For each category, several appropriate retrofitting solutions are presented and briefly explained in text and diagrams. The table also shows which retrofitting techniques are applicable to which housing types.

Though applicable for retrofitting, some techniques such as strengthening the foundations may not be feasible due to the complicated nature of the process. Such a type of comment is also included the table. It is also necessary to note that the aim of this table is to identify and introduce the retrofitting techniques and therefore the explicit procedures are not shown. Furthermore, the identification of whether a technique can be applied to a particular building type is based either on current practice or on prior research. Therefore, there may also a chance that the same technique could be applied to other building types with or without some additional modifications, even if they are not presented here. 
Table 4.1: Retrofitting technologies for non-engineered construction

\begin{tabular}{|c|c|c|c|c|c|c|}
\hline \multirow{2}{*}{$\begin{array}{l}\text { Structural Elements } \\
\text { and Connections } \\
\text { Requiring Retrofit }\end{array}$} & \multirow[t]{2}{*}{ Retrofitting Technologies } & \multirow[t]{2}{*}{ Visual } & \multirow[t]{2}{*}{ Comments } & \multicolumn{3}{|c|}{ Wall Materials } \\
\hline & & & & Brick & Mud & Stone \\
\hline \multirow[t]{4}{*}{ Roof construction } & $\begin{array}{l}\text { - Diagonal struts and braces } \\
\text { O Installing struts on the underside the ceiling beams (in the case of a flat roof } \\
\text { deck) or at the underside of the rafter or purlins (in case of pitched timber roof) } \\
\text { next to where they are resting on walls with two nails/screws at each end. } \\
\text { o K or X arrangements can be adopted so that the angle between bracing and } \\
\text { struts is close to } 45 \text { degrees. Z pattern arrangements are also possible for } \\
\text { pitched roofs. }\end{array}$ & $\begin{array}{l}\text { Figures } \\
4.3 \\
4.4,4.5\end{array}$ & $\begin{array}{l}\text { For houses with flat } \\
\text { timber roof deck } \\
\begin{array}{l}\text { For a pitched timber } \\
\text { roof }\end{array} \\
\end{array}$ & $\checkmark$ & $\checkmark$ & $\checkmark$ \\
\hline & - Tying rafters to the roof truss & & $\begin{array}{l}\text { All tiles and purlins in } \\
\text { the vicinity of the roof } \\
\text { level need to be } \\
\text { removed first }\end{array}$ & $\checkmark$ & $\checkmark$ & $\checkmark$ \\
\hline & - Anchoring roofing tiles and sheeting to understructure & & & $\checkmark$ & $\checkmark$ & $\checkmark$ \\
\hline & $\begin{array}{l}\text { - Remove mud overlay atop the roof (limit to } 200 \mathrm{~mm} \text { ) } \\
\text { Additionally, lay black polythene sheet at mid-thickness of the } 20 \mathrm{~cm} \text { thick soil on } \\
\text { roof for water proofing. }\end{array}$ & & & $\checkmark$ & $\checkmark$ & $\checkmark$ \\
\hline
\end{tabular}

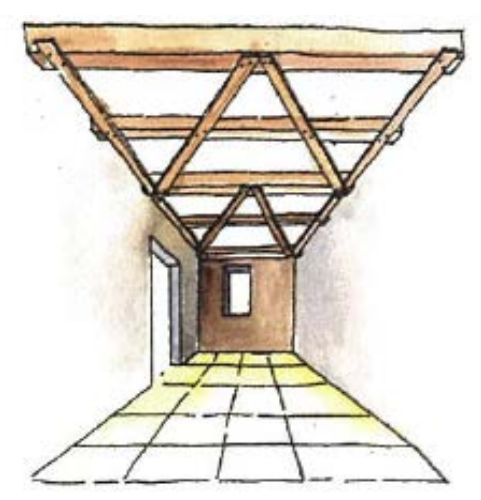

Figure 4.3: 'K' arrangement bracing (Desai \& Desai, 2007)

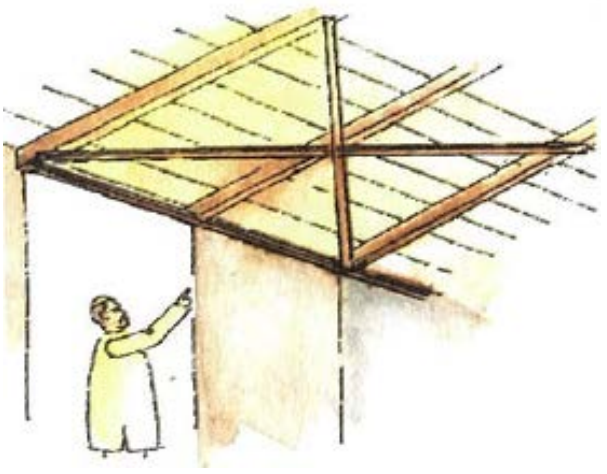

Figure 4.4: ' $X$ ' arrangement bracing (Desai \& Desai, 2007)

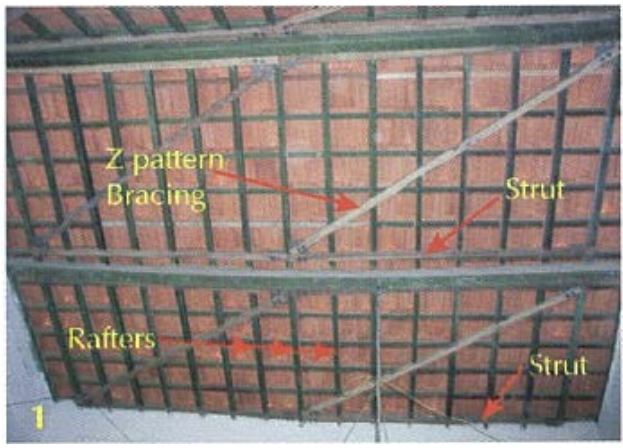

Figure 4.5: ' $Z$ ' arrangement bracing (Desai \& Desai, 2008) 


\begin{tabular}{|c|c|c|c|c|c|c|}
\hline \multirow[t]{2}{*}{ Structural Elements } & \multirow{2}{*}{ Retrofitting Technologies } & \multirow[t]{2}{*}{ Visual } & \multirow[t]{2}{*}{ Comments } & \multicolumn{3}{|c|}{ Wall Materials } \\
\hline & & & & Brick & Mud & Stone \\
\hline $\begin{array}{l}\text { Roof construction } \\
\text { (contd.) }\end{array}$ & - Install horizontal collar beams between the opposite rafters & \begin{tabular}{|l|} 
Figure \\
4.6 \\
\end{tabular} & For pitched roofs & $\checkmark$ & $\checkmark$ & $\checkmark$ \\
\hline Wall strength & $\begin{array}{l}\text { - Installation of seismic belt } \\
\text { o Made with reinforcement consisting of galvanized welded wire mesh (WWM) } \\
\text { and bars that are anchored to the wall via 'Shear connectors' (see pg. 79) and } \\
\text { fully encased in cement plaster or micro-concrete. } \\
\text { o Eaves/Roof belt- required at the eaves level of pitched roofs or where flexible } \\
\text { wood joist roof or precast roofing units are used. } \\
\text { o Gable belt- used to enclose the triangular part of masonry walls and join the } \\
\text { horizontal eaves level band. } \\
\text { o The belt should be continuous (Desai \& Desai, 2008): } \\
\text { o When it is possible to install a belt on only three walls (U-shaped wall) then } \\
\text { adjacent to the fourth wall a tie rod must be installed to ensure some } \\
\text { continuity. }\end{array}$ & $\begin{array}{l}\text { Figures } \\
4.7 \text { and } \\
4.8\end{array}$ & $\begin{array}{l}\text { Can also be considered } \\
\text { as a wall } \\
\text { reinforcement } \\
\text { technique (see section } \\
\text { wiremesh on pg. 76) }\end{array}$ & $\checkmark$ & $\checkmark$ & $\checkmark$ \\
\hline
\end{tabular}

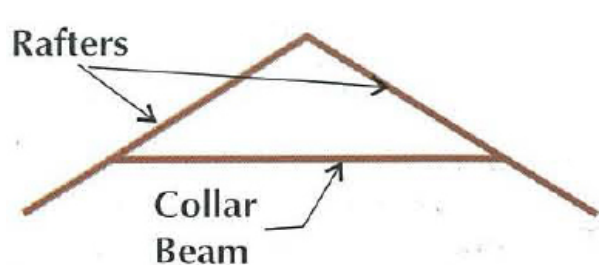

Figure 4.6: Collar beam for rafters in pitched roof building (Desai \& Desai, 2008)

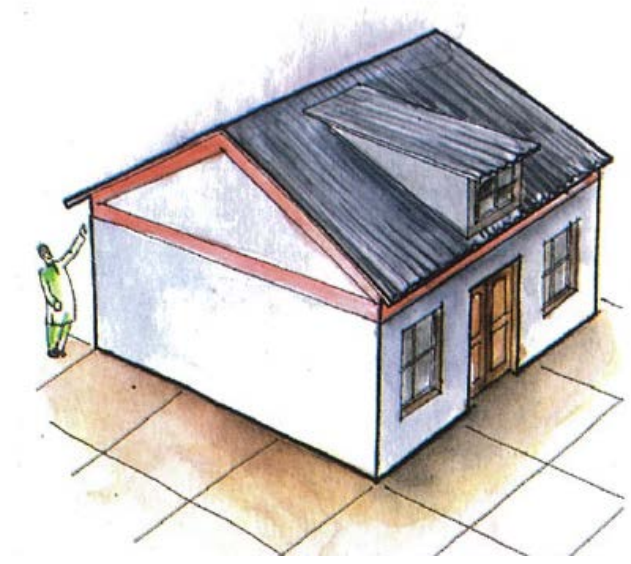

Figure 4.7: Seismic belt for pitched roof building (Desai \& Desai, 2007)
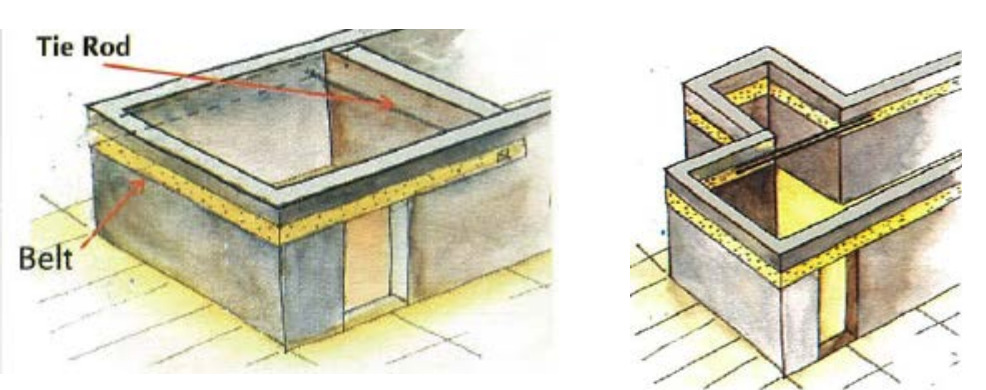

Figure 4.8: Ensuring continuity of seismic belt with tie-rod connections (Desai \& Desai, 2008) 


\begin{tabular}{|c|c|c|c|c|c|c|}
\hline \multirow[t]{2}{*}{ Structural Elements } & \multirow[t]{2}{*}{ Retrofitting Technologies } & \multirow[t]{2}{*}{ Visual } & \multirow[t]{2}{*}{ Comments } & \multicolumn{3}{|c|}{ Wall Materials } \\
\hline & & & & Brick & Mud & Stone \\
\hline \multirow[t]{2}{*}{$\begin{array}{l}\text { Wall strength } \\
\text { (contd.) }\end{array}$} & $\begin{array}{l}\text { - Strengthening with plastered wire mesh } \\
\text { o Steel mesh (welded wire fabric) is placed on the two sides of the wall and } \\
\text { connected by through ties. } \\
\text { o A } 20 \text { to } 40 \mathrm{~mm} \text { thick cement mortar or micro-concrete layer is then applied over } \\
\text { the mesh thus giving rise to two interconnected vertical wall plates. }\end{array}$ & $\begin{array}{l}\text { Figure } \\
4.9\end{array}$ & & $\checkmark$ & $\checkmark$ & $\checkmark$ \\
\hline & $\begin{array}{l}\text { - Shotcreting } \\
\text { o The coating may be applied in two layers: after completing the first layer of } \\
\text { shotcrete, the steel mesh is installed with through-wall ties and second layer is } \\
\text { applied. }\end{array}$ & $\begin{array}{l}\text { Figure } \\
4.10\end{array}$ & $\begin{array}{l}\text { Requires special } \\
\text { equipment not readily } \\
\text { available }\end{array}$ & $\checkmark$ & $\checkmark$ & $\checkmark$ \\
\hline
\end{tabular}

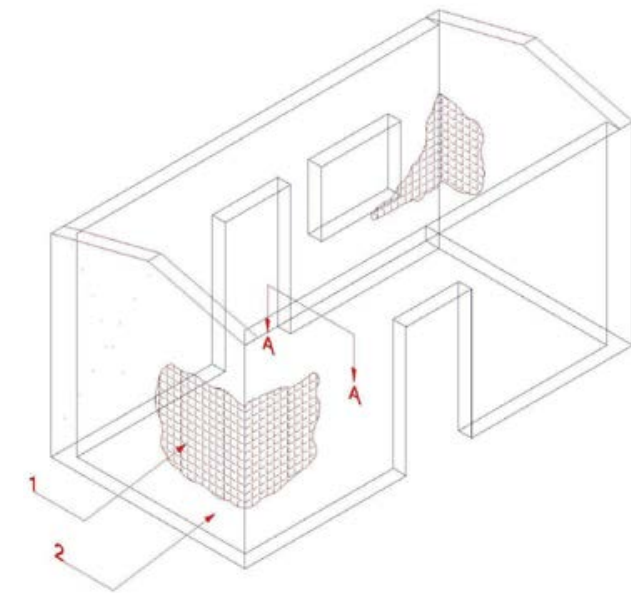

Figure 4.9: Wire-mesh strengthening (The International Association for Earthquake Engineering, 2001)

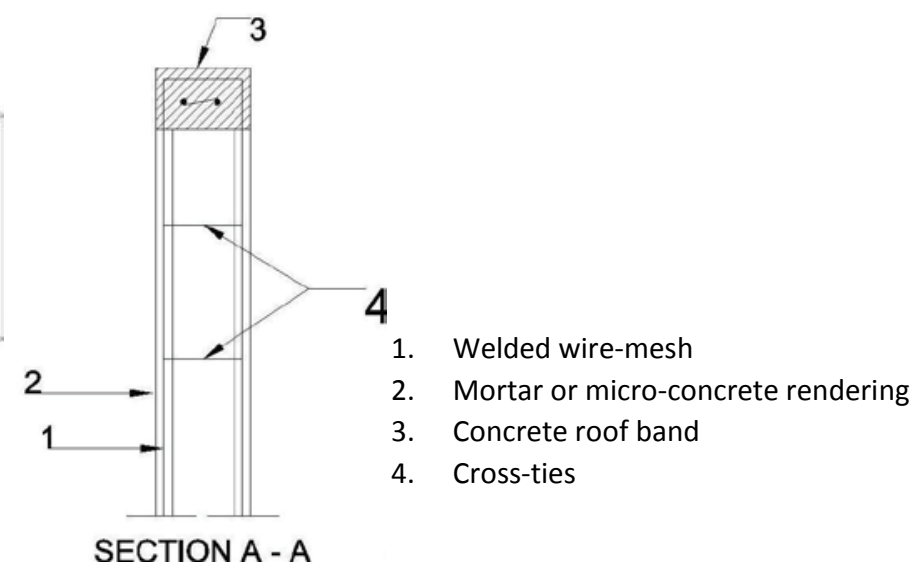

SECTION A - A

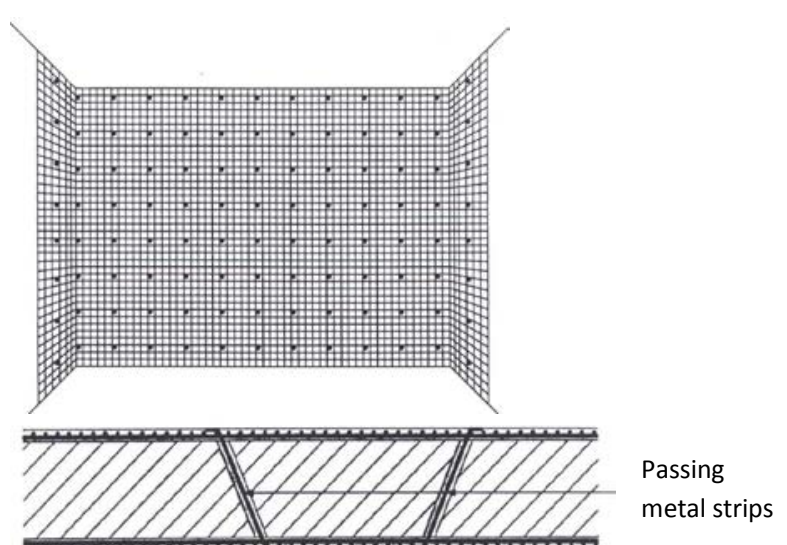

Figure 4.10: Shotcreting steel mesh installation with throughwall ties (D'Ayala, Speranza, \& D'Ercole, 2002) 


\begin{tabular}{|c|c|c|c|c|c|c|}
\hline \multirow[t]{2}{*}{ Structural Elements } & \multirow[t]{2}{*}{ Retrofitting Technologies } & \multirow[t]{2}{*}{ Visual } & \multirow[t]{2}{*}{ Comments } & \multicolumn{3}{|c|}{ Wall Materials } \\
\hline & & & & Brick & Mud & Stone \\
\hline \multirow[t]{2}{*}{$\begin{array}{l}\text { Wall strength } \\
\text { (contd.) }\end{array}$} & $\begin{array}{l}\text { - Reinforced tie beams } \\
\text { o Constructed atop the walls, tie-beam reinforcement is similar to 'column } \\
\text { reinforcement' (see pg.89) -four longitudinal bars and stirrups at equal spacing } \\
\text { - Tie-beams can be connected to tie-columns at the intersections }\end{array}$ & $\begin{array}{l}\text { Figure } \\
4.11\end{array}$ & $\begin{array}{l}\text { Primarily for new } \\
\text { construction, but } \\
\text { could be used as a } \\
\text { retrofit. Requires the } \\
\text { removal of roof; so is } \\
\text { complicated. }\end{array}$ & $\checkmark$ & $\checkmark$ & $\checkmark$ \\
\hline & $\begin{array}{l}\text { - Shear connecters } \\
\text { o An L-shaped bar in a RC bond element with its bent leg sticking out of the wall } \\
\text { used to anchor seismic belts and vertical reinforcement to the wall } \\
\text { o For seismic belt shear connector- one end of the bar must be bent like a hook } \\
\text { and the other like an 'L' to which welded wire mesh (WWM) is tied. } \\
\text { o For vertical reinforcement shear connector- one end of the bar must be bent } \\
\text { like a hook and the other end bent like an 'L' to which the vertical rod or WWM } \\
\text { is tied to anchor it onto wall corner. }\end{array}$ & $\begin{array}{l}\text { Figure } \\
4.12 \\
\text { and } \\
4.13\end{array}$ & & $\checkmark$ & & $\checkmark$ \\
\hline
\end{tabular}
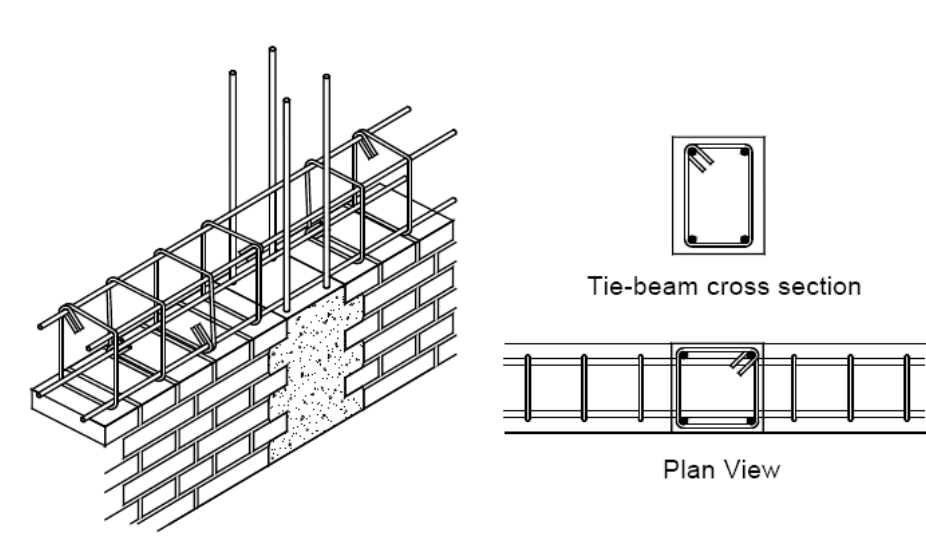

Plan View

Figure 4.11: Tie-column \& tie-beam reinforcement (S. Brzev, 2007)

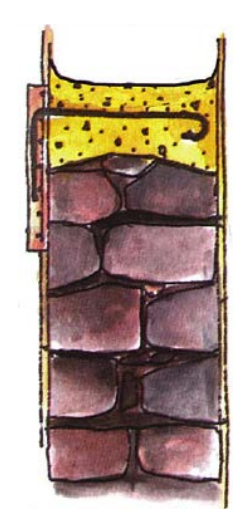

Figure 4.12: Seismic belt shear connector (Desai \& Desai, 2007)

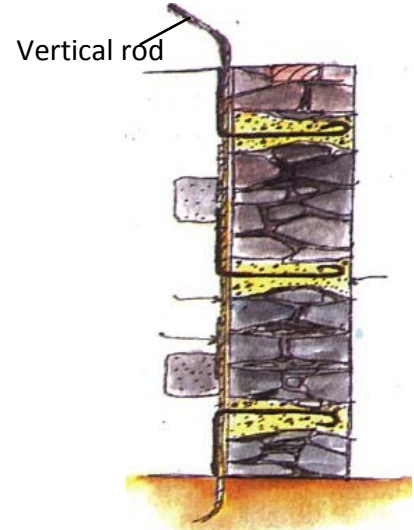

Figure 4.13: Vertical reinforcement shear connector (Desai \& Desai, 2007) 


\begin{tabular}{|c|c|c|c|c|c|c|c|c|}
\hline \multirow[t]{2}{*}{ Structural Elements } & \multirow{2}{*}{\multicolumn{3}{|c|}{ Retrofitting Technologies }} & \multirow[t]{2}{*}{ Visual } & \multirow[t]{2}{*}{ Comments } & \multicolumn{3}{|c|}{ Wall Materials } \\
\hline & & & & & & Brick & Mud & Stone \\
\hline \multirow[t]{6}{*}{$\begin{array}{l}\text { Wall strength } \\
\text { (contd.) }\end{array}$} & \multicolumn{3}{|c|}{$\begin{array}{l}\text { Appropriate for well-built cut dressed-stone coursed walls on lime-cement } \\
\text { mortar. } \\
\text { o A number of holes are drilled in the wall and cement water mixture is grouted } \\
\text { at low pressure in the holes starting from the lower holes and going up. }\end{array}$} & $\begin{array}{l}\text { Figure } \\
4.14\end{array}$ & $\begin{array}{l}\text { This technique may } \\
\text { not increase the wall's } \\
\text { lateral resistance (Virdi } \\
\text { \& Rashkoff, [Accessed } \\
\text { 2010]) }\end{array}$ & $\checkmark$ & & $\checkmark$ \\
\hline & \multicolumn{3}{|c|}{ - Masonry buttresses may be added externally when there is a long wall } & \multirow{5}{*}{$\begin{array}{l}\text { Figure } \\
4.15\end{array}$} & \multirow{5}{*}{$\begin{array}{l}\text { Complicated } \\
\text { procedure for } \\
\text { retrofitting especially } \\
\text { when linking the } \\
\text { buttress with the } \\
\text { existing wall (see } \\
\text { 'Inserting new walls' } \\
\text { on pg.83 for details) }\end{array}$} & \multirow[t]{5}{*}{$\checkmark$} & \multirow[t]{5}{*}{$\checkmark$} & \multirow[t]{5}{*}{$\checkmark$} \\
\hline & Building type & $\begin{array}{l}\text { Max. wall length without } \\
\text { buttress }\end{array}$ & $\begin{array}{l}\text { Buttress spacing along long } \\
\text { wall }\end{array}$ & & & & & \\
\hline & $\begin{array}{l}\text { Masonry in mud } \\
\text { mortar }\end{array}$ & $5.0 \mathrm{~m}$ & $3.5 \mathrm{~m}$ & & & & & \\
\hline & $\begin{array}{l}\text { Masonry in } \\
\text { cement mortar }\end{array}$ & $7.0 \mathrm{~m}$ & $5.0 \mathrm{~m}$ & & & & & \\
\hline & \multicolumn{3}{|c|}{$\begin{array}{l}\text { - Buttresses and also pilasters can also be provided at corners and junctions of walls } \\
\text { to improve the strength of those weak points }\end{array}$} & & & & & \\
\hline
\end{tabular}

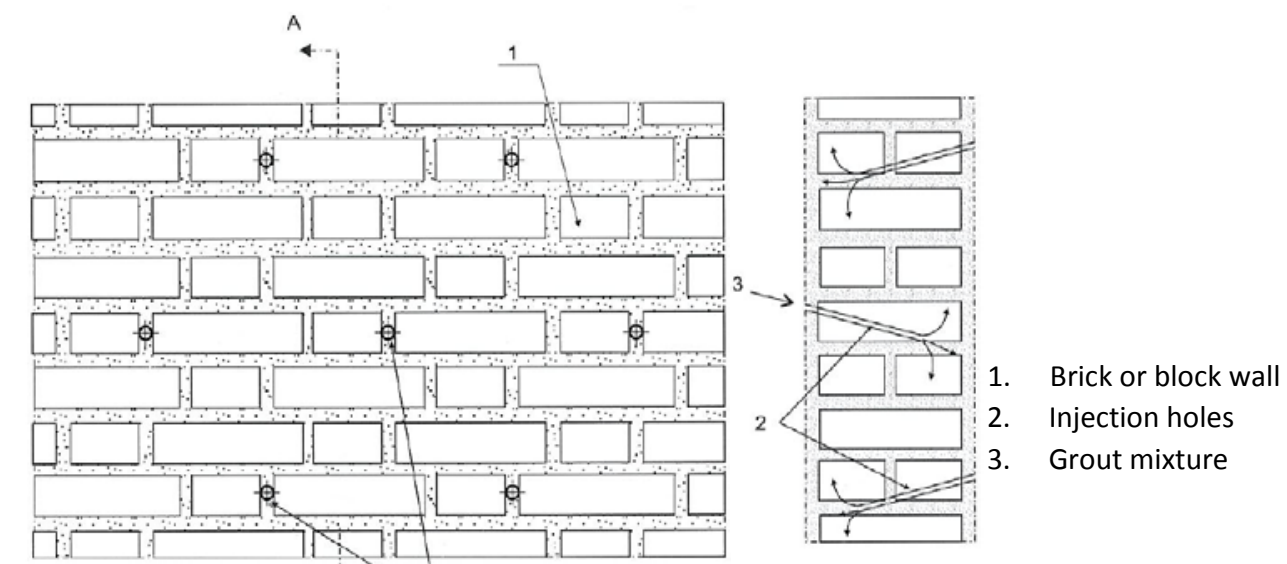

A 4
Section A - A

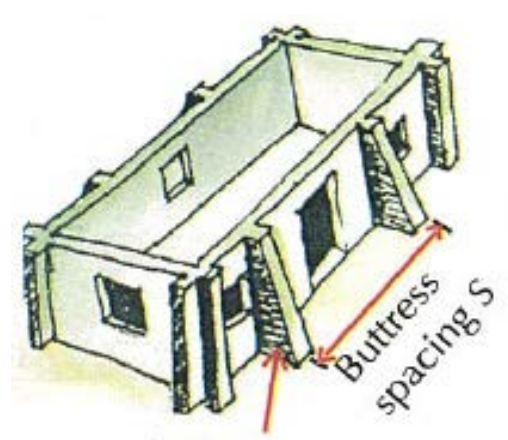

Buttress

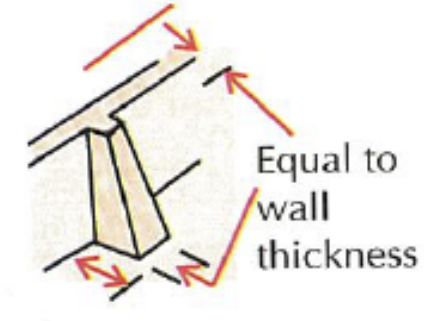

Equal to $1 / 6$ wall height

Figure 4.14: Inserting grout in walls (IAEE, 2001)

Figure 4.15: Inserting buttresses and pilasters (Desai \& Desai, 2008) 


\begin{tabular}{|c|c|c|c|c|c|c|}
\hline \multirow[t]{2}{*}{ Structural Elements } & \multirow[t]{2}{*}{ Retrofitting Technologies } & \multirow[t]{2}{*}{ Visual } & \multirow[t]{2}{*}{ Comments } & \multicolumn{3}{|c|}{ Wall Materials } \\
\hline & & & & Brick & Mud & Stone \\
\hline \multirow[t]{3}{*}{$\begin{array}{l}\text { Wall strength } \\
\text { (contd.) }\end{array}$} & $\begin{array}{l}\text { - Stitching wall wythes together by installing cast in-situ RC bond elements } \\
0 \text { Is beneficial when there is absence of bond elements or 'through' stones } \\
\text { between the wythes. } \\
\text { o After selectively removing stones in a wall and raking out the mortar from } \\
\text { around these holes, a rebar (hooked at both ends) is placed in a dumbbell } \\
\text { shaped hole and filled with non-shrink cement concrete. }\end{array}$ & $\begin{array}{l}\text { Figure } \\
4.16\end{array}$ & $\begin{array}{l}\text { No more than } 6 \text { holes } \\
\text { should be made at a } \\
\text { time in a single wall }\end{array}$ & & & $\checkmark$ \\
\hline & $\begin{array}{l}\text { - Installation of through-stones } \\
\text { o Stones at selected locations are removed and long stones (those that go across } \\
\text { the thickness of the wall) are inserted at every } 1200 \mathrm{~mm} \text { horizontal distance and } \\
\text { at every } 600 \mathrm{~mm} \text { height in a staggered manner. } \\
\text { o When long stones are not available, RC 'through-stones' with a hooked rod can } \\
\text { be made. }\end{array}$ & $\begin{array}{l}\text { Figure } \\
4.17 \\
\text { and } \\
4.18\end{array}$ & $\begin{array}{l}\text { Requires training of } \\
\text { local artisans and must } \\
\text { be performed } \\
\text { carefully. }\end{array}$ & & & $\checkmark$ \\
\hline & $\begin{array}{l}\text { Tyre strap reinforcement } \\
\text { o Circumferentially cut straps from the treads of used car tyres are joined with a } \\
\text { nailed joint. } \\
\text { o Holes are formed through the adobe house walls to allow straps to pass } \\
\text { through. } \\
\text { o Straps are then wrapped horizontally and vertically around the walls with pairs } \\
\text { of vertical straps passing under the foundations (can be done by excavating the } \\
\text { foundations) rising up the walls to be nailed to roof timbers. }\end{array}$ & $\begin{array}{l}\text { Figure } \\
4.19\end{array}$ & $\begin{array}{l}\text { Technique aimed for } \\
\text { light to medium- } \\
\text { weight roofs. } \\
\text { Necessary to plaster } \\
\text { over the tyre straps to } \\
\text { prevent them from the } \\
\text { weather. }\end{array}$ & & $\checkmark$ & \\
\hline
\end{tabular}

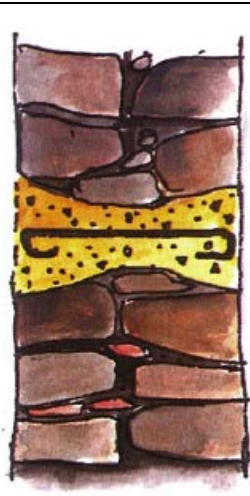

Figure 4.16: Stitching wall wythes with RC bond element (Desai \& Desai, 2007)

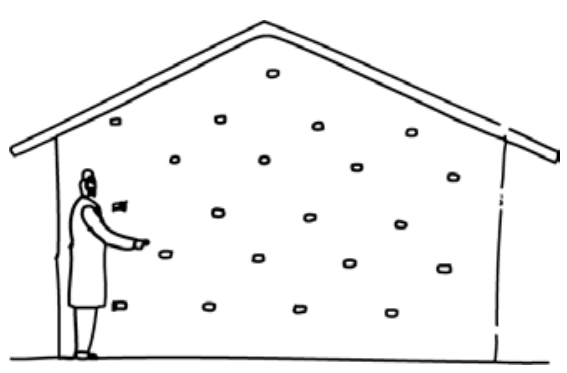

Figure 4.17: Stitching wall wythes with RC bond element (Desai \& Desai, 2007)

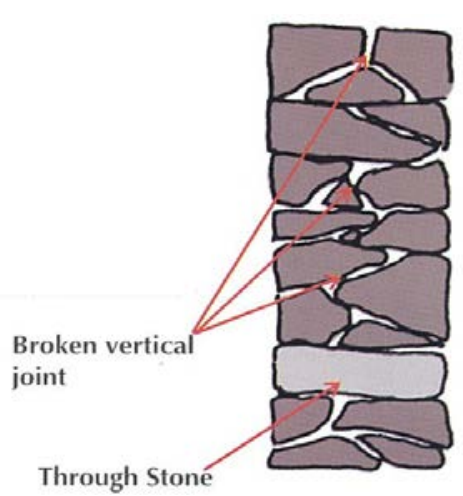

Figure 4.18: Through-stone in wall (Desai \& Desai, 2008)

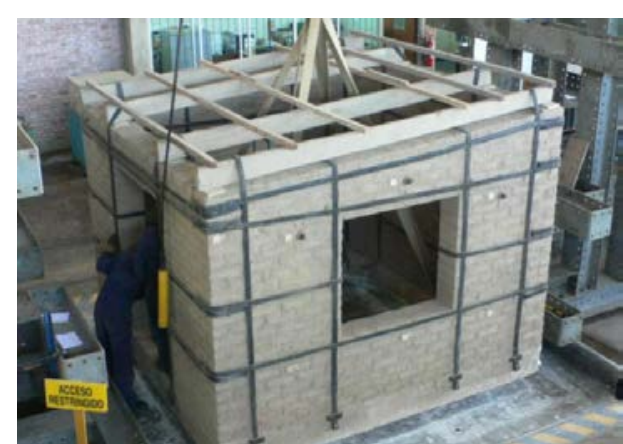

Figure 4.19: Tyre strap reinforcement (Charleson, 2009) 


\begin{tabular}{|c|c|c|c|c|c|c|}
\hline \multirow[t]{2}{*}{ Structural Elements } & \multirow[t]{2}{*}{ Retrofitting Technologies } & \multirow[t]{2}{*}{ Visual } & \multirow[t]{2}{*}{ Comments } & \multicolumn{3}{|c|}{ Wall Materials } \\
\hline & & & & Brick & Mud & Stone \\
\hline \multirow[t]{3}{*}{$\begin{array}{l}\text { Wall strength } \\
\text { (contd.) }\end{array}$} & $\begin{array}{l}\text { - Post-tensioning elastometric tyre straps (Scrap Tyre Rings (STR)) } \\
\text { o Two sides of scrap tyres are cut out and connection between STRs is done by } \\
\text { passing them through two steel pipes of } 5 \mathrm{~cm} \text { diameter which are connected by } \\
\text { bolts passed through two drilled holes on the wall on either side of the pipes. } \\
\text { o STRs connected to each other, using pipe connectors, form a chain of STRs. }\end{array}$ & $\begin{array}{l}\text { Figure } \\
4.20\end{array}$ & $\begin{array}{l}\text { Technique tested on } \\
\text { rural masonry houses } \\
\text { with heavy earthen } \\
\text { roofs. } \\
\text { The tyres are likely to } \\
\text { deteriorate and } \\
\text { become ineffective. }\end{array}$ & $\checkmark$ & & \\
\hline & $\begin{array}{l}\text { - External bamboo reinforcement } \\
\text { o Horizontal holes are drilled in rows at top, middle, and bottom of each wall and } \\
\text { polypropylene string loops are inserted through the holes (which are then filled } \\
\text { with mud and allowed to dry) to hold the bamboo in place. } \\
\text { o Timber ring/crown beam is placed on top of wall and connected with bamboo } \\
\text { dowels. } \\
\text { o If desired, the bamboo, string, and wire can be covered with a mud or lime } \\
\text { render to provide an attractive finish as well as afford protection from } \\
\text { weathering. }\end{array}$ & $\begin{array}{l}\text { Figure } \\
4.21\end{array}$ & $\begin{array}{l}\text { Bamboo may not be } \\
\text { readily available in } \\
\text { parts. }\end{array}$ & & $\checkmark$ & \\
\hline & $\begin{array}{l}\text { - Polymer mesh (geomesh) } \\
\text { o The mesh is attached to the adobe walls by nylon strings and is covered by mud } \\
\text { plaster (similar procedure to 'Strengthening with wiremesh' see pg. 78) }\end{array}$ & $\begin{array}{l}\text { Figure } \\
4.22\end{array}$ & & & $\checkmark$ & \\
\hline
\end{tabular}

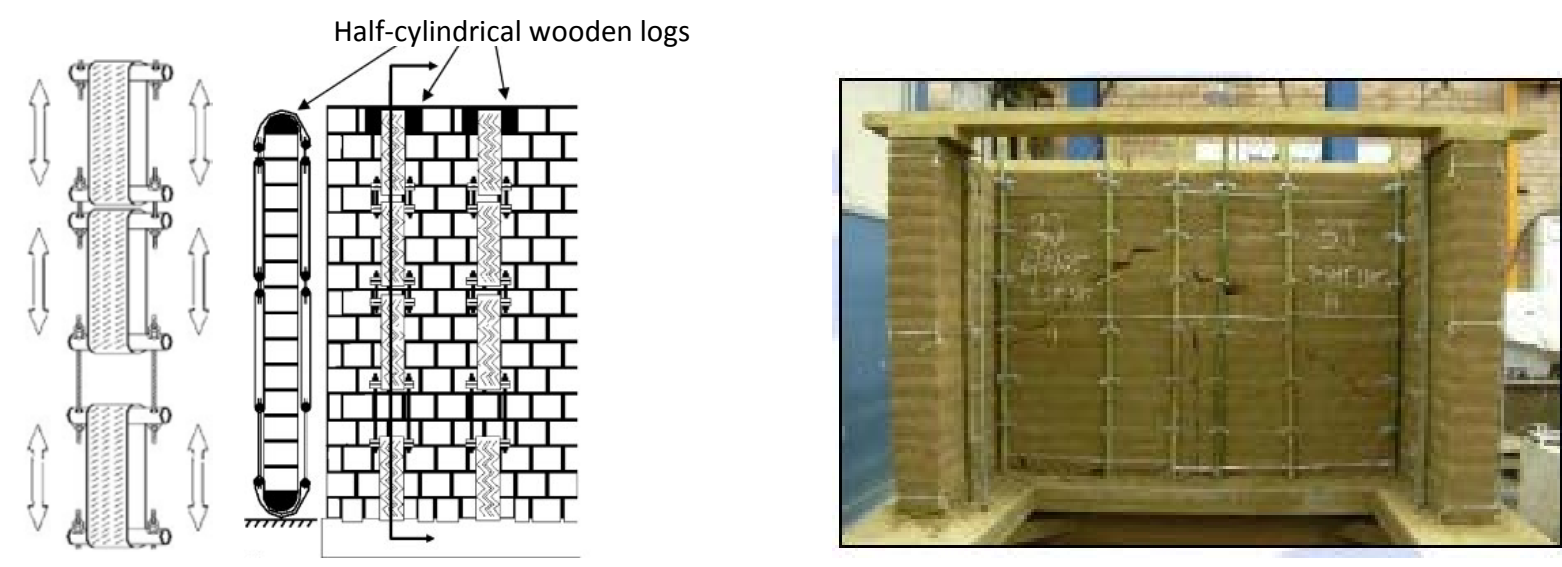

Figure 4.20: Post-tensioning elastometric tyre 82 straps on walls (Turer, Korkmaz, \& Korkmaz, 2007)
Figure 4.21: External bamboo reinforcement (Dowling \& Samali, 2006)

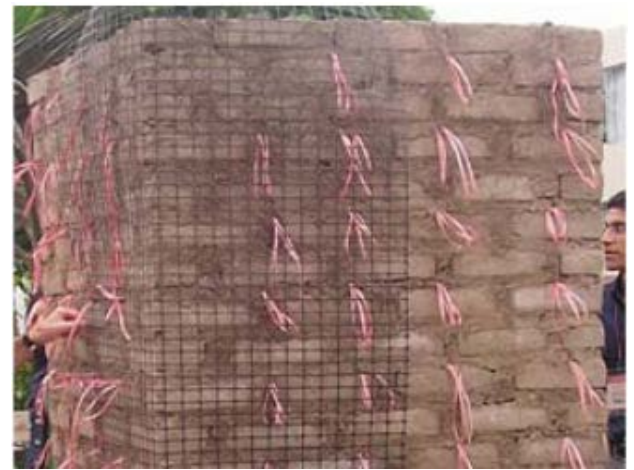

Figure 4.22: Polymer mesh reinforcement (Asian Disaster Preparedness Center, 2010) 


\begin{tabular}{|c|c|c|c|c|c|c|}
\hline \multirow[t]{2}{*}{ Structural Elements } & \multirow[t]{2}{*}{ Retrofitting Technologies } & \multirow[t]{2}{*}{ Visual } & \multirow[t]{2}{*}{ Comments } & \multicolumn{3}{|c|}{ Wall Materials } \\
\hline & & & & Brick & Mud & Stone \\
\hline \multirow[t]{2}{*}{$\begin{array}{l}\text { Wall strength } \\
\text { (contd.) }\end{array}$} & $\begin{array}{l}\text { - Polypropylene band mesh } \\
\text { o The building is wrapped from inside and outside by cut mesh with some overlap } \\
\text { and the polypropylene (PP)-band meshes are fixed at the foundation layer. } \\
\text { o Inner and outer meshes are connected by wires and aluminium plates }(2 \times 2 \mathrm{~cm}) \text {. } \\
\text { The meshes around the openings are overlapped onto the other side of the wall } \\
\text { and fixed with connectors. }\end{array}$ & $\begin{array}{l}\text { Figure } \\
4.23\end{array}$ & & $\checkmark$ & $\checkmark$ & $\checkmark$ \\
\hline & $\begin{array}{l}\text { - Inserting new walls can reduce the asymmetry and compartmentalize long wall } \\
\text { openings for stability } \\
\text { o To connect the new walls with old, a number of keys can be made in the old } \\
\text { walls and steel rods inserted in them with local cement infill. } \\
\text { o Depending on the case, a connection can be achieved by a number of steel bars } \\
\text { inserted in small length drilled holes which substitute keys. Appropriate } \\
\text { thickness of walls are (Desai \& Desai, } 2008 \text { ): } \\
\text { - Brick masonry: in mud mortar }=340 \mathrm{~mm} \text {; in cement mortar }=230 \mathrm{~mm} \\
\text { - Stone masonry: in mud mortar }=450 \mathrm{~mm} \text {; in cement mortar }=380 \mathrm{~mm}\end{array}$ & $\begin{array}{l}\text { Figure } \\
4.26\end{array}$ & & $\checkmark$ & $\checkmark$ & $\checkmark$ \\
\hline
\end{tabular}

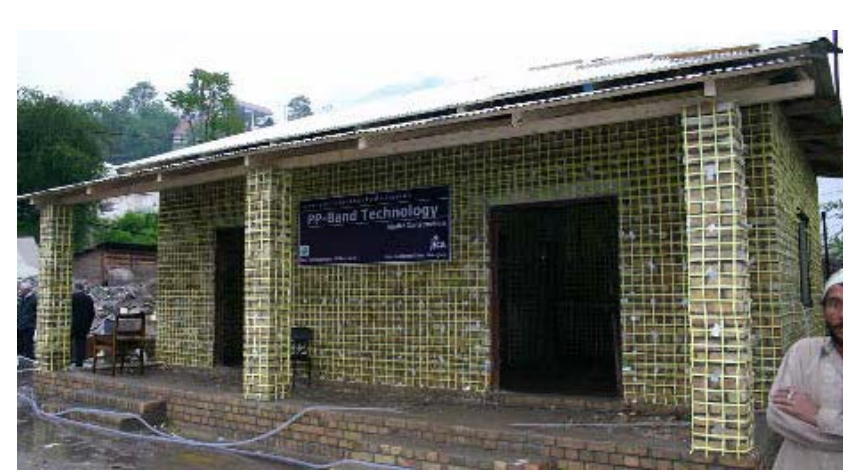

Figure 4.23: PP-band mesh around the walls (Mayorca \& Meguro, 2008)

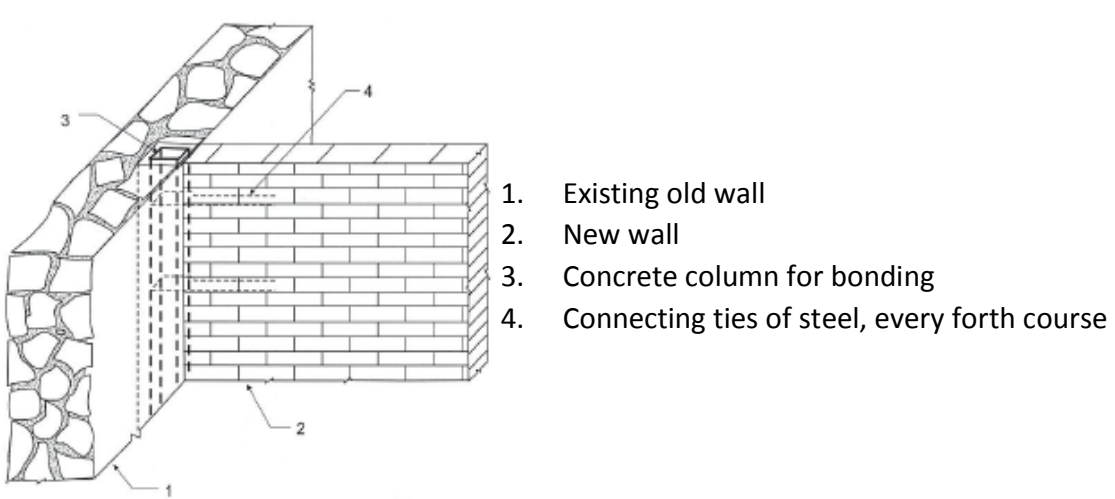

Figure 4.24: Connection of new and old walls at T-junction (IAEE, 2001) 


\begin{tabular}{|c|c|c|c|c|c|c|}
\hline \multirow[t]{2}{*}{ Structural Elements } & \multirow[t]{2}{*}{ Retrofitting Technologies } & \multirow[t]{2}{*}{ Visual } & \multirow[t]{2}{*}{ Comments } & \multicolumn{3}{|c|}{ Wall Materials } \\
\hline & & & & Brick & Mud & Stone \\
\hline \multirow[t]{3}{*}{$\begin{array}{l}\text { Wall-to-wall } \\
\text { connection }\end{array}$} & $\begin{array}{l}\text { - Previously mentioned wall reinforcement techniques that are effective for wall-to- } \\
\text { wall connections also: tie column, horizontal and vertical WWM seismic belts, } \\
\text { polymer mesh, and tyre strap reinforcement. }\end{array}$ & & & N/A & $\mathrm{N} / \mathrm{A}$ & $\mathrm{N} / \mathrm{A}$ \\
\hline & $\begin{array}{l}\text { - Provision of wooden bracing at regular interval in walls } \\
\text { o Can be applied to both inner and outer sides of the walls. }\end{array}$ & $\begin{array}{l}\text { Figure } \\
4.25\end{array}$ & & $\checkmark$ & $\checkmark$ & $\checkmark$ \\
\hline & $\begin{array}{l}\text { - Dowels at corners and junctions can be used when connecting seismic belts ending } \\
\text { on one face of wall to the belt on other face } \\
\text { o 'L' shaped TOR bars can be inserted on holes through the wall connecting the } \\
\text { two belts. }\end{array}$ & $\begin{array}{l}\text { Figure } \\
4.26\end{array}$ & & $\checkmark$ & $\checkmark$ & $\checkmark$ \\
\hline
\end{tabular}

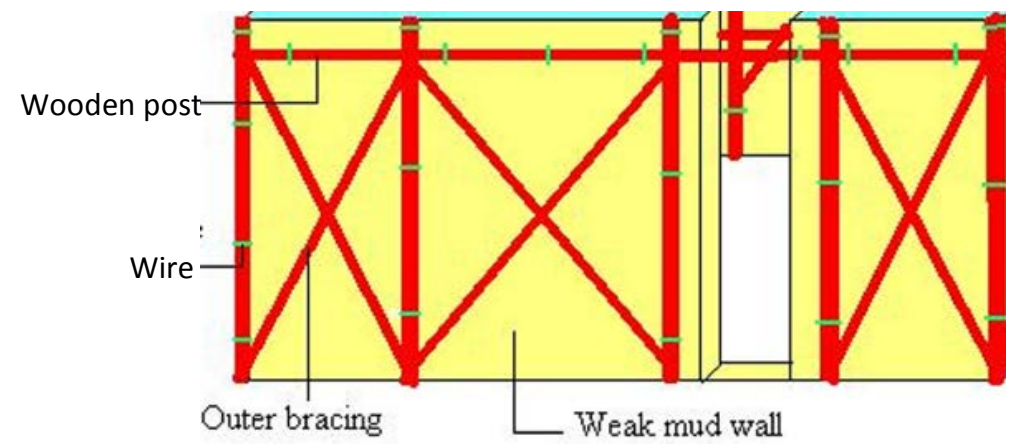

Figure 4.25: Provision of wooden bracing at regular intervals in walls (Das, Islam, Alam, \& Hoque, 2007)

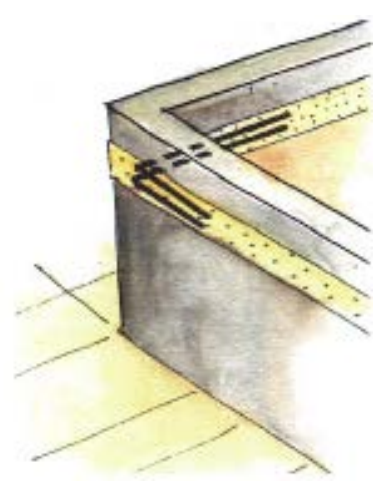

Figure 4.26: Using dowels for belt continuity through wall (Desai \& Desai, 2007) 


\begin{tabular}{|c|c|c|c|c|c|c|}
\hline \multirow[t]{2}{*}{ Structural Elements } & \multirow[t]{2}{*}{ Retrofitting Technologies } & \multirow[t]{2}{*}{ Visual } & \multirow[t]{2}{*}{ Comments } & \multicolumn{3}{|c|}{ Wall Materials } \\
\hline & & & & Brick & Mud & Stone \\
\hline $\begin{array}{l}\text { Wall-to-wall } \\
\text { connection (contd.) }\end{array}$ & $\begin{array}{l}\text { - Tie-beam to tie-column connection } \\
\text { o Tie-column reinforcement is extended into the tie-beam as much as possible, } \\
\text { preferably up to the underside of the top tie-beam reinforcement, and a } \\
\text { hooked anchorage is provided }\left(90^{\circ} \text { hooks) for both the tie-column and tie-beam }\right. \\
\text { reinforcement. }\end{array}$ & $\begin{array}{l}\text { Figure } \\
4.27\end{array}$ & & $\checkmark$ & $\checkmark$ & $\checkmark$ \\
\hline \multirow[t]{2}{*}{$\begin{array}{l}\text { Wall-roof } \\
\text { connections }\end{array}$} & $\begin{array}{l}\text { - Bracing of frame (knee-brace/diagonal brace) to strengthen post-to-beam } \\
\text { connections using timber or steel elements } \\
\text { o One knee brace is installed for each beam resting on column from different } \\
\text { directions. }\end{array}$ & $\begin{array}{l}\text { Figure } \\
4.28\end{array}$ & $\begin{array}{l}\text { Possible if there are } \\
\text { existing wooden posts } \\
\text { already }\end{array}$ & $\checkmark$ & $\checkmark$ & $\checkmark$ \\
\hline & $\begin{array}{l}\text { - Anchor roof to walls with brackets } \\
\text { o Brackets can be installed on the wall with mechanical anchors such as expansion } \\
\text { bolts. } \\
\text { o Anchor plates on seismic belts can also be anchored with brackets. }\end{array}$ & $\begin{array}{l}\text { Figure } \\
4.29\end{array}$ & & $\checkmark$ & & \\
\hline
\end{tabular}
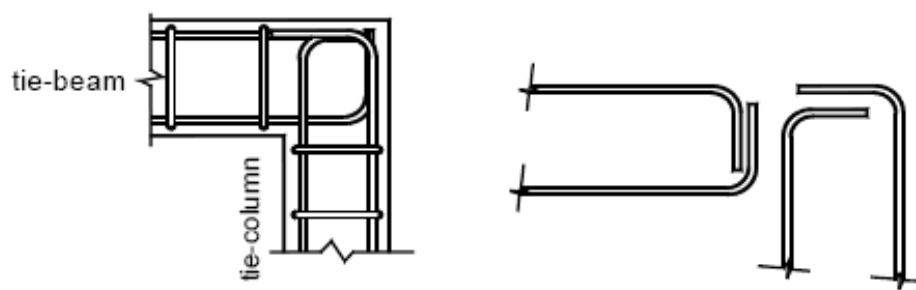

Figure 4.27: Tie-beam-to-tie-column connection (S. Brzev, 2007)

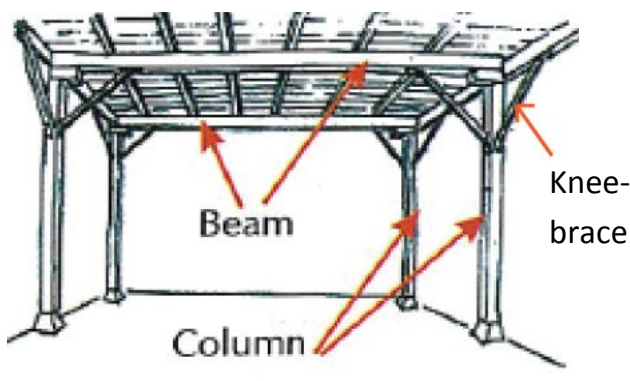

Figure 4.28: Knee-bracing for post-tobeam connection (Desai \& Desai, 2008)

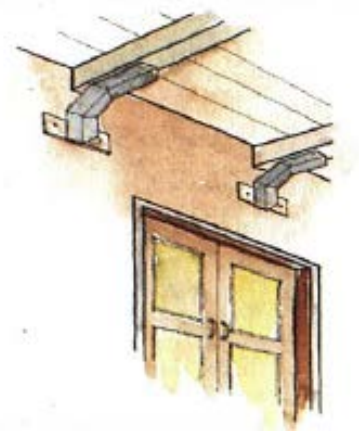

Figure 4.29: Brackets to anchor roof to wall (Desai \& Desai, 2007) 


\begin{tabular}{|c|c|c|c|c|c|c|}
\hline \multirow[t]{2}{*}{ Structural Elements } & \multirow[t]{2}{*}{ Retrofitting Technologies } & \multirow[t]{2}{*}{ Visual } & \multirow[t]{2}{*}{ Comments } & \multicolumn{3}{|c|}{ Wall Materials } \\
\hline & & & & Brick & Mud & Stone \\
\hline \multirow[t]{2}{*}{$\begin{array}{l}\text { Wall-roof } \\
\text { connections } \\
\text { (contd.) }\end{array}$} & $\begin{array}{l}\text { - Single vertical reinforcing bar } \\
\text { o The vertical bar can be placed at the bottom of an excavated flooring area bent } \\
\text { in ' } L \text { ' shape, and going up the height of the wall, it can be connected through } \\
\text { shear connectors in both walls intersecting at the corner or junction. } \\
\text { o Concrete is poured to completely encase the entire length of the vertical bar. } \\
\text { o Where roof is of RC slab, the bottom concrete cover is broken to expose the } \\
\text { slab reinforcing bars and the top bent portion of the vertical bar is connected to } \\
\text { the exposed bars of the slab using binding wires. } \\
\text { o The bar must be installed at the inside corner of a wall-to-wall ' } L \text { ' type junction. } \\
\text { In the case of a 'T' junction it may be installed on either side of the junction. }\end{array}$ & $\begin{array}{l}\text { Figure } \\
4.30 \\
\text { and } \\
4.31\end{array}$ & $\begin{array}{l}\text { For RC slabs, a better } \\
\text { detail is of the vertical } \\
\text { bar to be taken right } \\
\text { through the slab and } \\
\text { then bent over as per } \\
\text { Figure } 4.31 .\end{array}$ & $\checkmark$ & $\checkmark$ & $\checkmark$ \\
\hline & $\begin{array}{l}\text { - Vertical seismic belt } \\
\text { o When it is not possible to install a vertical rod inside a room because of some } \\
\text { obstruction, welded wire mesh belt can be used on the outside of ' } L \text { ' type wall- } \\
\text { to-wall junction, and in a flat configuration on the outside of a ' } T \text { ' type junction. } \\
\text { o The installation technique is the same as (refer to pg. 77) except that it is } \\
\text { vertical in orientation. }\end{array}$ & $\begin{array}{l}\text { Figure } \\
4.32\end{array}$ & & $\checkmark$ & $\checkmark$ & $\checkmark$ \\
\hline
\end{tabular}

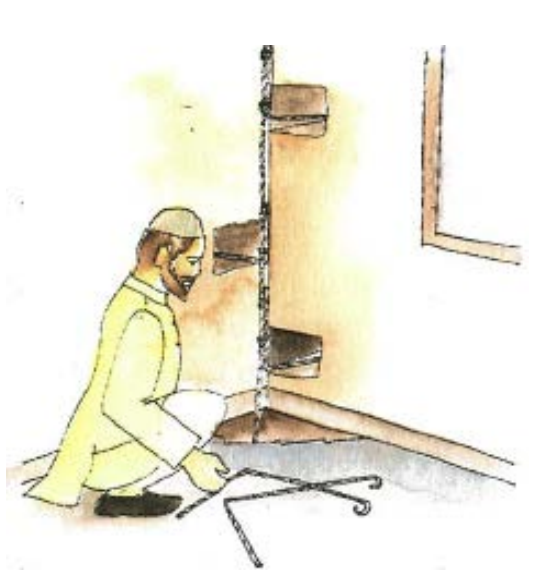

Figure 4.30: Internal vertical reinforcing bar in corner (Desai \& Desai, 2007)

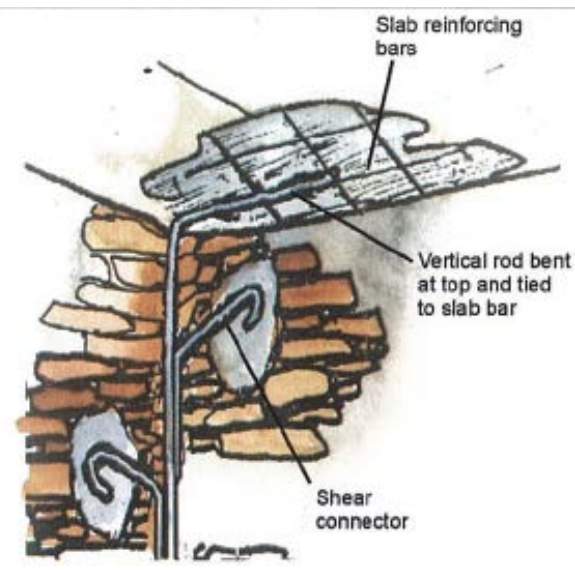

Figure 4.31: Internal connections when inserting vertical bar (Desai \& Desai, 2007)

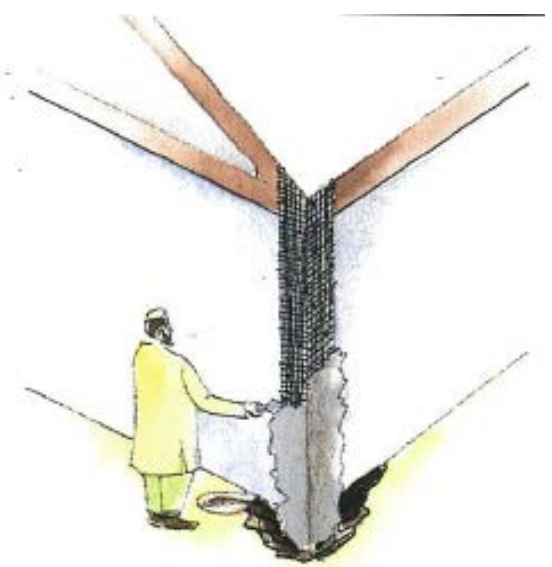

Figure 4.32: External vertical seismic WWM belt (Desai \& Desai, 2007) 


\begin{tabular}{|c|c|c|c|c|c|c|c|c|c|}
\hline \multirow[t]{2}{*}{ Structural Elements } & \multicolumn{4}{|c|}{ Retrofitting Technologies } & \multirow[t]{2}{*}{ Visual } & \multirow[t]{2}{*}{ Comments } & \multicolumn{3}{|c|}{ Wall Materials } \\
\hline & & & & & & & Brick & Mud & Stone \\
\hline \multirow[t]{6}{*}{ Wall openings } & \multicolumn{4}{|c|}{ - Reduce large openings } & \multirow{5}{*}{\begin{tabular}{|l|} 
Figure \\
4.33
\end{tabular}} & \multirow{5}{*}{$\begin{array}{l}\text { Openings should } \\
\text { always be centrally } \\
\text { located. }\end{array}$} & \multirow[t]{5}{*}{$\checkmark$} & \multirow[t]{5}{*}{$\checkmark$} & \multirow[t]{5}{*}{$\checkmark$} \\
\hline & Building type & $\begin{array}{l}\text { Total Openings on } \\
\text { wall }(A+B+C) \text { as } \% \text { of } \\
\text { the total length }(L)\end{array}$ & $\begin{array}{l}\text { Spacing between } \\
\text { openings (D) }\end{array}$ & $\begin{array}{l}\text { Distance of } \\
\text { opening from } \\
\text { corner of wall (E) }\end{array}$ & & & & & \\
\hline & $\begin{array}{l}\text { Masonry in mud } \\
\text { mortar* }\end{array}$ & $33 \% \max$ & $600 \mathrm{~mm}$ & $600 \mathrm{~mm}$ & & & & & \\
\hline & $\begin{array}{l}\text { Masonry in } \\
\text { cement mortar* }\end{array}$ & $50 \% \max$ & $\begin{array}{l}560 \mathrm{~mm} \text { (brick), } \\
600 \mathrm{~mm} \text { (stone) }\end{array}$ & $\begin{array}{l}450 \mathrm{~mm}, \\
1200 \mathrm{~mm} \text { (adobe) }\end{array}$ & & & & & \\
\hline & \multicolumn{4}{|c|}{$\begin{array}{l}\text { *for one storey building in Seismic Zone IV (India) } \\
\text { o The opening can be reduced by placing a structural reinforcement in the area to } \\
\text { be filled. For example, inserting a tie column to the remaining area. }\end{array}$} & & & & & \\
\hline & \multicolumn{4}{|c|}{$\begin{array}{l}\text { - Lintel belts } \\
\text { o Seismic belts of welded wire mesh (WWM) that can be incorporated at all } \\
\text { door and window lintels. } \\
\text { O Where the belt alignment crosses an opening, the reinforcement of the bars } \\
\text { and the WWM without plaster can either be continued, or can be discontinued } \\
\text { and replaced with a rod across the opening with adequate overlap. }\end{array}$} & $\begin{array}{l}\text { Figure } \\
4.34\end{array}$ & & $\checkmark$ & $\checkmark$ & $\checkmark$ \\
\hline
\end{tabular}

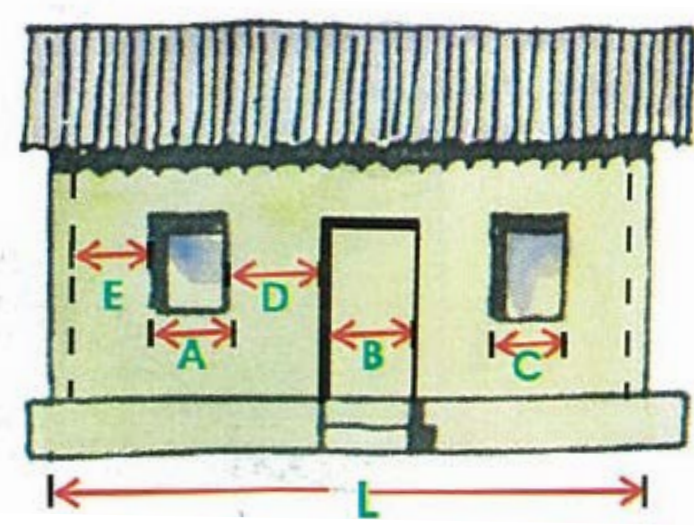

Figure 4.33: Appropriate wall opening specifications (Desai \& Desai, 2008)

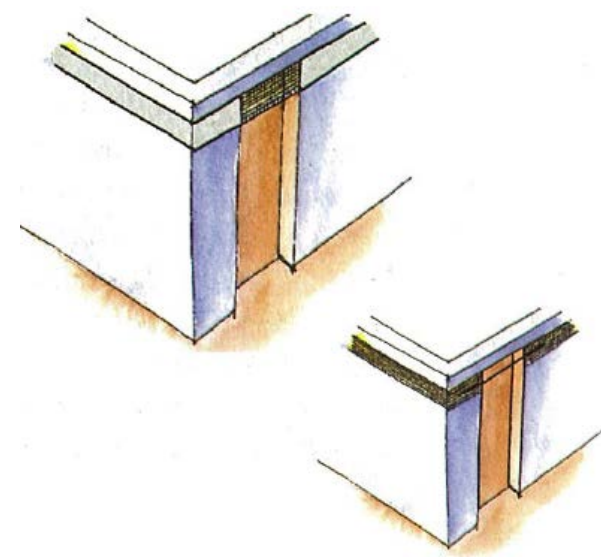

Figure 4.34: Belt reinforcement at openings (Desai \& Desai, 2007) 


\begin{tabular}{|c|c|c|c|c|c|c|}
\hline \multirow[t]{2}{*}{ Structural Elements } & \multirow[t]{2}{*}{ Retrofitting Technologies } & \multirow[t]{2}{*}{ Visual } & \multirow[t]{2}{*}{ Comments } & \multicolumn{3}{|c|}{ Wall Materials } \\
\hline & & & & Brick & Mud & Stone \\
\hline $\begin{array}{l}\text { Wall openings } \\
\text { (contd.) }\end{array}$ & $\begin{array}{l}\text { - Proper peripheral reinforcement } \\
\text { o Can be applied on one face of a wall around every opening. } \\
\text { o The installation procedure is exactly the same as that used for the horizontal } \\
\text { and vertical seismic belt (pg. } 76 \text { and } 85 \text { ). } \\
\text { o If lintel belt is installed, the encasement belt is required only on the side and } \\
\text { under the window openings (for window openings), and only on the sides of } \\
\text { doors (for doors). }\end{array}$ & $\begin{array}{l}\text { Figure } \\
4.35\end{array}$ & & $\checkmark$ & & $\checkmark$ \\
\hline \multirow[t]{2}{*}{$\begin{array}{l}\text { Foundation-wall } \\
\text { connection }\end{array}$} & $\begin{array}{l}\text { - Steel mesh or wooden dowels at corners and junctions } \\
0 \text { This can be installed as part of the RC strip foundation }\end{array}$ & & & $\checkmark$ & $\checkmark$ & $\checkmark$ \\
\hline & $\begin{array}{l}\text { - Horizontal seismic belt at plinth level } \\
\text { o Refer to the seismic belt section for detail (pg. 77) } \\
\text { o Should be constructed on top of the foundation }\end{array}$ & $\begin{array}{l}\text { Figure } \\
4.36\end{array}$ & $\begin{array}{l}\text { Essentially for new } \\
\text { construction; probably } \\
\text { too complicated for a } \\
\text { retrofitting. }\end{array}$ & $\checkmark$ & & $\checkmark$ \\
\hline
\end{tabular}

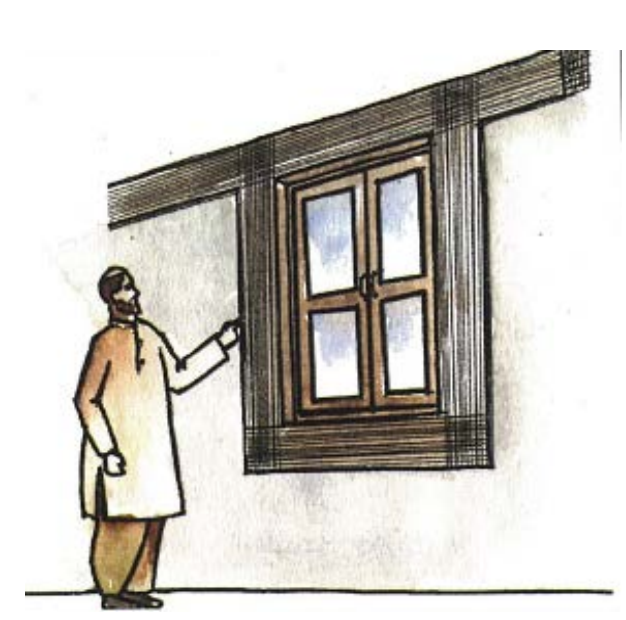

Figure 4.35: Peripheral WWM reinforcement around window opening (Desai \& Desai, 2007)

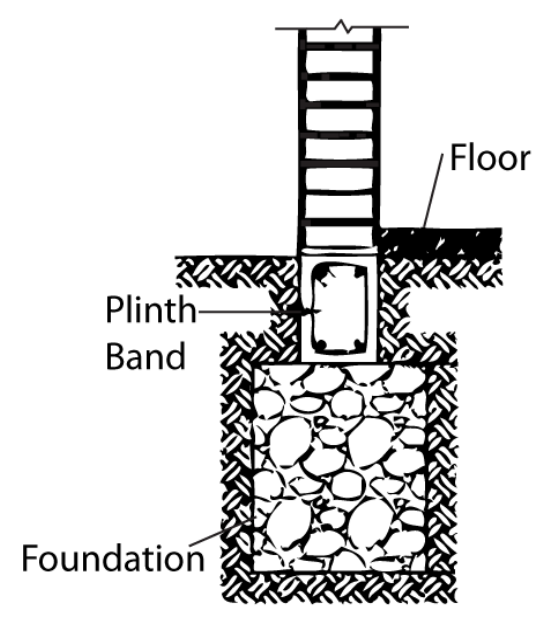

Figure 4.36: Inserting plinth band above the foundation (S. Brzev, 2007) 


\begin{tabular}{|c|c|c|c|c|c|c|}
\hline \multirow[t]{2}{*}{ Structural Elements } & \multirow[t]{2}{*}{ Retrofitting Technologies } & \multirow[t]{2}{*}{ Visual } & \multirow[t]{2}{*}{ Comments } & \multicolumn{3}{|c|}{ Wall Materials } \\
\hline & & & & Brick & Mud & Stone \\
\hline Foundations & $\begin{array}{l}\text { - Reinforced concrete strip foundations } \\
\text { o RC strips can be attached to both sides of the existing foundation linked by a } \\
\text { number of keys inserted into the existing footing. } \\
\text { o The extra width may be provided above or at the level of the existing footing. }\end{array}$ & $\begin{array}{l}\text { Figure } \\
4.37 \\
\text { and } \\
4.38\end{array}$ & $\begin{array}{l}\text { Is a complicated } \\
\text { process as proper } \\
\text { investigation and } \\
\text { design is called for. }\end{array}$ & $\checkmark$ & $\checkmark$ & $\checkmark$ \\
\hline $\begin{array}{l}\text { Column } \\
\text { Reinforcement }\end{array}$ & $\begin{array}{l}\text { - Strengthen masonry column with jacketing } \\
\text { o Remove the plaster and rake the joints; install shear connectors in pre-drilled } \\
\text { holes in columns for anchoring vertical rods to them; install two rods on each } \\
\text { face along with column-ties; at top connect the bars with rebars of slab or } \\
\text { beams with adequate overlap; cover all reinforcement including joint at top } \\
\text { with cement mortar. } \\
\text { o An alternative to jacketing is attaching a wooden post to the column and } \\
\text { wrapping it around the column so as to improve its function. (Desai \& Desai, 2008) }\end{array}$ & $\begin{array}{l}\text { Figure } \\
4.39\end{array}$ & & $\checkmark$ & & $\checkmark$ \\
\hline
\end{tabular}

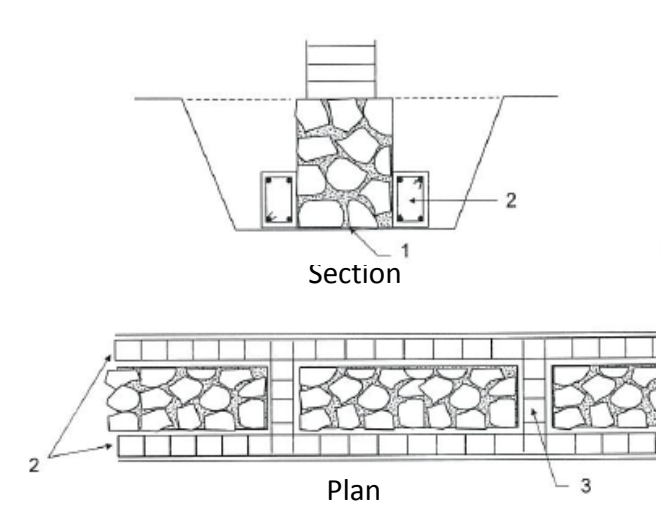

Figure 4.37: Inserting RC beams for foundation strengthening (IAEE, 2001)

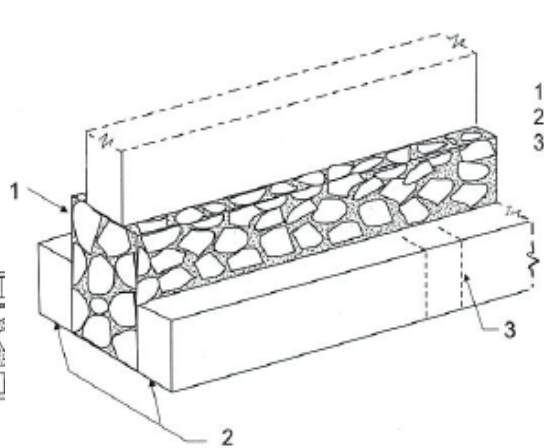

1 - Old foundation - New concrete beams - Connecting lateral
concrete beams

Figure 4.38: RC strip foundation (alternative

Fo

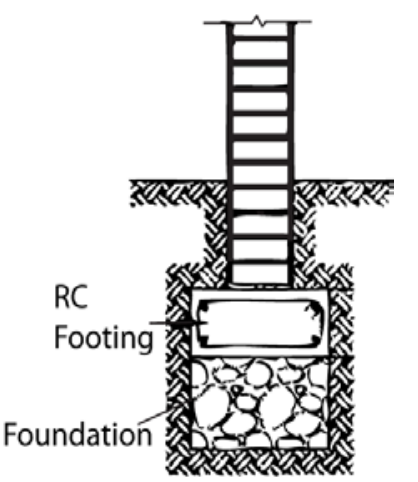

arrangement) (S. Brzev, 2007)

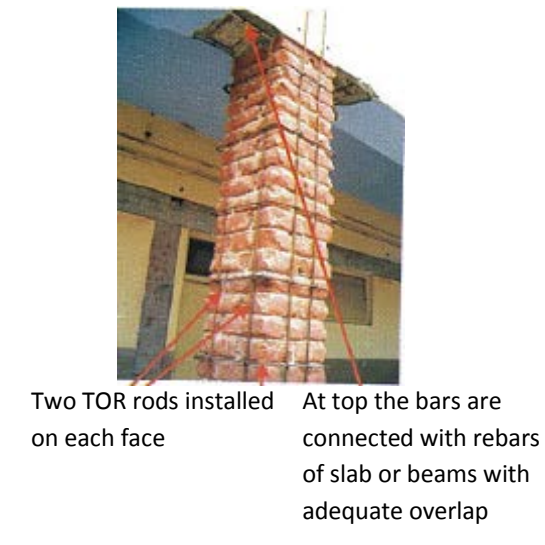

Figure 4.39: Jacketing of masonry column (Desai \& Desai, 2008) 
In addition to the retrofitting techniques mentioned in the table, there are also other 'indirect' strengthening measures that can be applied for better performance during earthquakes. These include improving the drainage around the building foundation to prevent saturation of foundation soil to obviate any problems of liquefaction (IAEE, 2001). An impermeable apron can be applied around the building to drain off the water before direct contact with the foundation. Replacing a false ceiling of brittle material with non-brittle material like hessian cloth, bamboo matting, or light foam substances is also another technique to improve seismic performance (IAEE, 2001). Likewise, re-pointing of exterior walls in cement mortar is often carried out as part of the retrofitting process and can help improve the strength of the mortar.

Although retrofitting the structural elements is the first priority, non-structural elements can also be very dangerous in earthquakes. Though these are not discussed in detail in the table being beyond the scope of this research, it is worth mentioning that for residential housing, parapets and chimneys projecting above the roof are subjected to greatly amplified motion and easily fail by bending and overturning. These failures can be eliminated by properly tying elements to the lower structure for better performance.

The quality of workmanship is also important and is reflected in the performance of the structure during ground shaking. Some techniques are more complicated than others and may require special knowledge or training which is almost as important as the cost factor in carrying out a retrofit. When properly implemented however, these retrofitting techniques can strengthen the weak non-engineered structure and provide increased safety from earthquakes.

\subsection{Summary}

Earthquakes are unpredictable, irregular, and vastly damaging geological events. When combined with poorly built masonry structures of developing countries, the result can be fatal. Though earthquake prediction is yet to be an accurate science, at least buildings can be designed to withstand these additional loads, ensuring life safety by providing a longer collapse time.

The brittle and weak characteristics of non-engineered masonry houses result in great vulnerability; tragically proven time and time again, through distinctive failure patterns. In an effort to reduce full collapse, several new reinforcing systems have been developed by researchers. Techniques applicable to 
strengthen a masonry house in its post-construction phase are useful as they are economically and socially feasible for the low-income population. These retrofit solutions present the basis on which possible modifications can be discussed for the integration of thermal comfort features. These integrative solutions are presented in the following chapter. 


\section{Integrative Solutions}

The information presented in the previous two chapters form the basis of the integrative solutions presented here. The previously identified appropriate retrofitting strategies are matched with the recommended passive comfort strategies for the three different regions, and possible integrative techniques are investigated. Finally, the techniques appropriate for each region are listed and discussed in greater detail with the use of diagrams and text.

\subsection{Possible techniques}

The climatic analysis and discomfort indices presented in Chapter 3, identified the three types of passive comfort strategies applicable to the regions of this study: ventilation, high thermal mass with or without night ventilation, and passive heating. Similarly, Chapter 4 identified several retrofitting techniques that could be applied to non-engineered residential buildings.

In order to explore possible integration of the comfort and structural improvement strategies, a working matrix is set in place (see Table 5.1). Due to the limitations of this study in terms of economic, social, and technological constraints of the population in consideration, the integrative possibilities are also limited. Furthermore, it must also be understood that not all retrofitting techniques allow room for integration due to their primary requirement to maintain structural integrity, and hence the scope for integrative solutions are also limited.

A fact to be noted is that several passive comfort techniques, especially shading and passive solar gain, are dependent on building and site orientation. However, since this study is limited to improvements on existing houses, the consideration of factors such as building configuration and landscaping are omitted. However, by understanding the orientation of the existing building and the sun's movement in relation to it, effective outcomes can be produced if the integrative techniques are applied to the appropriate facades of the building.

It is also necessary to define the extent to which an idea can be considered 'integrative'. For example, utilizing a soaked jute mat and letting air through it is often recommended as a passive cooling solution in India as it cools the interior via evaporation. However, this cannot be considered as an integrative 
technique if it is hung from the collar beam and located near a ventilation channel; it is not appropriate since no modification of the original retrofitting technique is implied. Techniques such as this are more considered of an addition of two techniques rather than integration, and therefore are not included as part of the integrative techniques table. Though not addressed in this study, this type of technique can still be utilized effectively to improve the comfort level within the building.

The following matrix presents the integrative solutions in coloured cells; blue indicates that the suggested technique is appropriate for cooling, while green indicates that the technique can be used for both heating or cooling (mostly the case for insulation so as the optimum interior thermal condition can be maintained for longer). Multiple techniques can be used together to provide an effective level of thermal comfort. These solutions are then described in detail with diagrams and text explanations. 
Table 5.1: Integrative solutions matrix

\begin{tabular}{|c|c|c|c|c|}
\hline $\begin{array}{l}\text { Elements } \\
\text { Requiring Retrofit }\end{array}$ & Retrofitting Technology & Insulation & Ventilation & Shading \\
\hline \multirow[t]{5}{*}{ Roof } & Diagonal struts and braces & & & \\
\hline & Tying rafters to the roof truss & & & \\
\hline & Anchoring roofing tiles and sheeting to the structure & & & \\
\hline & $\begin{array}{l}\text { Weight reduction of the roof by reducing the mud } \\
\text { overlay thickness atop the roof to } 200 \mathrm{~mm}\end{array}$ & $\begin{array}{l}\text { Insert a layer of } \\
\text { insulation material } \\
\text { followed by a plastic } \\
\text { layer for weather- } \\
\text { proofing sandwiched in } \\
\text { mud } \\
\text { (see Figure 5.1) }\end{array}$ & & \\
\hline & Diagonal collar beams between the rafters & & & \\
\hline \multirow[t]{6}{*}{ Wall strength } & $\begin{array}{l}\text { Installation of seismic belt } \\
\text {-eaves/roof belt } \\
\text {-gable belt } \\
\text {-ridge band } \\
\text {-ensure the continuity of the seismic belt }\end{array}$ & & & $\begin{array}{l}\text { The seismic belt can be } \\
\text { extended beyond the } \\
\text { wall surface to provide } \\
\text { external shading over } \\
\text { the windows } \\
\text { (see Figure } 5.2 \text { ) }\end{array}$ \\
\hline & $\begin{array}{l}\text { Stitching wall wythes together by installing cast in-situ } \\
\text { RC bond elements }\end{array}$ & & \multirow{2}{*}{$\begin{array}{l}\text { A roughened bamboo } \\
\text { pipe can be put } \\
\text { through the wall } \\
\text { wythes instead of an RC } \\
\text { bond element; or a } \\
\text { hollow pipe can be } \\
\text { used with metal ties } \\
\text { (see Figure 5.3, 5.4, 5.5, } \\
5.6 \text { and 5.7) }\end{array}$} & \\
\hline & Installation of through-stones & & & \\
\hline & Strengthening with plastered wire mesh & \multirow{3}{*}{$\begin{array}{l}\text { A layer of insulation } \\
\text { material can be put in } \\
\text { between the wall and } \\
\text { the layer of wire mesh } \\
\text { and reinforced cement } \\
\text { coating, attached } \\
\text { through reinforcing } \\
\text { steel bars and concrete } \\
\text { infill to tie everything }\end{array}$} & & \\
\hline & Shotcrete the walls & & & \\
\hline & Polymer mesh (geomesh) & & $\begin{array}{l}\text { Nylons strings for tying } \\
\text { the walls and the mesh } \\
\text { together can pass } \\
\text { through the inserted } \\
\text { bamboo pipes and also }\end{array}$ & \\
\hline
\end{tabular}




\begin{tabular}{|c|c|c|c|c|}
\hline \multirow{10}{*}{$\begin{array}{l}\text { Wall strength } \\
\text { (contd.) }\end{array}$} & \multirow[b]{2}{*}{ Polypropylene band mesh } & \multirow{2}{*}{$\begin{array}{l}\text { together. } \\
\text { (see Figure 5.8, } 5.9 \text { and } \\
5.10 \text { ) }\end{array}$} & \multirow[t]{2}{*}{$\begin{array}{l}\text { allow room for air } \\
\text { (see Figure 5.5) }\end{array}$} & \\
\hline & & & & \\
\hline & Reinforced tie-beams & & & \\
\hline & Shear connectors & & & \\
\hline & Grouting & & & \\
\hline & Addition of masonry buttresses & & & $\begin{array}{l}\text { Can also support the } \\
\text { load of adding some } \\
\text { shading over the walls } \\
\text { (in general or as in } \\
\text { Figure 5.2) } \\
\end{array}$ \\
\hline & Tyre strap reinforcement & $\begin{array}{l}\text { Instead of placing the } \\
\text { straps in rebates, they } \\
\text { could be mounted on } \\
\text { the surface and a layer } \\
\text { of insulation material } \\
\text { can be inserted } \\
\text { between the straps and } \\
\text { the wall, with mud } \\
\text { plaster applied to cover } \\
\text { (see Figure } 5.9 \& 5.10 \text { ) }\end{array}$ & & \\
\hline & Post-tensioning elastometric tyre straps & & & \\
\hline & External bamboo reinforcement & $\begin{array}{l}\text { Insulation can be put in } \\
\text { between the bamboo } \\
\text { reinforcement } \\
\text { (see Figure } 5.11 \text { ) }\end{array}$ & $\begin{array}{l}\text { Keep the hot air } \\
\text { circulating (stack effect) } \\
\text { within the bamboo to } \\
\text { prevent the heat from } \\
\text { radiating inside } \\
\text { (see Figure } 5.12 \text { ) }\end{array}$ & \\
\hline & Inserting new walls to reduce asymmetries & & & \\
\hline Wall-to-wall & Provision of wooden bracing at regular interval in walls & & & \\
\hline connection & Dowels at corners and junctions & & & \\
\hline & Tie-beam to tie-column connection & & & \\
\hline Wall-roof & Installation of metallic ties & & & \\
\hline connections & $\begin{array}{l}\text { Bracing of frame (knee-brace/diagonal brace) to } \\
\text { strengthen post-to-beam connections using timber or } \\
\text { steel elements }\end{array}$ & & & \\
\hline
\end{tabular}




\begin{tabular}{|l|l|l|l|}
\hline \multirow{4}{*}{} & Anchor roof to walls with brackets & & \\
\cline { 2 - 4 } & Single vertical reinforcement bar & & \\
\cline { 2 - 5 } & Vertical seismic belt & & \\
\hline \multirow{2}{*}{ Wall openings } & Reduce large openings & & \\
\cline { 2 - 5 } & Peripheral reinforcement & & \\
\hline $\begin{array}{l}\text { Foundation-wall } \\
\text { connection }\end{array}$ & Steel mesh or wooden dowels at corners and junctions & & $\begin{array}{l}\text { Extension shading over } \\
\text { the windows (see } \\
\text { Figure 5.2) }\end{array}$ \\
\hline & Horizontal seismic belt at plinth level & & \\
\hline Foundation & Reinforced concrete strip foundation & & \\
\hline $\begin{array}{l}\text { Column } \\
\text { reinforcement }\end{array}$ & Strengthen masonry column with jacketing & & \\
\hline
\end{tabular}


Since non-engineered houses often have a very heavy mud layer on the roof which is prone to collapse in earthquakes, it is suggested that the mud layer be reduced to $200 \mathrm{~m}$ or less. However, keeping in mind the reason for the thick mud layer in these regions (to provide a layer of insulation from the intense heat), the integrative technique recommends the inclusion of a light-weight insulative layer to replace the heaviness of the mud (see Figure 5.1). The roof should also have a layer of plastic sheeting underneath the insulation so that moisture is not trapped inside and can evaporate out. These layers are both sandwiched between the top and bottom mud layer to retain the original appearance, and perform the same insulative function as before while improving seismic performance.

The installation of a seismic belt at the eaves level helps ensure a continuous connection between all the walls of the structure and enables box-like behaviour during earthquakes. Extending the seismic band out into the exterior (for approx. 200mm) can allow for shading above the windows or around the periphery of the house (see Figure 5.2). However, in doing this it is necessary to ensure that the reinforcing bar which connects the belt and the wall is placed above the middle of the shade encasement and is slightly inclined. This prevents cracking at the top of the shade device.

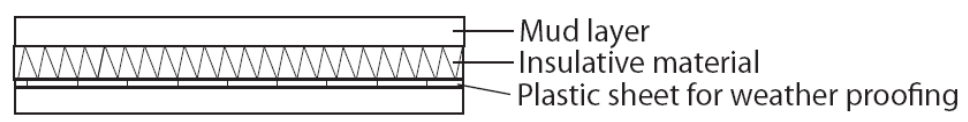

Figure 5.1: Mud roof with insulation

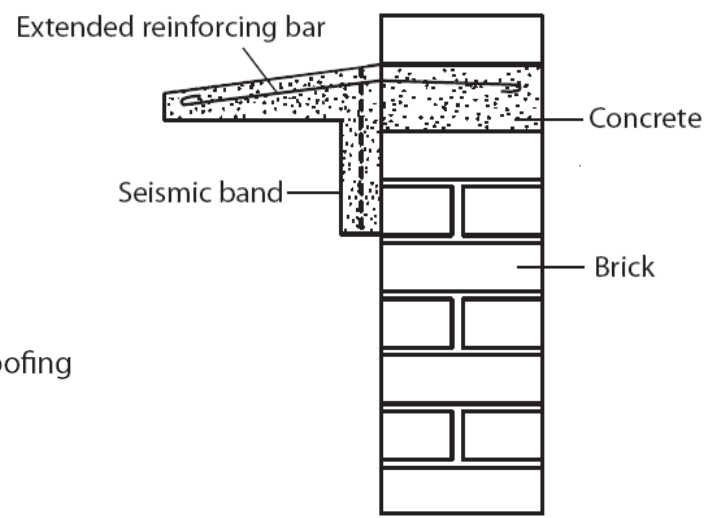

Figure 5.2: Horizontal extension of seismic belt for shading

Stone buildings, especially are prone to delamination during earthquakes because wall wythes are not stitched together. To solve this problem, installing cast in-situ reinforced concrete (RC) bond elements or through-stones is recommended. These can be modified to also function as ventilation channels. The 
bond elements or through-stones can be replaced with hollow pipes of metal or bamboo (if more readily available). An additional piece of metal ring can be attached on the pipe ends and embedded with concrete to keep it intact (see Figure 5.3 and 5.4). In the case of bamboos, small groves can be cut at the ends and concrete infill can be injected (see Figure 5.5). These pipes will act as tension ties and prevent the wall from delaminating during earthquakes. Additionally, if positioned effectively, these hollow ties can provide natural cross-ventilation to keep the room cool. If the inlet is at the bottom of the wall situated in the direction of the prevailing wind and the outlet is at the top end of the opposite wall, it will enable cool air to flow inside the room and hot air that rises to flow out (see Figure 5.6). Since these openings are small, there need to be more than one hollow pipe installed for adequate air movement. As multiple through-stones or RC bond elements need to be installed over the total area of the wall to strengthen it, where ventilation pipes are not required, regular through-stones or RC bond elements can be installed in a staggered manner (see Figure 5.7).

Section A

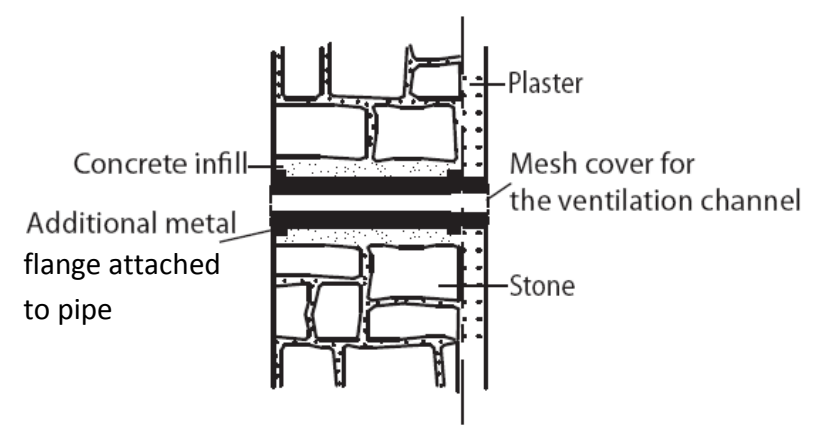

Figure 5.3: Section view of a ventilation pipe attached with metal flanges embedded in place of through-stones

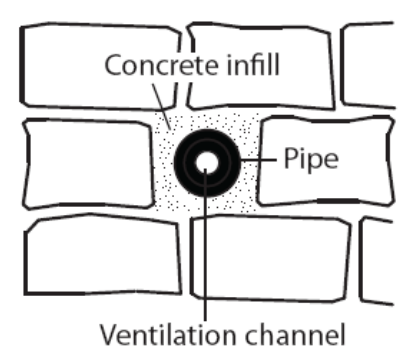

Figure 5.4: Section A -Front elevation (plaster can be layered over this and a mesh cover for the pipe can be attached to prevent insects)

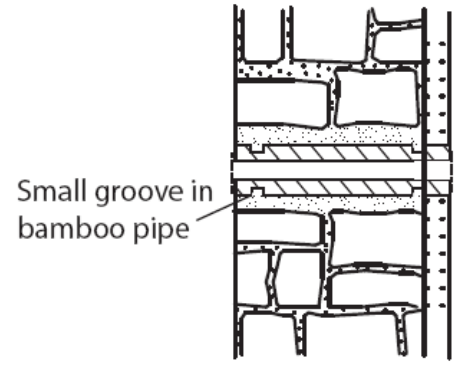

Figure 5.5: Section view of bamboo ventilation pipe 


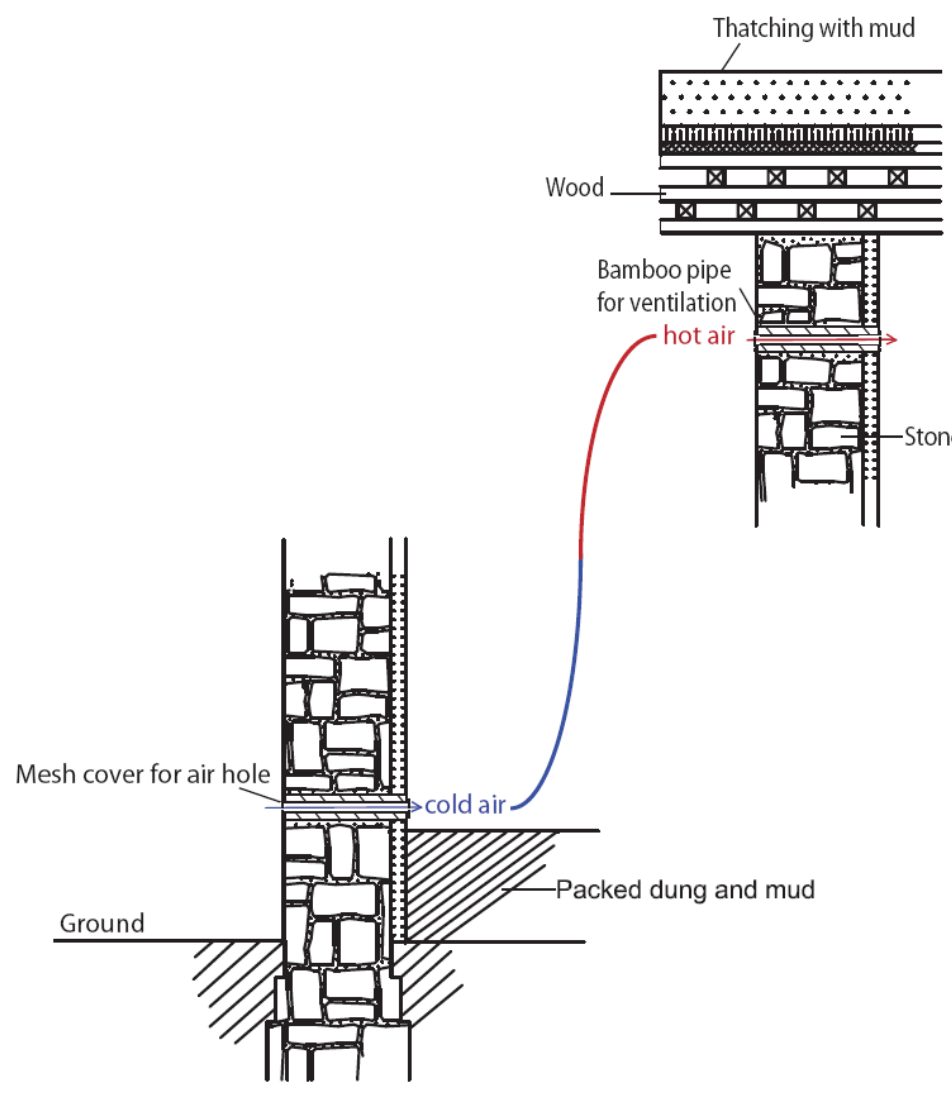

Figure 5.6: Air flow through the interior with the inlet and outlets on opposite walls for cross-ventilation

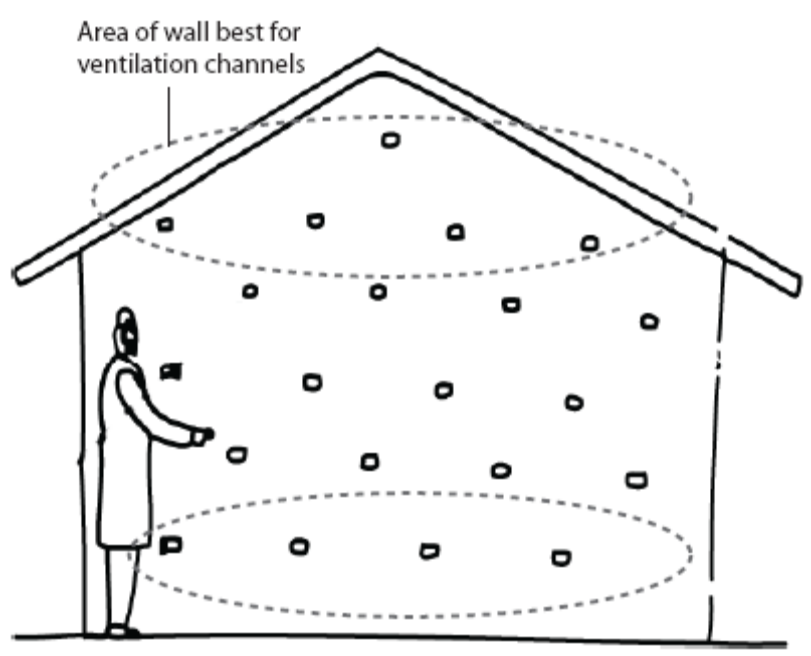

Figure 5.7: Wall areas appropriate for replacing throughstones or $\mathrm{RC}$ bond elements with ventilation pipes

Retrofitting techniques such as welded-wire mesh, polymer mesh, and polypropylene (PP)-band mesh are similar types of techniques which require the mesh to be applied all over the wall, which is then attached by nails, nylon strings, and metallic plates, respectively. By putting an insulation layer in between the wire mesh and the walls, the thermal mass of the walls can be mobilzed (see Figure 5.8). For wire mesh and PP-band mesh, a reinforcing bar which stitches the wall wythes together can be extended out through the insulation layer to be attached to the wire mesh. The concrete infill where the reinforcing bar is placed will help keep it intact and shotcreting and plastering the walls over the wire mesh layer will further strengthen it and prevent from corroding. Since polymer mesh is tied through the wall with nylon strings, bamboo ventilation pipes as in Figure 5.5 can be installed and the strings can be passed through the pipes to provide both rigidity and ventilation. When wire mesh is applied to only one side of the wall, it resists movement from only one direction, therefore in these cases the concrete layer needs to be thicker (see Figure 5.9) as opposed to when there is wire mesh on both sides (see Figure 5.10). The insulation layer can also be placed on the interior instead (provided there is wire mesh 
on that side) if required. This same form of technique can be applied to wall reinforcement with tyre straps, where instead of being placed in a rebate, the tyre straps can be mounted and a layer of insulation can be put in between the straps and the wall and then the surface can be covered in mud plaster coating.

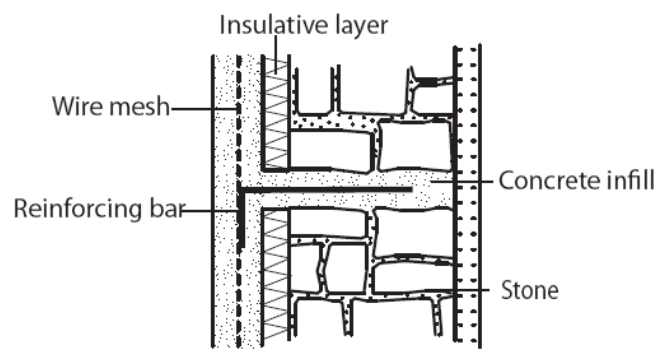

Figure 5.8: Insulation layer in between wall and wire mesh
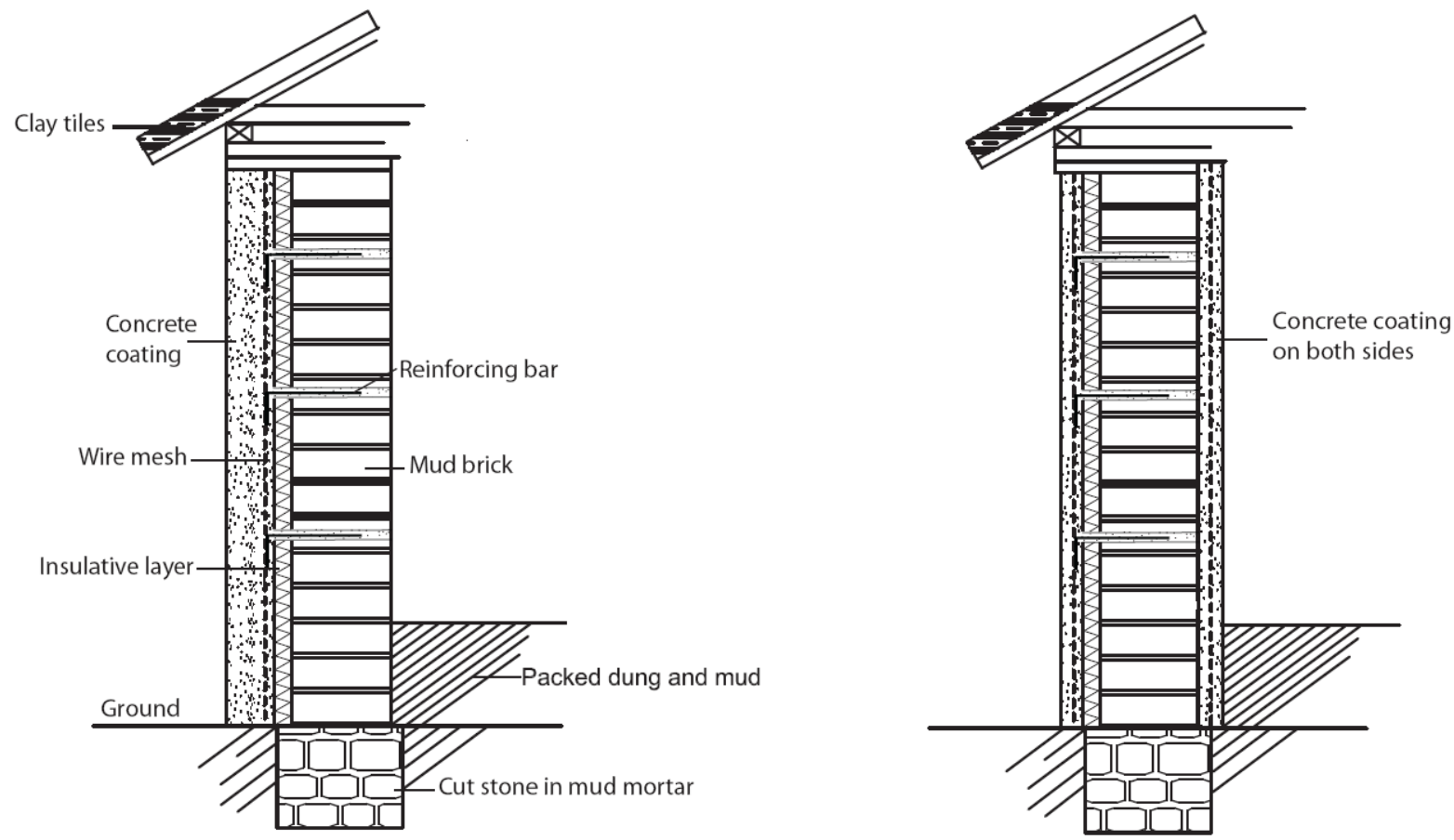

Figure 5.9: Insulation on wall with wire mesh on one side of wall

Figure 5.10: Insulation on wall with wire mesh on both sides of wall

Several orientations of external bamboo reinforcement retrofitting techniques have been tested by Dowling, Samali \& Li (2005) on adobe houses, and among the best performing test specimens were the vertical bamboos at attached to the wall with polypropylene strings. The vertical bamboo reinforcement can be attached on one side, or both sides of the wall for better resistance. As an integrative solution, 
the blocks of space that emerge in-between the adjacent bamboos can be filled with an insulative layer and plastered over to provide higher thermal mass (see Figure 5.11).
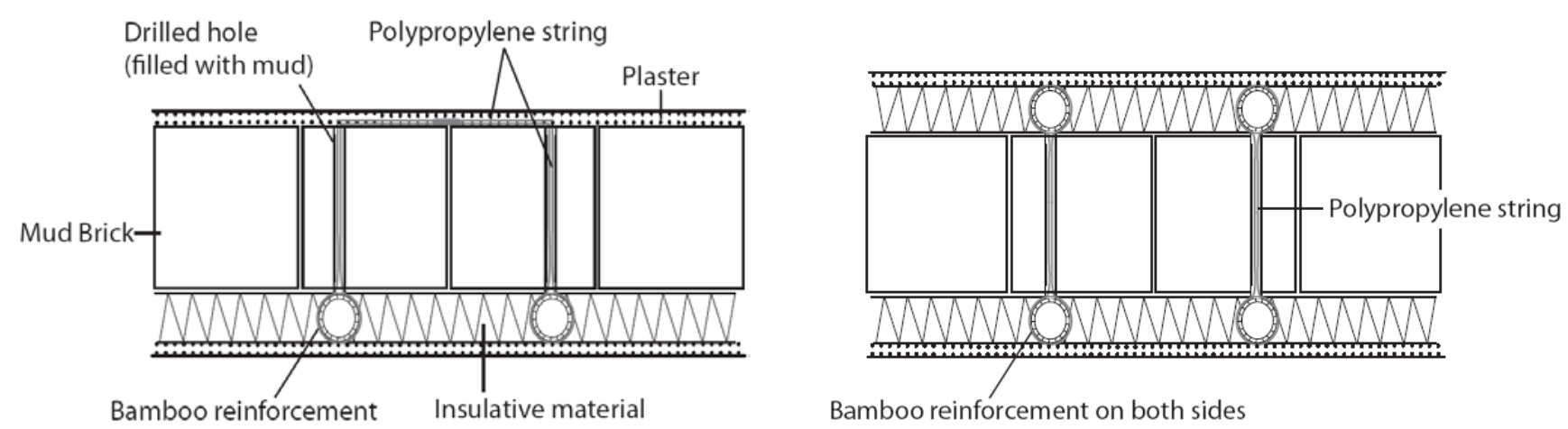

Figure 5.11: Plan view of external vertical bamboo reinforcement (on one side and both sides of wall) with additional insulation layer

The same vertical bamboo reinforcement can also be used as a means to prevent the heat from entering the building by creating a channel for air circulation within the bamboo. Following the principle of the stack effect, the aim is to regulate the hot air that rises to the exterior and reduce the amount of heat transfer to the interior of the building (see Figure 5.12). However it is likely that this integrative technique will only prove effective when there is no other form of insulation provided on the wall since its impact is assumed to be minimal. Nevertheless it can be combined with other techniques to keep the

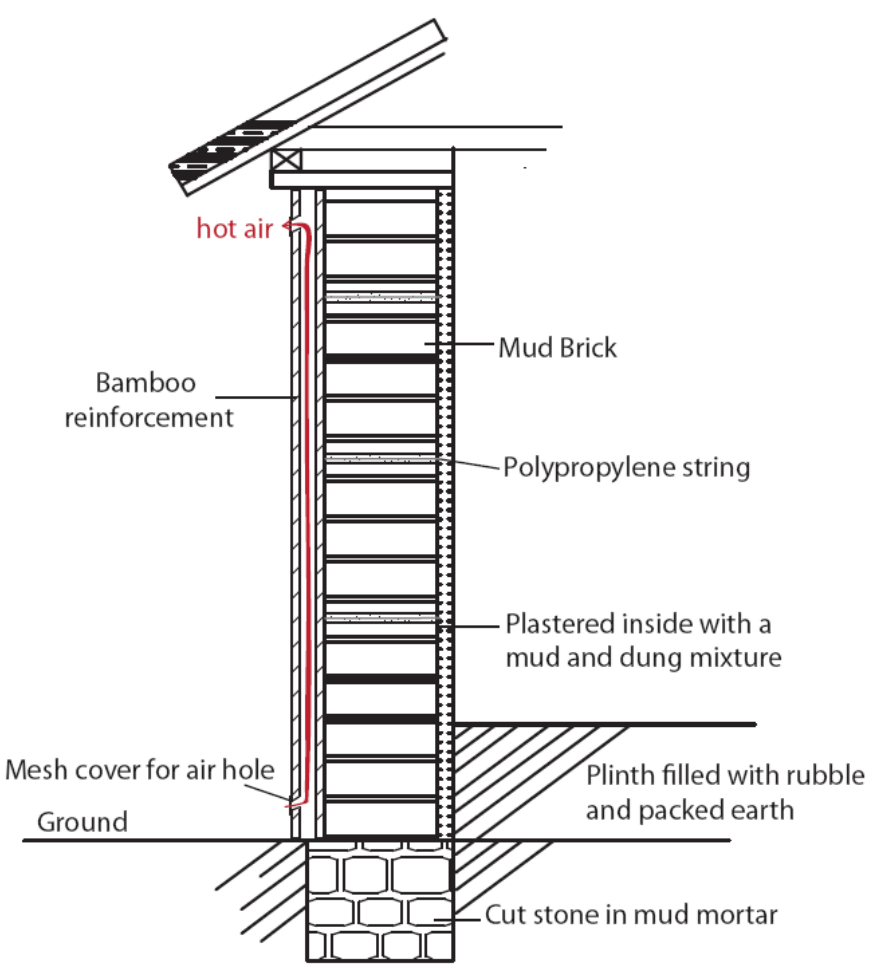

Figure 5.12: Vertical bamboo reinforcement as air circulation channel

building interior cooler in hot regions. 
In addition to these proposed solutions, some retrofitting techniques already have minor passive features which could be utilized effectively. For example, if the addition of masonry buttresses is done with consideration to the sun orientation in respect to the building, it can provide some form of shading. Simple techniques such as painting the building exterior white can also reduce heat gain as shown by Givoni (1994). These can be easily combined with the integrative retrofitting solutions for better thermal comfort performance.

It is worth mentioning that the scope of this research is limited to investigating the possibilities of integrating passive comfort features with seismic retrofitting techniques. Thus, details regarding type of materials to be used (e.g. for insulation) and implementation procedures are not addressed here. Significant further research is required to realize these ideas into implementable techniques and some suggested techniques may or may not prove effective, but this will require prototype testing and further development of the ideas.

\subsection{Summary}

As is apparent from Table 5.1, there are limited possibilities for integrative solutions that can satisfy both the safety and comfort requirements of residential buildings within the economic restraints of lowincome populations. However there is still scope for further research and the same matrix framework can be applied to explore new integrative ideas under different constraints and criteria.

The integrative techniques that have been presented are inserting insulation on the roof in between mud layers; inserting insulation between walls and reinforcing mesh or bamboo reinforcement; extending the seismic belt horizontally to provide external shading; replacing through-stones and RC bond elements with hollow metal or bamboo pipes embedded in concrete to provide ventilation; and creating an air circulation channel within the bamboo reinforcement to reduce exterior heat from radiating into the buildings. These techniques would be low cost and in some cases with no extra cost to the original seismic retrofitting techniques. They definitely have potential for further development via prototype testing and analytical and implementation studies. 


\section{Conclusions}

This study has investigated the possibilities for integrating passive thermal comfort features with existing seismic retrofitting techniques for non-engineered houses. The process has required careful consideration of the target population in terms of their economic standing and its consequent effect on the living standard of the people. A climatic design process has been followed in which the appropriate comfort zones for the target population have been deduced and the ratio of discomfort for a naturally ventilated house has been analysed for each region. These have provided with a clear understanding as to which thermal comfort strategies are required when.

Discussing the primary passive technologies enabled the author to identify which techniques had the potential to be integrated with the structural retrofitting and which could not. Following this, the seismic strengthening techniques that are specifically appropriate for non-engineered residential construction were identified and discussed in terms of their applicability for each of the typical housing types.

Finally, the integration of thermal comfort features with seismic retrofitting techniques was investigated. It was found that there is not a lot of scope for integration of these two features due to several reasons including the fact that many of the techniques are conflicting in principle (i.e. ventilation requiring openings and inlets while seismic retrofitting promotes the reduction of openings in a house). However, even then, some integrative techniques have been conceptualised and these show potential for further development.

\subsection{Recommendations for target regions}

Through the climatic analysis and discomfort index calculation in Chapter 3, the passive strategies suitable for each region were identified. For Palanpur (Gujarat) mostly cooling techniques were suggested, including natural ventilation and thermal mass with or without night ventilation. Heating requirements are minor for Palanpur but major for Gangtok (Sikkim). Jammu (Kashmir) requires both heating and cooling strategies due to its fluctuating temperature range throughout the year. Keeping 
these factors in mind, the appropriate integrative retrofitting techniques for each region can also be identified.

Buildings in hot-dry and composite climates like Palanpur and Jammu respectively, can use all the techniques mentioned here. Particularly, the ventilation techniques of extended seismic band shading, and installing bamboo or metal pipes through the wall wythes would be effective for hot summers. The insulative techniques of adding insulation on roofs and in between walls and reinforcement can work to both delay the heat energy from reaching the interior and also to trap the heat inside the building in winter. Similarly, the vertical bamboo technique would keep the heat outside of the building in the summer. For buildings located in a cold climate like Gangtok, only the insulative retrofitting techniques would be useful as a passive strategy.

The use of a particular technique on a building, however, would essentially depend on whether the primary retrofitting technique (one without the integrative features) is applicable to that type of construction (see Table 4.1 in Chapter 4). The availability of natural resources required, such as bamboo, is also another factor to consider for implementation.

\subsection{Further research}

There is considerable amount of research that still needs to be done in order to further develop the systems. Feasibility studies, computer modelling, prototype testing, and implementation projects would take the current findings further and transform the concepts into useful products. Detailed engineering calculations are now required and should be balanced with architectural and constructional aspect in order to maintain the holistic approach of design and development.

This study has taken an innovative approach to reducing the lack of strengthened buildings in India and other developing countries. By aiming to provide multiple benefits of day-to-day thermal comfort as well as seismic safety, the research has presented new possibilities in the field of seismic retrofitting. It provides a stable foundation on which future research and developmental work can be built. 


\section{References}

Ailawadi, V. S., \& Bhattacharyya, S. C. (2006). Access to energy services by the poor in India: Current situation and need for alternative strategies. Natural Resources Forum, 30(1), 2-14.

American Institute of Architects Foundation. (1982). Design. Passive heating and cooling. Washington, D.C.: American Institute of Architects.

ANSI/ASHRAE 55-2004. Thermal Environment Conditions for Human Occupancy, American Society of Heating, Refrigerating and Air Conditioning Engineers. Atlanta.

Arya, A. S. (2000). Non-Engineered Construction in Developing Countries -An Approach Toward Earthquake Risk Preduction. World Conference on Earthquake Engineering 21.

ASC. (2008, 21 February). Seismicity of Sikkim. Retrieved 24 May, 2010, from http://asc-india.org/seismi/seis-sikkim.htm

Asian Disaster Preparedness Center. (2010). Earthquake Risk Management. Thailand.

Auliciems, A., \& Szokolay, S. V. (2007). Thermal Comfort (2nd ed.). Brisbane: PLEA: Passive and Low Energy Architecture International in association with The University of Queensland.

Bharatonline.com. (2010). Sikkim Weather. Retrieved 24 May, 2010, from http://www.bharatonline.com/sikkim/travel-tips/weather.html

Brrzev, S. N., Greene, M., \& Sinha, R. (2002). Rubble stone masonry walls with timber frame and timber roof. Retrieved June 2010, from World Housing Encyclopedia: http://www.world-housing.net/whereport1view.php?id=100051

Brzev, S. (2007). Earthquake-Resistant Confined Masonry Construction. Kanpur: National Information Cener of Earthquake Engineering (NICEE), Indian Institute of Technology (IIT).

Brzev, S. N., Greene, M., \& Sinha, R. (2002). Rubble stone masonry walls with timber frame and timber roof. Retrieved June 2010, from World Housing Encyclopedia: http://www.world-housing.net/whereport1view.php?id=100051

Bureau of India Standards. (2002). IS 1893-2002Criteria for Earthquake Resistant Design of Structures Part1 General Provisions and Buildings. New Delhi: Bureau of India Standards.

Chandra, M. (1995). Passive and Low-energy Cooling Systems of Buildings -a Review with Special Reference to Indian Conditions. Journal of the Institution of Engineers (India), 76(September), $12-21$. 
Channa, S. M. (2010). What Do People Live On? Living Wages in India. Anthropology of Work Review, 31(1), 15-29.

Charleson, A. (2008). Seismic Design for Architects (1st ed.): Elsevier Ltd.

Charleson, A. (2009). Research on Used Car Tyre Strap Reinforced Adobe Construction in Peru. Paper presented at the 2009 NZSEE Conference. Retrieved from http://db.nzsee.org.nz/2009/Paper34.pdf

Coburn, A., \& Spence, R. (2002). Earthquake Protection (2nd ed.). West Sussex: John Wiley \& Sons.

D'Ayala, D., Speranza, E., \& D'Ercole, F. (2002, 05/06/2002). Single-family Historic brick masonry house (Casa unifamiliare in centro storico, Centro Italia). Retrieved 15 Nov., 2010, from http://www.world-housing.net/whereport1view.php?id=100062

Das, A., Islam, M. S., Alam, D. M. J., \& Hoque, N. (2007). Mud House of Bangladesh. Retrieved December, 2010, from World Housing Encyclopedia http://www.world-housing.net/whereport1view.php?id=100161

De Dear, R., Brager, G., \& Cooper, D. (1997). Developing an adaptive model of thermal comfort and preference : final report [on] ASHRAE RP-884. Sydney: Macquarie Research Ltd.

De Dear, R. J., \& Brager, G. S. (2001). The adaptive model of thermal comfort and energy conservation in the built environment. International Journal of Biometeorology 45(2), 100-108.

Desai, R., \& Desai, R. (2007). Manual for Restoration and Retrofitting of Rural Structures in Kashmir -How to Reduce Vulnerability of Exiting Structures in Earthquake Affected Areas of Jammu and Kashmir. New Delhi: UNESCO New Delhi Office.

Desai, R., \& Desai, R. (2008). Manual on Hazard Resistant Construction in India -For reducing vulnerability in buildings built without engineers. Gujarat: National Center For People's - Actiona in Disaster Preparedness (NCPDP).

Dickey, S. (2000). Permeable Homes: Domestic Service, Household Space, and the Vulnerability of Class Boundaries in Urban India American Ethnologist, 27(2), 462 - 489.

Dowling, D. M., \& Samali, B. (2006). Low-cost and Low-Tech Reinforcement Systems for Improved Earthquake Resistance of Mud Brick Buildings. Paper presented at the Proceedings of the Getty Seismic Adobe Project 2006 Colloquium Los Angeles, U.S.A.

Dowling, D. M., Samali, B., \& Li, J. (2005). An Improved Means of Reinforcing Adobe Walls -External Vertical Reinforcement. Paper presented at the SismoAdobe.

Egan, M. D. (1975). Concepts in Thermal Comfort. New Jersey: Prentice-Hall. 
Givoni, B. (1992). Comfort, climate analysis and building design guidelines. Energy and Buildings, 18(1), 11-23.

Givoni, B. (1994). Passive and Low Energy Cooling of Buildings. New York: Van Nostrand Reinhold.

Givoni, B. (1998). Climatic Considerations in Building and Urban Design. New York: John Wiley and Sons.

Government of India. (2001a). Gujarat Housing Profile: Census of India 2001. Retrieved from http://censusindia.gov.in/Census Data 2001/States at glance/State Links/24 guj.pdf

Government of India. (2001b). Jammu \& Kashmir Housing Profile: Census of India 2001. Retrieved from http://censusindia.gov.in/Census Data 2001/States at glance/State Links/01 jk.pdf

Government of India. (2001c). Sikkim Housing Profile: Census of India 2001. Retrieved from http://censusindia.gov.in/Census Data 2001/States at glance/State Links/11 sik.pdf

Hirway, I. (1987, 08/22/1987). Housing for the Rural Poor. Economic and Political Weekly, 22, 1455-1460.

HPCB. (2010, 2010). Climate Zone Map of India. Retrieved 5 July, 2010, from http://high-performancebuildings.org/climate-zone.php

Humphreys, M. A., \& Nicol, J. F. (1998). Understanding the Adaptive Approach to Thermal Comfort. ASHRAE transactions., 104(1), 991.

IAEE. (2001). Guidelines for Earthquake Resistant Non-Engineered Construction (Revised Edition ed.). Tokyo: The International Association for Earthquake Engineering.

IndiaRetailBiz. (2006, 15 October). Socio Economic Classes (SEC categories). from http://www.indiaretailbiz.com/blog/2006/10/15/socio-economic-classes-sec-categories/

Indraganti, M. (2008). Behavioural adaptation and the use of environmental controls in summer for thermal comfort in apartments in India. Energy and Buildings.

Institute of Seismological Research. (2007, 08 July). Criteria for earthquake resistant design of structures (IS 1893: 2002). Retrieved 08 July 2010, 2010, from http://www.isr.gujarat.gov.in/Seismic Zoning India.shtm

INTERTECT. (1984). Vernacular Housing in Seismic Zones of India. Albuquerque: The University of New Mexico.

Janzen, M. (2010). Thermal mass vs insulation. Retrieved March, 2011, from http://www.tinyhousedesign.com/2010/01/01/thermal-mass-vs-insulation/

Joshi, R., \& Kumar, R. P. (2008). A Note on the Accuracy of Seismic Hazard in Peninsular India. Paper presented at the The 14th World Conference on Earthquake Engineering.

Karan, P. P. (1989). Environment and Development in Sikkim Himalaya: A Review. Human Ecology, 17(2). 
Kaushik, H. B., Dasgupta, K., Sahoo, D. R., \& Kharel, G. (2006). Reconnaissance Report: Sikkim Earthquake of 14 February 2006. Kanpur: National Information Center of Earthquake Engineering, Indian Institute of Technology.

Kayal, J. R. (2008). Microearthquake Seismology and Seismotectonics of South Asia. New Delhi: Capital Publishing Company.

Kennedy, J. F. (2004). Building Without Borders --Sustainable Construction for the Global Village. Canada: New Society Publishers.

Khosla, R. (1983). Architecture of Rural Housing: Some Issues in India. Social Scientist, 11(4), 56-60.

Koch-Nielsen, H. (2002). Stay Cool. London: James \& James (Science Publishers) Ltd.

Kumar, A. (2002a). Rural mud house with pitched roof. Retrieved March, 2010, from World Housing Encyclopedia: http://world-housing.net/whereport1view.php?id=100056

Kumar, A. (2002b). Unreinforced brick masonry walls with pitched clay tile roof. Retrieved March, 2010, from World Housing Encyclopedia:

http://www.world-housing.net/whereport1view.php?id=100055

Lechner, N. (2009). Heating, Cooling, Lighting: Sustainable Design Methods for Architects (3rd ed.). New Jersey: John Wiley \& Sons.

Maldonado, T., \& Cullars, J. (1991). The Idea of Comfort. Design Issues, 8(1), 35-43.

Maslak, M. A., \& Singhal, G. (2008). The identity of educated women in India: confluence or divergence? Gender \& Education, 20(5), 481-493.

Mayorca, P., \& Meguro, K. (2008). A Step Towards te Formulation of a Simple Method to Design PP-Band Mesh Retrofitting for Adobe/Masonry Houses. Paper presented at The 14th World Conference on Earthquake Engineering.

Meli, R., \& Alcocer, S. M. (2004). Implementation of Structural Earthquake - Disaster Mitigation Programs in Developing Countries. Natural Hazards Review, ASCE (copyright), 5(1), 29 - 39.

Mishra, V. (2003). Effect of Indoor Air Pollution from Biomass Combustion on Prevalence of Asthma in the Elderly. Environmental Health Perspectives, 111(1), 71-77.

Murty, C. V. R. (2005). Earthquake Tip 03: What are Magnitude and Intensity? Earthquake Tips Learning Earthquake Design and Construction. (pp. 5-6). Kanpur: National Information Center of Earthquake Engineering.

National Academy of Sciences. (1974). Roofing in Developing Countries: Research for New Technologies. Washington D.C.: National Research Council for the Board on Science and Technology for International Development Commission on International Relations. 
Naveen, P. (2003). IN PICTURES - Middle Class, or Upper Class? Retrieved 22 May, from http://www.indiatogether.org/photo/2003/class.htm

Oxford English Dictionary. (Ed.) (2009). Oxford University Press.

Pallasmaa, J. (2005). Eyes of the Skin. West Sussex, England: John Wiley \& Sons Ltd.

Papanikolaou, A., \& Taucer, F. (2004). Review of non-engineered houses in Latin America with reference to building practices and self-construction projects. Italy: Institute for the Protection and Security of the Citizen European Laboratory for Structural Assessment (ELSA).

Parikh, J., \& Laxmi, V. (2000). Biofuels, Pollution and Health Linkages: A Survey of Rural Tamil Nadu. Economic \& Political Weekly, 35(47), 4125-4137.

Parikh, K. S. (1996). Equitable Sustainable Development of Gujarat. Economic and Political Weekly, 31(19), 1151-1164.

Parsons, K. (2003). Human Thermal Environments (2nd ed.). London \& New York: Taylor \& Francis.

Patel, T., Patel, T., \& Hemani, R. (2006). Risk Reduction Through Community Based Disaster Preparedness Plans. Ahmedabad, Gujarat: Centre for Integrated Development (CfID).

Reddy, P. R., \& Lefebvre, B. (1993). Rural Housing and Perception of Inhabitants -Case Study of an Indian Village. Housing Science, 17(1), 049-055.

RMS. (2007). India Earthquake: Risk Managements Solutions, Inc.

Saigal, A. (2009). Poor Women and Community-Based Participation in Literacy Work in India. In J. Zajda \& K. Freeman (Eds.), Race, Ethnicity and Gender in Education (pp. 125-140). Netherlands: Springer Science+Business Media

Saturn Resource Management. (2008). Thermal Mass and Wall Insulation from http://srmi.biz/Tips.Insulation Air Sealing.Insulation thermal mass.htm

Sena, G. W. C. (1991). The Global Vulnerability. In I. Davies \& Y. Aysan (Eds.), Disasters and the small dwelling: perspectives for the UN IDNDR (pp. 30). London: James \& James.

Sengupta, S. (1975). Rural poor and the new programme. New Delhi: Communist Party of India.

Sethi, C. (2008). Impact of Diabetes in different economic sectors In Northern Indian Region. Retrieved from http://knol.google.com/k/kriti/impact - of - diabetes - in - different/Isxnfojwntzs/3

Sharma, A., \& Tiwari, R. (2007). Evaluation of data for developing an adaptive model of thermal comfort and preference. Environmentalist, 27, 73-81.

Shuttleworth, M. (2008). Research Variables. Retrieved 24 May, from http://www.experiment-resources.com/research-variables.html

Szokolay, S. V. (1990). Climate Indices. International Journal of Ambient Energy, 11(3), 115-120. 
Szokolay, S. V. (2004). Introduction to Architectural Science: The Basis of Sustainable Design. Burlington, MA: Architectural Press: Elsevier Science.

The International Association for Earthquake Engineering. (2001). Guidelines for Earthquake Resistant Non-Engineered Construction (Revised Edition ed.). Tokyo: The Associated Cement Companies Limited.

The Times of India. (2005). Socio-Economic Classification NRS 2005. Retrieved 20 May, 2010, from http://www.timm.indiatimes.com/timm/ecoclass.jsp

Toftum, J., Andersen, R. V., \& Jensen, K. L. (2009). Occupant performance and building energy consumption with different philosophies of determining acceptable thermal conditions. Building and Environment, 44, 2009-2016.

Tuohy, P. G., Humphreys, M. A., Nicol, J. F., Rijal, H. B., \& Clarke, J. A. (2009). Occupant behaviour in naturally ventilated and hybrid buildings. ASHRAE Transactions.

Turer, A., Korkmaz, S. Z., \& Korkmaz, H. H. (2007). Performance Improvement Studies of Masonry Houses Using Elastic Post-tensioning Straps. Earthquake Engineering and Structural Dynamics, $36,683-705$.

Virdi, K. S., \& Rashkoff, R. D. Repair and Strenghtening of Stone Masonry - Low - rise Residential Construction Detailing to Resist Earthquakes. Retrieved 24, Nov., 2010, from http://www.staff.city.ac.uk/earthquakes/Repairstrengthening/RSStoneMasonry.htm

Weather 2. (2010). Climate Profile. Retrieved 11 November, 2010, from http://www.myweather2.com/City-Town/India/Palanpur/climate-profile.aspx; http://www.myweather2.com/City-Town/India/Jammu/climate-profile.aspx

WeatherReports. (2010). Retrieved December 2010, from http://www.weatherreports.com/India/Gangtok/averages.html?n=3

Williams, S. (1996). Behavioural responses to maintain thermal comfort in office environments Loughborough University, UK.

Yadav, R. B. S., Tripathi, J. N., Rastogi, B. K., \& Chopra, S. (2008). Probabilistic Assessment of Earthquake Hazard in Gujarat and Adjoining Region of India. Pure and Applied Geophysics(165), 1813-1833.

Yanay, U., \& Griffel, A. (1985). Ordering Urban Communities According to Their Socio-Economic Characteristics. Social Indicators Research, 17(4), 421-433.

Yang, L., Lam, J. C., \& Liu, J. (2005). Bioclimatic building designs for different climates in China. Architectural Science Review, 48(2), 187-194.

Zurick, D., \& Pacheco, J. (2006). Illustrated Atlas of the Himalaya. Lexington: University Press of Kentucky 